\title{
A Numerical Model for Investigating the Steam Conformance along the Dual-String Horizontal Wells in SAGD Operations
}

\author{
Peng $\mathrm{Li}^{1,2}$, Yanyu Zhang ${ }^{1,2, *}$, Xiaofei Sun ${ }^{1,2, *} \mathbb{}$, Huijuan Chen ${ }^{3}$ and Yang Liu ${ }^{4}$ \\ 1 School of Petroleum Engineering, China University of Petroleum (East China), Qingdao 266580, China; \\ lipupc@163.com \\ 2 Key Laboratory of Unconventional Oil \& Gas Development (China University of Petroleum (East China)), \\ Ministry of Education, Qingdao 266580, China \\ 3 Shanghai Institute of Applied Mathematics and Mechanics, Shanghai University, Shanghai 200072, China; \\ iichj@126.com \\ 4 Research Institute of Petroleum Exploration and Development, PetroChina, Beijing 100083, China; \\ qwfyliu@petrochina.com.cn \\ * Correspondence: yyzhang@upc.edu.cn (Y.Z.); xfsun@upc.edu.cn (X.S.); Tel.: +86-18753231107 (Y.Z.); \\ $+86-13021678278$ (X.S.)
}

Received: 20 June 2020; Accepted: 29 July 2020; Published: 2 August 2020

\begin{abstract}
Non-uniformity of the steam-assisted gravity drainage (SAGD) steam chamber significantly decreases the development of heavy oil reservoirs. In this study, to investigate the steam conformance in SAGD operations, a wellbore model is developed for fluid flow in dual-string horizontal wells. Then, a three-dimensional, three-phase reservoir model is presented. Next, the coupled wellbore and reservoir model is solved with a fully implicit finite difference method. Finally, the effects of the injector wellbore configuration, steam injection ratio and injection time on the steam conformance are investigated. The results indicate that under different injector wellbore configurations, the closer the differences between the pressure drop from the landing position of the short string to the heel of the wellbore and the pressure drop from the landing position of the short string to the toe of the wellbore, the better is the steam conformance. The smaller the difference in the steam injection rate between the long and short injection strings, the higher is the uniformity of the steam chamber. The injector annular pressure profile uniformity is consistent with the steam conformance. Creating a more uniform steam pressure in the annulus of the injector improves the uniformity of the steam chamber. The steam conformance decreases with increasing injection time, so the optimization method of steam chamber uniformity should be adjusted according to different injection times.
\end{abstract}

Keywords: heavy oil; SAGD; steam conformance; dual-string; numerical model

\section{Introduction}

Heavy oil is an important energy source [1-4], and Steam-assisted gravity drainage (SAGD) is an effective technology for the economic recovery of heavy oil [5-8]. The SAGD process usually employs two parallel horizontal wells. The horizontal injector is closely placed above the producer, which is usually near the base of the reservoir [9-12]. In traditional SAGD well pair operations, only the heel string is used for injection and production. The pressure drop along the wellbore usually leads to a non-uniform steam chamber growth (Figure 1a), which is not conducive to the efficient development of heavy oil reservoirs [13-15]. Therefore, it is important to improve the steam conformance. In recent years, the dual-string completion scheme has been adopted in SAGD wells. Successful field testing of the SAGD process has demonstrated that the dual-string completion scheme has the potential to 
improve the steam chamber conformance [16]. This completion scheme offers two injection points in the injector and two production points in the producer to reduce the pressure gradients inside the liner, which leads to improvements in steam chamber conformance in comparison to injecting steam at a single point only (Figure 1b).

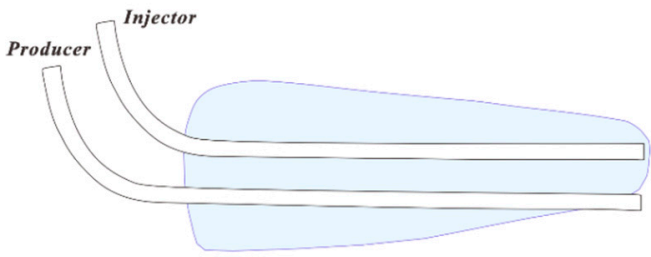

(a)

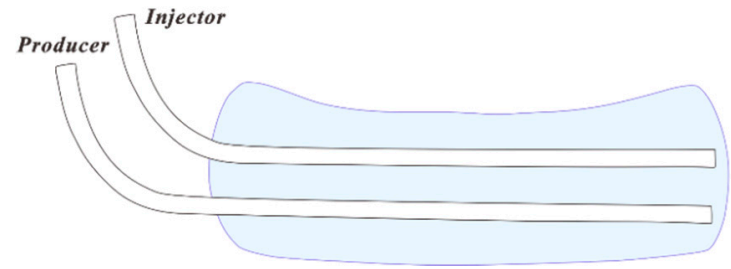

(b)

Figure 1. Schematic of steam chamber distribution: (a) traditional steam-assisted gravity drainage (SAGD); (b) dual-string SAGD.

Kumar et al. [17] optimized the length and positioning of multiple tubular strings within a liner for both injection and production wells. They found that the positioning of tubular strings in a multiple tubing completion SAGD well pair had a significant impact on the steam chamber growth and productivity. Rivas et al. [18] observed that with the dual-tubing-string configuration applied in the Lindbergh area in Alberta, Canada, a more uniform steam chamber could be achieved. In 2020, Dong et al. [19] developed a physical model to experimentally study the steam conformance with a single-string well configuration and a dual-string well configuration. They found that a better steam conformance could be obtained with the two-points steam injection method. The dual-string injection and production technique is an important method for improving the steam conformance and enhancing oil recovery. However, the best way to optimize the well configuration and control the operational parameters to improve the steam conformance in SAGD operations is not fully understood.

Numerical simulation is a good method to solve these problems. Sun et al. [20] and Lin et al. [21] proposed mathematical models for calculating the steam parameters in the long string and annulus of the injector with the toe-point injection technique. Sun et al. [22] and Wu et al. [23] proposed analytical models for predicting the steam quality and steam pressure in a horizontal injection well under the condition of simultaneous dual-string injection.

In these previous models, various transition criteria for gas/liquid two-phase flow were established to determine the flow pattern, and the annulus was treated as a pipe based on the equivalent hydraulic diameter concept. However, precisely dividing flow patterns is difficult, and the flow patterns in the annulus have been shown to be different from pipe-flow patterns [24,25]. Calculation of the pressure drop may be a rough approximation [26,27]. In addition, these analytical models only simulated the steam injection performance of a single horizontal well. In other words, the coupling of a reservoir model and a wellbore model was not considered, and the injection and production performance of dual-string dual horizontal wells has not been studied.

The focus of the study is to propose a numerical model to investigate the steam conformance along the dual-string horizontal wells in SAGD operations. First, based on multiphase flow theory, a wellbore model is developed for fluid flow in the string and annulus of dual-string injection and production horizontal wells. Second, a three-dimensional, three-phase reservoir model is proposed for fluid flow in heavy oil reservoirs. Then, the coupled wellbore and reservoir model is solved with a fully implicit finite difference method. Finally, after the validation of the proposed model, the effects of the injector wellbore configuration, steam injection ratio and injection time on the steam conformance are investigated. Moreover, a uniformity evaluation model is developed to estimate the uniformity of the steam chamber, and reasonable suggestions are given to improve the steam chamber conformance. 


\section{Model Description}

\subsection{General Assumptions}

Figure 2 shows a schematic of fluid flow in dual-string horizontal wells during the SAGD process. The SAGD process usually consists of two stages, the circulation stage and SAGD operation. During the SAGD circulation stage, steam is injected through both the injector and the producer (Figure 2a). When the wells are converted to SAGD operation after circulation, steam is injected down the short and long strings in the injector, and both strings in the producer are used for production (Figure 2b). For clarity, assume that interfaces A, B, C and D are at the heel, the landing position of the short string, the steam convergence position and the toe, respectively. The major assumptions in deriving the numerical model are as follows:

1. The heavy oil reservoir is isotropic and homogeneous.

2. The injection parameters (e.g., injection pressure and steam quality) at the heel of the short and long strings in the injector and the production parameters (e.g., bottomhole pressure) at the heel of the short and long strings in the producer do not change with time.

3. The heat transfer in the wellbore is steady state, while the heat transfer in the reservoir is transient.

4. The flow of oil, water and steam in the reservoir obeys Darcy's law, the fluid flow in the reservoir only considers the laminar flow and oil and water are immiscible.

5. Heat convection and conduction are considered when the fluids flow in the reservoir.

6. The compressibilities of the rock and fluid are considered.

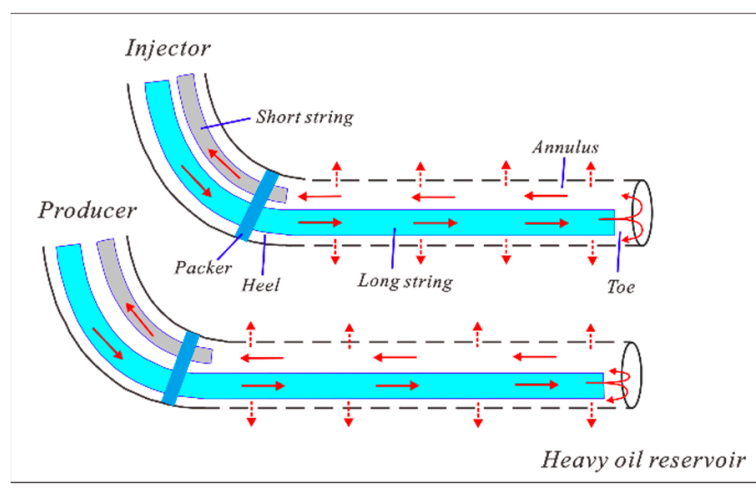

(a)

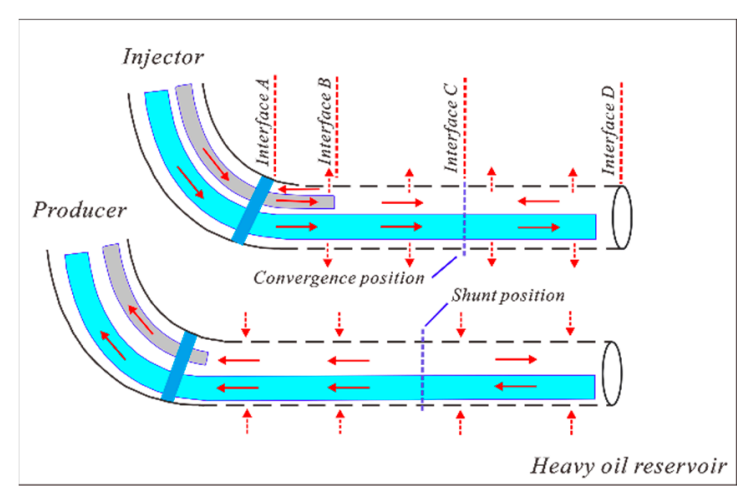

(b)

Figure 2. Schematic of the fluid flow in dual-string horizontal wells during the SAGD process: (a) circulation stage; (b) SAGD operation.

\subsection{Wellbore Model of the Injector}

\subsubsection{Steam Flow Model in the Short and Long Strings}

It is a constant mass flow process of steam flow in the short and long strings. The energy conservation equation can be expressed as:

$$
\frac{\mathrm{d} Q_{1}}{\mathrm{~d} l}=-m_{1} \frac{\mathrm{d}}{\mathrm{d} l}\left(h_{1}+\frac{v_{1}^{2}}{2}\right)
$$

According to the principle of mass conservation, the auxiliary equation can be written as:

$$
\frac{\mathrm{d} m_{1}}{\mathrm{~d} l}=0
$$




\subsubsection{Steam Flow Model in the Annulus}

When the steam flows from interface $B$ to $C$ and from interface $D$ to $C$, for a random micro-segment in the BD section of the annulus, the energy conservation equation can be derived as:

$$
\frac{\mathrm{d} Q_{\mathrm{a}}}{\mathrm{d} l}-\frac{\mathrm{d} Q_{1}}{\mathrm{~d} l}+m_{\mathrm{af}}\left(h_{\mathrm{a}}+\frac{v_{\mathrm{ar}}^{2}}{2}\right)=-\frac{\mathrm{d}}{\mathrm{d} l}\left[m_{\mathrm{a}}\left(h_{\mathrm{a}}+\frac{v_{\mathrm{a}}^{2}}{2}\right)\right]
$$

When the steam flows from interface B to A, there is heat exchange between the short and long injection strings and the annulus. For a random micro-segment in the $\mathrm{AB}$ section of the annulus, the energy conservation equation for steam flow in this micro-segment is:

$$
\frac{\mathrm{d} Q_{\mathrm{a}}}{\mathrm{d} l}-\frac{\mathrm{d} Q_{\mathrm{s}}}{\mathrm{d} l}-\frac{\mathrm{d} Q_{\mathrm{l}}}{\mathrm{d} l}+m_{\mathrm{af}}\left(h_{\mathrm{a}}+\frac{v_{\mathrm{ar}}^{2}}{2}\right)=-\frac{\mathrm{d}}{\mathrm{d} l}\left[m_{\mathrm{a}}\left(h_{\mathrm{a}}+\frac{v_{\mathrm{a}}^{2}}{2}\right)\right]
$$

According to the principle of mass conservation, the subsidiary equation is given by:

$$
\frac{\mathrm{d} m_{\mathrm{a}}}{\mathrm{d} l}=-m_{\mathrm{af}}
$$

As stated above, the method for the calculation of the pressure gradient in the string and annulus of the injector may be a rough approximation in the previous models. Here, a simplified approach was first used to calculate the pressure drop in the steam injection horizontal wellbore [26-34], as derived in Appendix A. According to Equations (1), (3) and (4), the pressure drops in the string, the BD section of the annulus and the $\mathrm{AB}$ section of the annulus can be obtained, as shown in Equations (6)-(8), respectively:

$$
\begin{gathered}
\frac{\mathrm{d} P_{1}}{\mathrm{~d} l}=\frac{\frac{\mathrm{dQ}}{\mathrm{d} l}}{m_{\mathrm{l}}\left(C_{\mathrm{Jml}} C_{\mathrm{pml}}-C_{\mathrm{pml}} \frac{\mathrm{d} T_{1}}{\mathrm{~d} P_{1}}+\frac{v_{1} v_{\mathrm{sgl}}}{P_{1}}\right)} \\
\frac{\mathrm{d} P_{\mathrm{a} \_\mathrm{BD}}}{\mathrm{d} l}=\frac{\frac{\mathrm{d} Q_{\mathrm{a}}}{\mathrm{d} l}-\frac{\mathrm{d} Q_{1}}{\mathrm{~d} l}+\frac{\mathrm{d} m_{\mathrm{a}}}{\mathrm{d} l}\left(\frac{v_{\mathrm{a}}^{2}-v_{\mathrm{ar}}^{2}}{2}\right)}{m_{\mathrm{a}}\left(C_{\mathrm{Jma}} C_{\mathrm{pma}}-C_{\mathrm{pma}} \frac{\mathrm{d} T_{\mathrm{a}}}{\mathrm{d} P_{\mathrm{a}}}+\frac{v_{\mathrm{a}} v_{\mathrm{gga}}}{P_{\mathrm{a}}}\right)} \\
\frac{\mathrm{d} P_{\mathrm{a} \_\mathrm{AB}}}{\mathrm{d} l}=\frac{\frac{\mathrm{d} Q_{\mathrm{a}}}{\mathrm{d} l}-\frac{\mathrm{d} Q_{\mathrm{s}}}{\mathrm{d} l}-\frac{\mathrm{d} Q_{1}}{\mathrm{~d} l}+\frac{\mathrm{d} m_{\mathrm{a}}}{\mathrm{d} l}\left(\frac{v_{\mathrm{a}}^{2}-v_{\mathrm{ar}}^{2}}{2}\right)}{m_{\mathrm{a}}\left(C_{\mathrm{Jma}} C_{\mathrm{pma}}-C_{\mathrm{pma}} \frac{\mathrm{d} T_{\mathrm{a}}}{\mathrm{d} P_{\mathrm{a}}}+\frac{v_{\mathrm{a}} v_{\mathrm{gga}}}{P_{\mathrm{a}}}\right)}
\end{gathered}
$$

When the steam flows in the horizontal injection wellbore, the steam may condensate into water. In this case, the value of steam quality is zero, and the detailed derivation of fluid pressure and temperature can be found in Appendix B.

\subsection{Wellbore Model of the Producer}

\subsubsection{Liquid Flow Model in the Long String}

When the fluid flows in the long string, the mass flow rate remains unchanged. Therefore, the energy and momentum conservation equations can be expressed as:

$$
\begin{gathered}
\frac{\mathrm{d} Q_{\mathrm{pl}}}{\mathrm{d} l}=-\frac{\mathrm{d}}{\mathrm{d} l}\left[m_{\mathrm{pl}}\left(h_{\mathrm{pl}}+\frac{v_{\mathrm{pl}}^{2}}{2}\right)\right] \\
\frac{\mathrm{d} P_{\mathrm{pl}}}{\mathrm{d} l}-\frac{\tau_{\mathrm{pl}}}{A_{\mathrm{pl}} \mathrm{d} l}=-\frac{\mathrm{d}\left(\rho_{\mathrm{pl}} v_{\mathrm{pl}}^{2}\right)}{\mathrm{d} l}
\end{gathered}
$$


According to the principle of mass conservation, the auxiliary equation can be written as:

$$
\frac{\mathrm{d} m_{\mathrm{pl}}}{\mathrm{d} l}=0
$$

\subsubsection{Liquid Flow Model in the Annulus}

When the fluid flows to the heel and toe from the liquid shunt position, for a random micro-segment in the annulus, the energy and momentum conservation equations can be derived as:

$$
\begin{gathered}
\frac{\mathrm{d} Q_{\mathrm{pa}}}{\mathrm{d} l}-\frac{\mathrm{d} Q_{\mathrm{pl}}}{\mathrm{d} l}-m_{\mathrm{paf}}\left(h_{\mathrm{pa}}+\frac{v_{\mathrm{par}}^{2}}{2}\right)=-\frac{\mathrm{d}}{\mathrm{d} l}\left[m_{\mathrm{pa}}\left(h_{\mathrm{pa}}+\frac{v_{\mathrm{pa}}^{2}}{2}\right)\right] \\
\frac{\mathrm{d} P_{\mathrm{pa}}}{\mathrm{d} l}-\frac{\tau_{\mathrm{pa}}}{A_{\mathrm{pa}} \mathrm{d} l}=-\frac{\mathrm{d}\left(\rho_{\mathrm{pa}} v_{\mathrm{pa}}^{2}\right)}{\mathrm{d} l}
\end{gathered}
$$

According to the principle of mass conservation, the subsidiary equation can be written as:

$$
\frac{\mathrm{d} m_{\mathrm{pa}}}{\mathrm{d} l}=-m_{\mathrm{paf}}
$$

\subsection{Reservoir Model}

In this Section, a three-dimensional, three-phase reservoir model is presented. The mass conservation equations of oil, water and steam are expressed as follows:

$$
\begin{gathered}
\nabla \cdot\left(\rho_{\mathrm{o}} \frac{\alpha_{1} k k_{\mathrm{ro}}}{\mu_{\mathrm{o}}} \nabla\left(P_{\mathrm{o}}-\rho_{\mathrm{o}} \mathrm{g} D\right)\right)+\rho_{\mathrm{o}} q_{\mathrm{o}}=\frac{\partial}{\partial t}\left(\rho_{\mathrm{o}} S_{\mathrm{o}} \varphi\right) \\
\nabla \cdot\left(\rho_{\mathrm{w}} \frac{\alpha_{2} k k_{\mathrm{rw}}}{\mu_{\mathrm{w}}} \nabla\left(P_{\mathrm{w}}-\rho_{\mathrm{w}} \mathrm{g} D\right)\right)+\rho_{\mathrm{w}} q_{\mathrm{w}}+m_{\mathrm{c}}=\frac{\partial}{\partial t}\left(\rho_{\mathrm{w}} S_{\mathrm{w}} \varphi\right) \\
\nabla \cdot\left(\rho_{\mathrm{g}} \frac{\alpha_{3} k k_{\mathrm{rg}}}{\mu_{\mathrm{g}}} \nabla\left(P_{\mathrm{g}}-\rho_{\mathrm{g}} \mathrm{g} D\right)\right)+\rho_{\mathrm{g}} q_{\mathrm{g}}-m_{\mathrm{c}}=\frac{\partial}{\partial t}\left(\rho_{\mathrm{g}} S_{\mathrm{g}} \varphi\right)
\end{gathered}
$$

The energy conservation equation is:

$$
\begin{aligned}
& \nabla \cdot\left(\lambda_{\mathrm{R}} \nabla T\right)+\nabla \cdot\left(\sum_{i=\mathrm{o}, \mathrm{w}, \mathrm{g}} \rho_{i} H_{i} \frac{k k_{\mathrm{ri}}}{\mu_{i}} \nabla\left(P_{i}-\rho_{i} \mathrm{~g} D\right)\right)-Q_{\mathrm{loss}}+Q_{\mathrm{H}}+ \\
& Q_{\mathrm{a}}+Q_{\mathrm{pa}}=\frac{\partial}{\partial t}\left[(1-\varphi) \rho_{\mathrm{R}} c_{\mathrm{R}} T+\varphi \sum_{i=\mathrm{o}, \mathrm{w}, \mathrm{g}} S_{i} \rho_{i} U_{i}\right]
\end{aligned}
$$

The equilibrium condition is:

$$
T=T_{\mathrm{s}}(P)
$$

The subsidiary equations used to reduce the variables can be found in references [35-37].

\subsection{Coupling Model}

The reservoir model and wellbore model can be coupled through the sink/source terms [38]. The calculation of sink and source terms is shown in Equations (22) and (23), respectively:

$$
\begin{gathered}
m_{\mathrm{g}}=\rho_{\mathrm{a}} I_{\mathrm{s}}\left(P_{\mathrm{a}}-P\right) \frac{2 \pi \sqrt{k_{\mathrm{h}} / k_{\mathrm{v}}} k_{\mathrm{v}} \mathrm{d} l}{\left[\ln \left(r_{\mathrm{e}} / r_{\mathrm{w}}\right)-0.75+S_{\mathrm{k}}\right]}\left(\frac{k_{\mathrm{ro}}}{B_{\mathrm{o}} \mu_{\mathrm{o}}}+\frac{k_{\mathrm{rw}}}{B_{\mathrm{w}} \mu_{\mathrm{w}}}\right) \\
m_{\text {liquid }}=\rho_{\mathrm{pa}}\left(P-P_{\mathrm{pa}}\right) \frac{2 \pi \sqrt{k_{\mathrm{h}} / k_{\mathrm{v}}} k_{\mathrm{v}} \mathrm{d} l}{\left[\ln \left(r_{\mathrm{e}} / r_{\mathrm{w}}\right)-0.75+S_{\mathrm{k}}\right]}\left(\frac{k_{\mathrm{ro}}}{B_{\mathrm{o}} \mu_{\mathrm{o}}}+\frac{k_{\mathrm{rw}}}{B_{\mathrm{w}} \mu_{\mathrm{w}}}\right)
\end{gathered}
$$




\subsection{Uniformity Evaluation Model}

The uniformity of the parameter along the horizontal well can be evaluated by choosing the non-uniformity coefficient as the evaluation criteria, and this equation is defined as:

$$
\alpha_{x}=\sqrt{\sum_{j}\left(x_{j}-\bar{x}\right)^{2}} / \bar{x}
$$

To evaluate the uniformity improvement effect of the parameter along the wellbore, the concept of the uniformity improvement coefficient is proposed:

$$
\beta_{x}=\frac{\alpha_{x, \text { base scheme }}-\alpha_{x, \text { non-basescheme }}}{\alpha_{x, \text { base scheme }}} \times 100 \%
$$

The smaller the non-uniformity coefficient, the more uniform is the parameter distribution along the wellbore. The larger the uniformity improvement coefficient, the better is the uniformity improvement effect of the parameter along the wellbore (compared with the base scheme).

\section{Solution Method of the Coupling Model}

The wellbore model was solved fully implicitly with the reservoir model. This process was programmed with a computer, and the flow chart is presented in Figure 3. The schematic with discretized grids and major parameters is shown in Figure 4. The solution procedures are given as follows:

Step 1: Enter the initial values of the reservoir and wellbore. The well is discretized into $n$ segments. The steam pressure drop $\Delta P_{\mathrm{s}}$, temperature drop $\Delta T_{\mathrm{s}}$ and steam quality drop $\Delta x_{\mathrm{s}}$ are estimated for each segment.

Step 2: The changes in the reservoir pressure $\Delta P_{\mathrm{o}}$, temperature $\Delta T$, water saturation $\Delta S_{\mathrm{w}}$ and gas saturation $\Delta S_{\mathrm{g}}$ are estimated for each grid block.

Step 3: Solution of the reservoir model

Combining Equations (16) and (17), the condensation term $m_{c}$ was eliminated. The condensation rate is thus implicitly represented within a set of four equations. Therefore, the reservoir model can be discretized by using the fully implicit finite difference method. In the discretization process of the reservoir model, pressure-dependent density and viscosity of steam while solving fluid flow equations are considered, and the gravity induced movement of steam is incorporated. The detailed derivation of the reservoir model is provided in Appendix C.

Step 4: Solution of the wellbore model

The wellbore model is solved with the straightforward numerical method and iteration technique. The calculation is repeated until the limitations of pressure, temperature and steam quality condition are satisfied.

Step 5: The calculation results are output when the simulation time reaches the set time. 


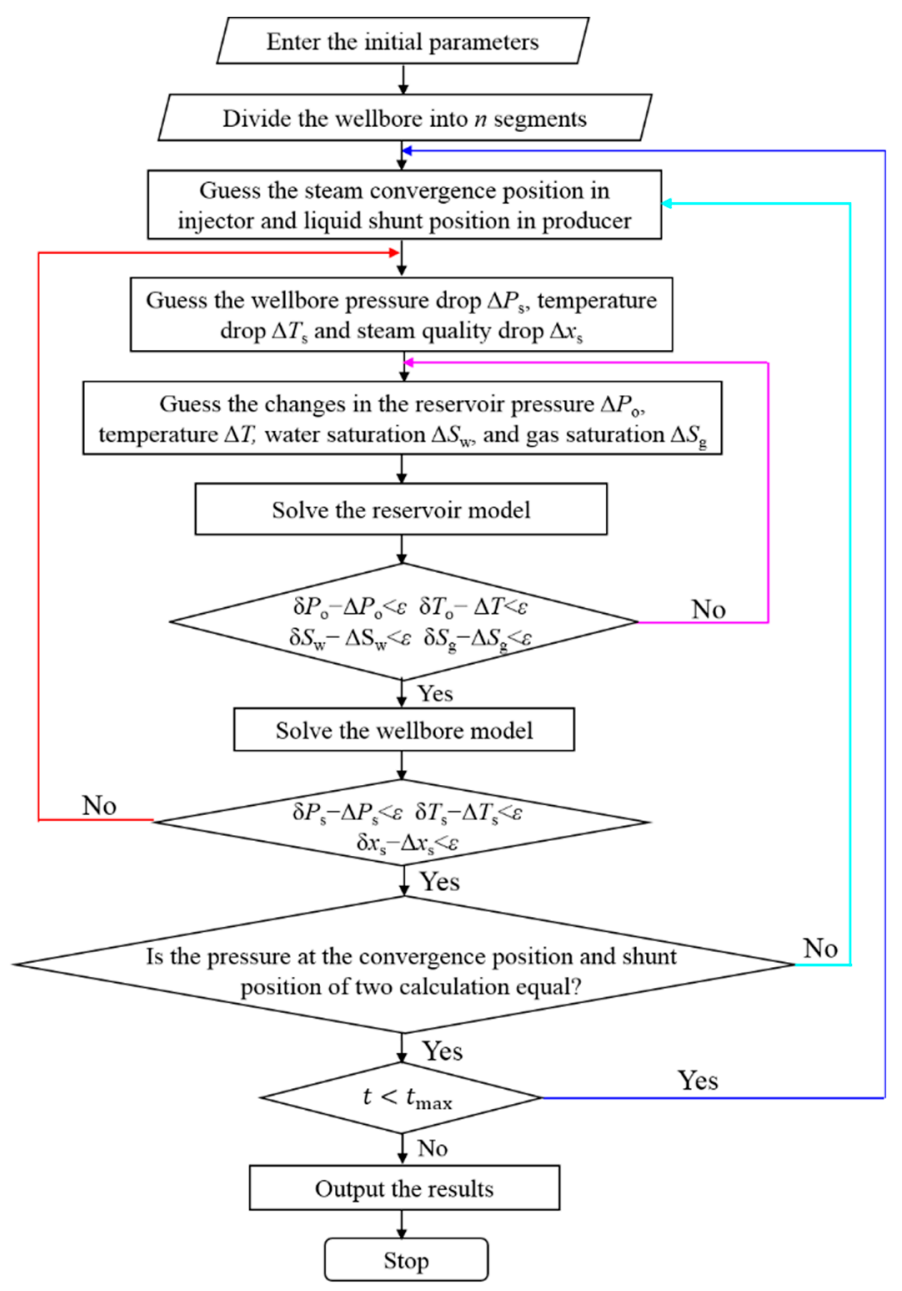

Figure 3. Calculation flow chart for the numerical model.

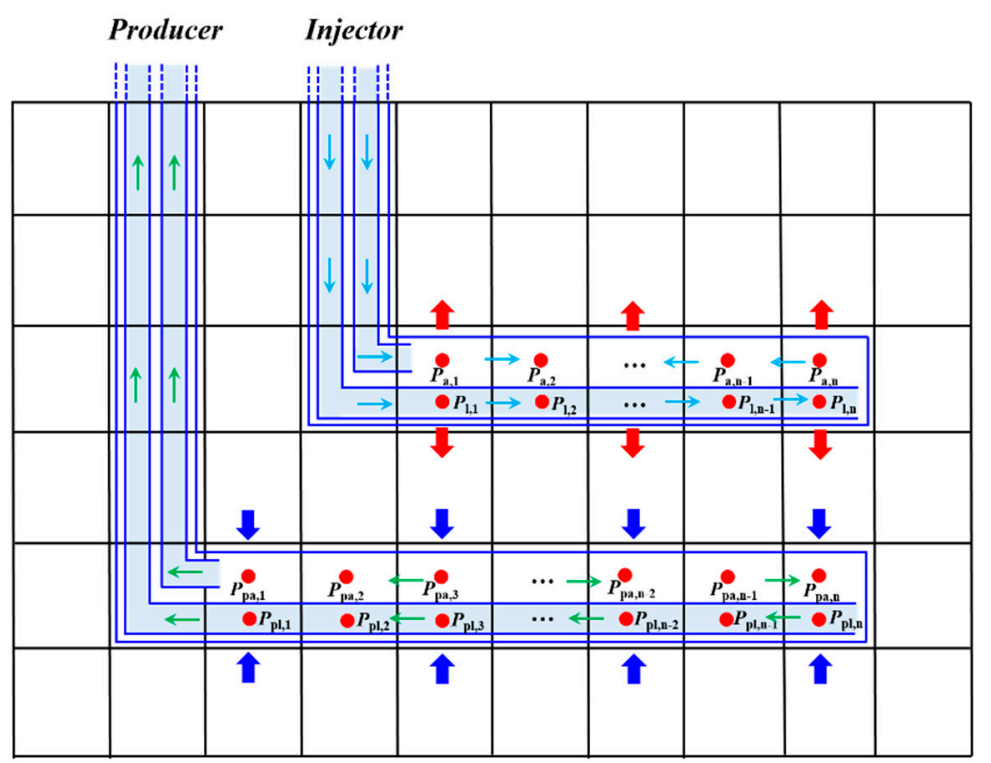

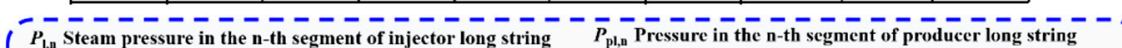
I $P_{\mathrm{a}, \mathrm{n}}$ Steam pressure in the $\mathrm{n}$-th segment of injector annulus $\quad P_{\mathrm{pa}, \mathrm{n}}$ Pressure in the $\mathrm{n}$-th segment of producer annulus $\rightarrow$ Steam flow direction in the injector

1. Steam flow direction from the annulus to the reservoir

$\leftarrow$ Liquid flow direction in the producer

Figure 4. The schematic with discretized grids and major parameters. 


\section{Results and Discussion}

\subsection{Verification of the Developed Model}

\subsubsection{Validation Using the Experimental Data}

The well configuration in the developed model is a dual-string well configuration; the fluid flow behaviour in the cases of the heel point injection mode and the toe point injection mode can be simulated by the developed model. The flow behaviour of the fluid in the cases of the heel point injection and the toe point injection modes in the developed model is similar to the flow behaviour of the fluid in the cases of the heel point injection and the toe point injection modes in Dong et al.'s experiment [19]. Therefore, the simulation results of the developed model can be compared with the experimental results of Dong et al. to validate the proposed model. The experimental data used for calculation are listed in Table 1. Major assumptions are made as follows: (1) the reservoir is homogeneous; (2) during the simulation, the steam pressure, steam injection rate and steam quality at the outlet of the string do not change with time; (3) the perforation diameter, density and phasing are the same in every micro-segment of the horizontal well. The results calculated using this model and the experimental results of Dong et al. are presented in Figure 5. Figure 5 illustrates that the average relative error of the pressure, which, in the cases of the heel point injection and toe point injection modes, is $2.52 \%$ and $2.81 \%$, respectively. The average relative error of the temperature in the cases of the heel point injection and toe point injection modes is $1.80 \%$ and $1.99 \%$, respectively. Results from the developed model and Dong et al.'s experiment have a relative error of $<5 \%$. The agreement between experimental results and the results obtained from the model is good, showing an acceptable average relative error. In addition, the simulation results are linear in the developed model, while the experimental results are non-linear in Dong et al.'s experiment. There are some small deviations between the simulation results of the developed model and the experimental results of Dong et al.'s experiment, because when the reservoir is assumed to be homogeneous, the experimental data input in the developed model for simulation are homogeneous, while the experimental data actually used in Dong et al.'s experiment may be not absolutely homogeneous due to the actual grain size of the quartz sand not being exactly the same.

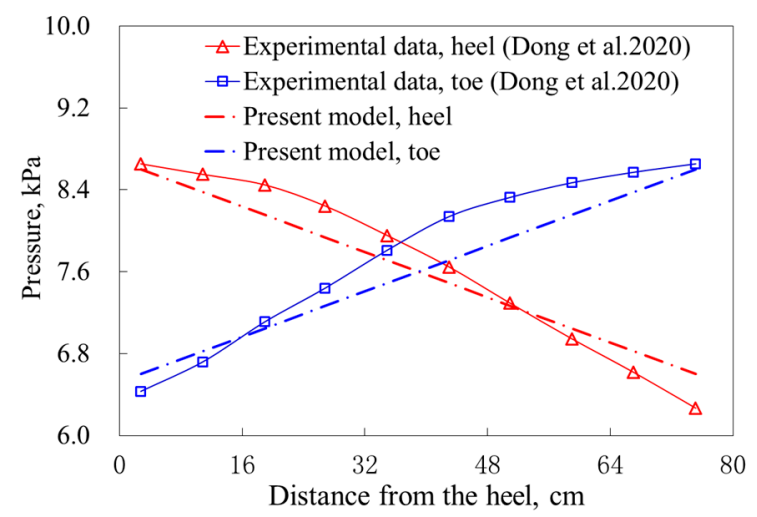

(a)

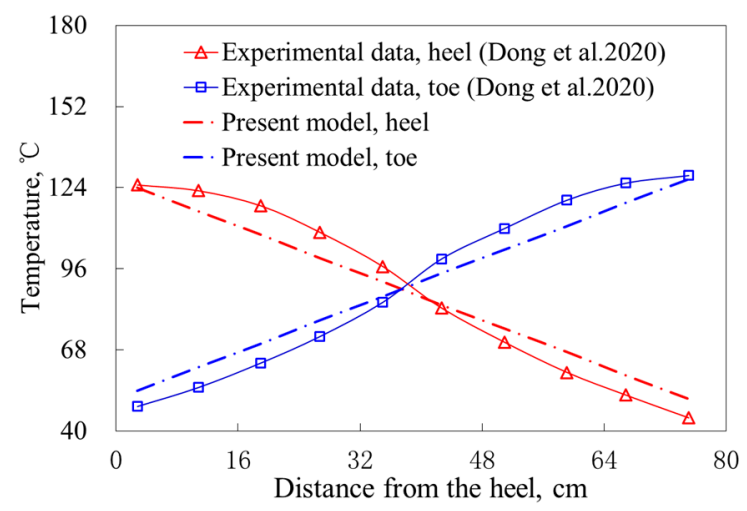

(b)

Figure 5. Comparison of the simulated results and experimental data: (a) pressure; (b) temperature. 
Table 1. Basic data used in the calculations.

\begin{tabular}{cccc}
\hline Items & Values & Items & Values \\
\hline Reservoir thickness, cm & 15 & Oil saturation, $\%$ & 75 \\
Porosity, $\%$ & 0.38 & Initial reservoir temperature, ${ }^{\circ} \mathrm{C}$ & 25 \\
Horizontal well length, $\mathrm{cm}$ & 80 & Reservoir permeability, $10^{-3} \mu \mathrm{m}^{2}$ & 3000 \\
Wellbore radius, $\mathrm{cm}$ & 6 & Steam temperature, ${ }^{\circ} \mathrm{C}$ & 130 \\
Steam injection rate, $\mathrm{cm}^{3} / \mathrm{min}$ & 40 & Steam injection time, $\mathrm{min}$ & 30 \\
\hline
\end{tabular}

\subsubsection{Verification against the Numerical Solution}

In this section, to validate the proposed model, a traditional SAGD process was simulated based on the field data from the MacKay River heavy oil reservoir, Western Canada, and the field data are listed in Table 2 . The relative permeability curves as well as the viscosity vs. temperature are shown in Figure 6. The 3D model has dimensions of $1100 \mathrm{~m} \times 110 \mathrm{~m} \times 20 \mathrm{~m}$, and the well configuration is a conventional single-pipe well configuration.

During the traditional SAGD circulation stage, steam is injected through both the injector and the producer. The steam injection pressure, steam quality and injection rate at the heel of the wellbore are $2.0 \mathrm{MPa}, 0.95$ and $80 \mathrm{~m}^{3} / \mathrm{d}$, respectively. After 120 days of circulation, the well pair is converted to the SAGD operation. The steam injection pressure and steam quality at the heel of the horizontal injection well are 2.12 MPa and 0.95, respectively. The bottomhole pressure at the heel of the horizontal production well is $1.5 \mathrm{MPa}$. The calculated results of this model are compared with the commercial thermal simulator, Computer Modelling Group (CMG) simulation results, as shown in Figures 7 and 8 .

Figure 7 illustrates that the average relative errors in the temperature and pressure values in each grid between the 3D present model and the CMG are $4.52 \%$ and $4.61 \%$ at the end of the circulation stage, respectively (outliers are not considered in error calculation). The visible differences between the CMG and the developed model in Figure 7 may be due to the different software utilizing different data processing methods. The calculation results of each grid by CMG are displayed in the form of a block fill in the CMG software interface. However, the calculation results of each grid using the developed model are displayed in the form of fill contours in the drawing software (Surfer 16) used herein. In addition, Figure 8 illustrates that the average relative error of the injector wellbore pressure at 160 days, 170 days and 180 days is $0.58 \%, 0.71 \%$ and $0.83 \%$, and the average relative error of the cumulative oil production and oil production rate is $1.37 \%$ and $1.45 \%$, respectively. Results from the developed model and CMG have a relative error of $<5 \%$. The calculation results of the developed model are consistent with the CMG simulated results, showing an acceptable average relative error. Thus, this model can predict the SAGD process.

Table 2. Reservoir data used in the calculations.

\begin{tabular}{|c|c|c|c|}
\hline Items & Values & Items & Values \\
\hline Initial reservoir pressure, $\mathrm{MPa}$ & 0.22 & Vertical permeability, $\left(10^{-3} \mu \mathrm{m}^{2}\right)$ & 1890 \\
\hline Initial oil density, $\mathrm{kg} / \mathrm{m}^{3}$ & 1004.15 & Initial water density, $\mathrm{kg} / \mathrm{m}^{3}$ & 1006.49 \\
\hline Oil heat capacity, $\mathrm{KJ} /\left(\mathrm{kg} \cdot{ }^{\circ} \mathrm{C}\right)$ & 2.2 & Water heat capacity, $\mathrm{KJ} /\left(\mathrm{kg} \cdot{ }^{\circ} \mathrm{C}\right)$ & 4.2 \\
\hline Rock heat conductivity coefficient, $\mathrm{W} /\left(\mathrm{m} \cdot{ }^{\circ} \mathrm{C}\right)$ & 5.2 & Rock compressibility coefficient, $\mathrm{MPa}^{-1}$ & 0.002 \\
\hline$\Delta x, \mathrm{~m}$ & 10 & Number of blocks along $x$ & 110 \\
\hline$\Delta y, \mathrm{~m}$ & 2 & Number of blocks along $y$ & 55 \\
\hline$\Delta z, \mathrm{~m}$ & 1 & Number of blocks along $z$ & 20 \\
\hline Time step, day & 0.01 & Porosity & 0.33 \\
\hline Outer diameter of the slotted liner, $\mathrm{mm}$ & 219.10 & Inner diameter of the slotted liner, $\mathrm{mm}$ & 201.20 \\
\hline
\end{tabular}




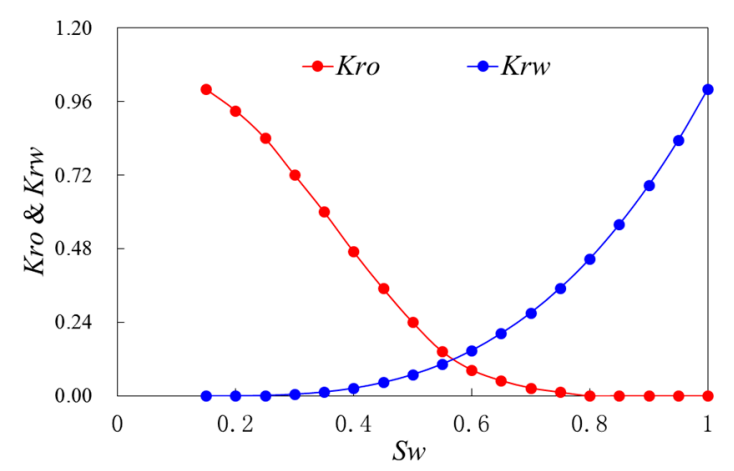

(a)

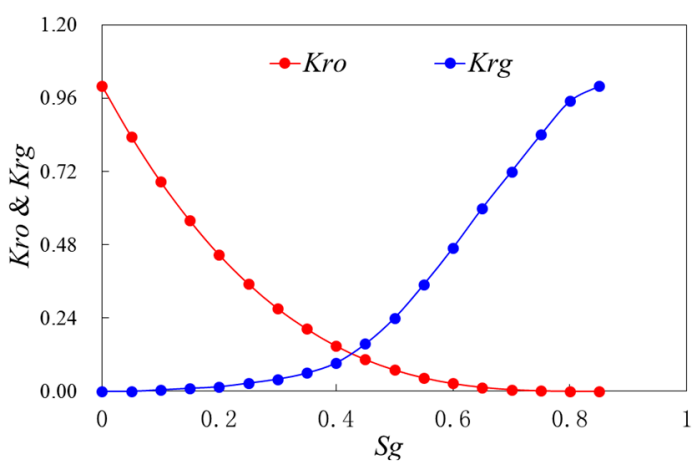

(b)

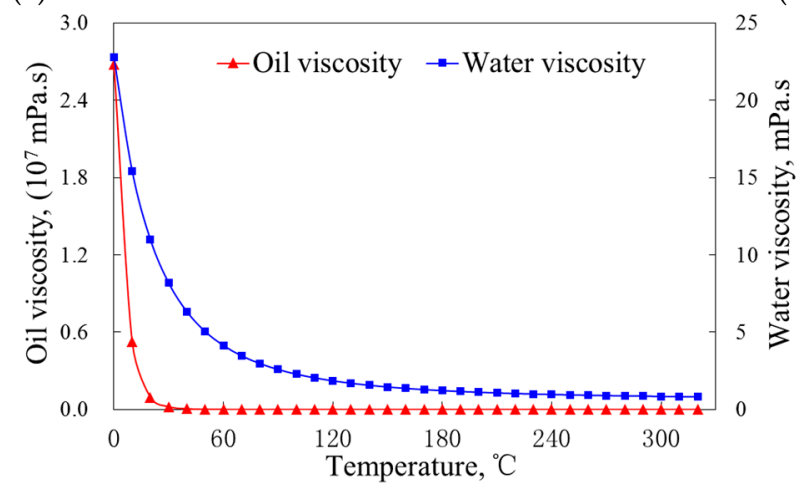

(c)

Figure 6. Relative permeability curve and viscosity vs. temperature: (a) Relative permeability curves of oil and water; (b) Relative permeability curves of oil and gas; (c) Viscosities of oil and water.
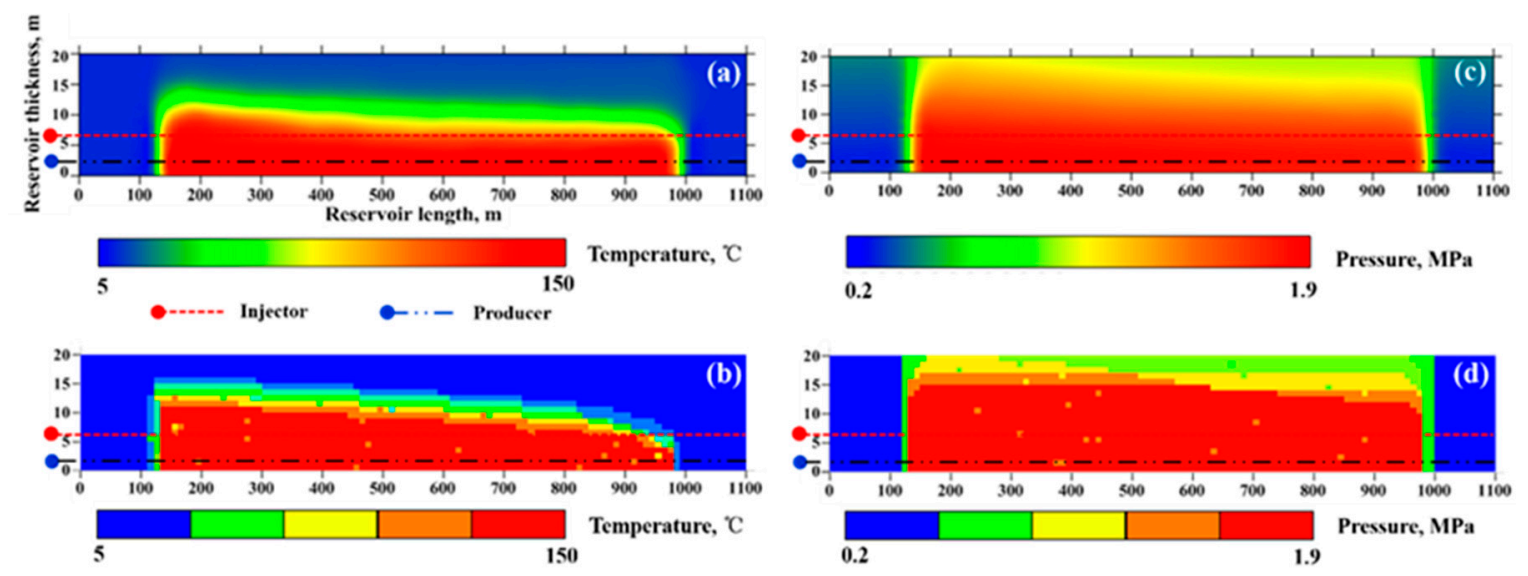

Figure 7. Comparison of the steam chamber and reservoir pressure profile along the well pair axis at the end of the circulation stage (vertical exaggeration 10 times): (a) steam chamber calculated by the developed model; (b) steam chamber simulated by CMG; (c) reservoir pressure profile calculated by the developed model; (d) reservoir pressure profile simulated by CMG. 


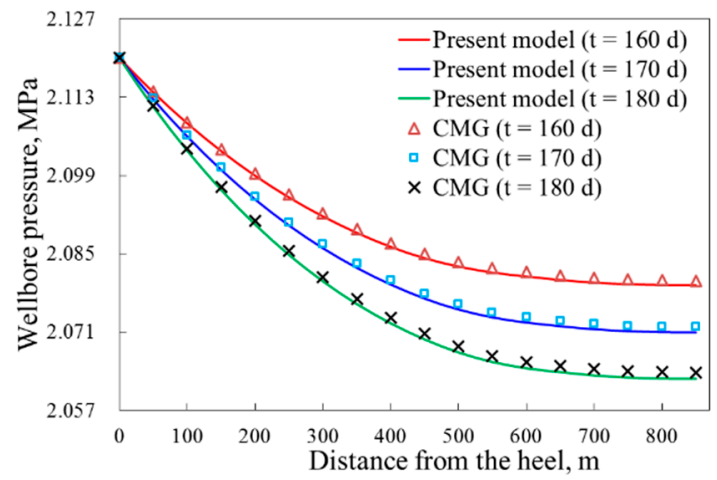

(a)

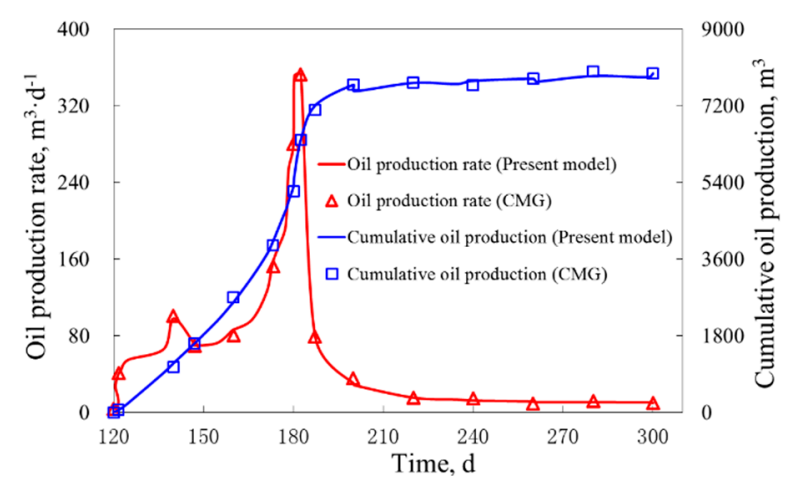

(b)

Figure 8. Comparison of the predicted results with CMG in the SAGD operation: (a) injector wellbore pressure; (b) oil production rate and cumulative oil production.

In addition, in the CMG wellbore model [39], various transition criteria for gas/liquid two-phase flow were established to determine the flow pattern, and the annulus was treated as a pipe based on the equivalent hydraulic diameter concept. However, precisely dividing flow patterns is difficult, and the flow patterns in the annulus have been demonstrated to be different from pipe-flow patterns [24,25]. The calculation of the pressure drop may be a rough approximation [26,27]. In the proposed model, a simplified approach was first used to calculate the pressure drop in the steam injection horizontal wellbore [26-28], as derived in Appendix A.

\subsection{Sensitivity Analysis}

To improve the steam conformance, the effects of the injector wellbore configuration, steam injection ratio and injection time on the steam conformance were investigated with dual-string horizontal wells in SAGD operations. The calculation parameters were based on the reservoir data in Table 2. The relative permeability curves as well as the viscosity vs. temperature are shown in Figure 6. For all of the studies, the short and long strings of the producer were landed at the heel and toe of the wellbore, respectively, and the bottomhole pressures at the heels of the short and long production strings are fixed values.

\subsubsection{Effect of the Injector Wellbore Configuration}

To study the effect of the injector wellbore configuration on the steam conformance, four schemes were designed. Namely, the short string of the injector was extended $0 \mathrm{~m}$ (heel of the wellbore), $150 \mathrm{~m}$, $275 \mathrm{~m}$ and $425 \mathrm{~m}$ into the well. In each scheme, the total steam injection rate was $110 \mathrm{~m}^{3} / \mathrm{d}$.

Figure 9 illustrates that the pressure drop in the annulus initially decreases and then increases as the landing position of the short string increases. When the short string was extended $0 \mathrm{~m}, 150 \mathrm{~m}$, $275 \mathrm{~m}$ and $425 \mathrm{~m}$ into the horizontal section, the total annulus pressure drops are $45.49 \mathrm{kPa}, 30.55 \mathrm{kPa}$, $141.29 \mathrm{kPa}$ and $315.10 \mathrm{kPa}$, respectively. It can be seen that the pressure drop mainly occurs in the $\mathrm{AB}$ section of the annulus. Because the cross-sectional area of the annulus space of the AB section is smaller than that of the annulus space of the BD section, as the short string was extended $150 \mathrm{~m}, 275 \mathrm{~m}$ and $425 \mathrm{~m}$ into the well, the pressure drop in the $\mathrm{AB}$ section is $27.10 \mathrm{kPa}, 132.87 \mathrm{kPa}$ and $313.14 \mathrm{kPa}$, which accounts for $88.71 \%, 94.04 \%$ and $99.38 \%$ of the total annulus pressure drop, respectively; the pressure drop in the BD section is $30.55 \mathrm{kPa}, 21.87 \mathrm{kPa}$ and $9.37 \mathrm{kPa}$, which accounts for $100 \%, 15.48 \%$ and $2.98 \%$ of the total annulus pressure drop, respectively. The pressure drop in the AB section is the main factor affecting the uniform distribution of steam pressure in the annulus, and the closer the differences in the pressure drop between the $\mathrm{AB}$ section and $\mathrm{BD}$ section, the better is the uniformity of the distribution of steam pressure in the annulus. In this study, a relatively uniform injector annular pressure profile could be obtained when the short string was pushed $150 \mathrm{~m}$ into the horizontal section. In practical 
situations, the steam pressure along the wellbore can be measured. Therefore, to obtain a uniform injector annular pressure profile under different injector wellbore configurations, it is recommended that production engineers monitor the pressure drop in the $\mathrm{AB}$ and $\mathrm{BD}$ sections. If the pressure drop in the $\mathrm{AB}$ section is larger than the pressure drop in the $\mathrm{BD}$ section, it is recommended that the landing position of the short string be shortened; if the pressure drop in the $\mathrm{AB}$ section is smaller than the pressure drop in the $\mathrm{BD}$ section, it is suggested that the landing position of the short string be extended. Finally, the pressure drop in the $\mathrm{AB}$ section is almost equal to the pressure drop in the BD section.

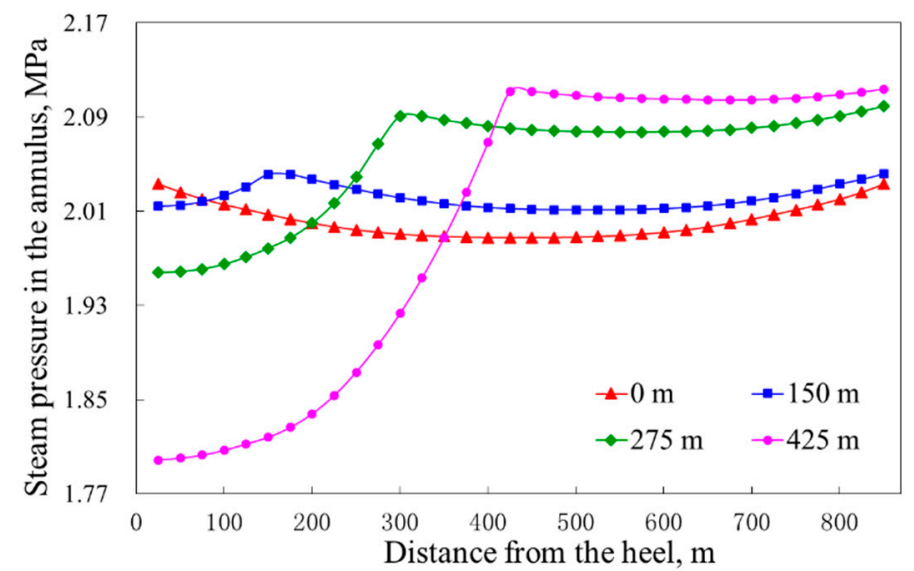

Figure 9. Effect of the injector wellbore configuration on the annulus pressure profiles of the injector.

Figure 10a shows that the steam flux rates are large at the landing position of the short injection string and at the toe of the wellbore. Because the annulus pressure is high at the landing position of the short injection string, the drainage area near the toe of the wellbore is large. Compared with the steam flux rate at the toe of the wellbore, the steam flux rate at the heel of the wellbore is small because the low annulus pressure at the heel restricts the advantage of the large drainage area around the heel. It can be observed that the distribution trends of the liquid production profiles and steam injection profiles are similar, as shown in Figure 10b. This phenomenon is due to the large amount of steam injected into the reservoir at a certain place contributing to a high fluid mobility and a high potential for fluid recovery. In addition, the fluctuation range of the injection and production profiles initially decrease and then increase as the landing position of the short string increases. When the short string was extended $0 \mathrm{~m}, 150 \mathrm{~m}, 275 \mathrm{~m}$ and $425 \mathrm{~m}$ into the well, the fluctuation range of the steam injection profile was $0.071 \mathrm{~m}^{3} /(\mathrm{d} \cdot \mathrm{m}), 0.068 \mathrm{~m}^{3} /(\mathrm{d} \cdot \mathrm{m}), 0.084 \mathrm{~m}^{3} /(\mathrm{d} \cdot \mathrm{m})$ and $0.097 \mathrm{~m}^{3} /(\mathrm{d} \cdot \mathrm{m})$, respectively. The fluctuation range of the liquid production profile was $0.073 \mathrm{~m}^{3} /(\mathrm{d} \cdot \mathrm{m}), 0.071 \mathrm{~m}^{3} /(\mathrm{d} \cdot \mathrm{m}), 0.088 \mathrm{~m}^{3} /(\mathrm{d} \cdot \mathrm{m})$ and $0.115 \mathrm{~m}^{3} /(\mathrm{d} \cdot \mathrm{m})$, respectively. Therefore, the steam breakthrough phenomenon around the heel of the wellbore could be mitigated, and the uniformity of the injection and production profiles could be improved as the short injection string was pushed $150 \mathrm{~m}$ into the horizontal section.

Figure 11 shows the steam chamber along the well pair axis at 210 days. It is observed that landing the short injection string at a certain position can effectively delay the occurrence of steam fingering around the heel section of the horizontal well. As the short string was pushed $150 \mathrm{~m}$ into the horizontal section, the steam conformance was improved, and a higher cumulative oil production was achieved. Table 3 shows that when the short injection string was pushed $150 \mathrm{~m}$ into the horizontal section, the uniformity of each parameter distribution along the wellbore was the highest, and the uniformity improvement coefficient of the steam chamber was $19.49 \%$ compared with the base scheme (the short string was landed at the heel of the well). Therefore, a more uniform steam conformance was created, and the oil recovery was enhanced as the short injection string was landed at $150 \mathrm{~m}$ in the well. 


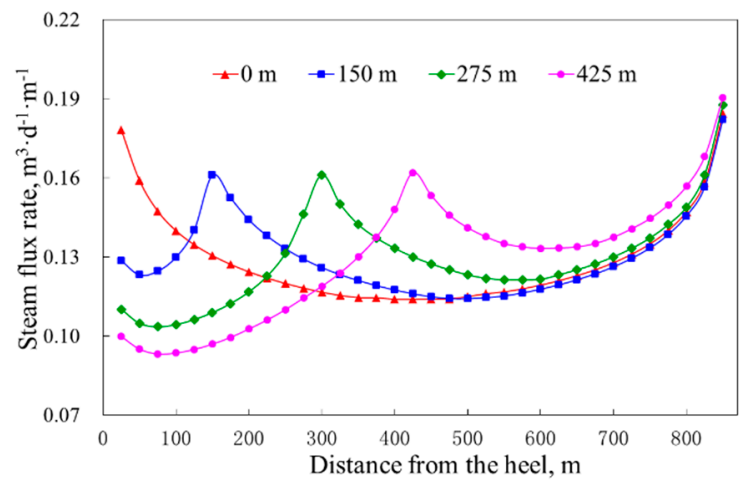

(a)

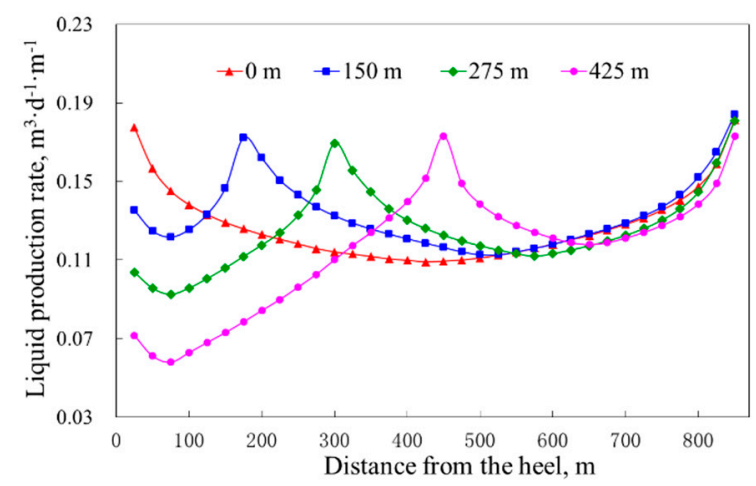

(b)

Figure 10. Effect of the injector wellbore configuration on the injection and production profiles: (a) steam flux rate; (b) liquid production rate.

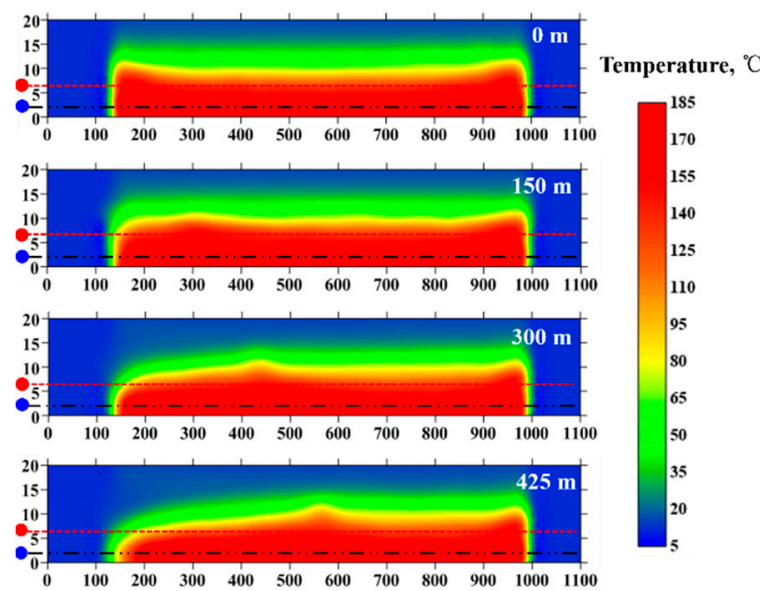

(a)

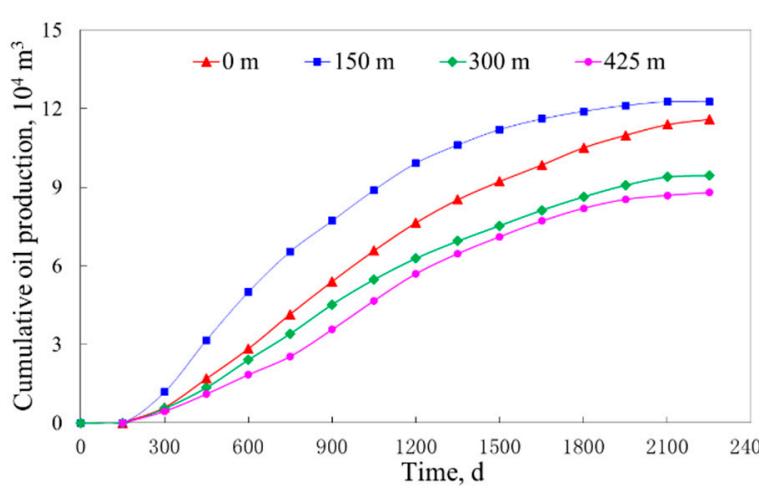

(b)

Figure 11. Effect of the injector wellbore configuration on the steam chamber and cumulative oil production: (a) steam chamber; (b) cumulative oil production. 
Table 3. Calculation results of the non-uniformity coefficients and uniformity improvement coefficient.

\begin{tabular}{|c|c|c|c|c|c|c|c|c|c|}
\hline \multirow[b]{2}{*}{$\begin{array}{l}\text { Items } \\
\text { Scheme }\end{array}$} & & \multicolumn{4}{|c|}{ Non-uniformity Coefficients } & \multicolumn{4}{|c|}{ Uniformity Improvement Coefficients } \\
\hline & & $\begin{array}{c}\text { Annulus } \\
\text { Pressure, } \\
\text { MPa }\end{array}$ & $\begin{array}{c}\text { Steam Flux } \\
\text { Rate, } \\
\left(\mathrm{m}^{3} \cdot \mathrm{d}^{-1} \cdot \mathrm{m}^{-1}\right)\end{array}$ & $\begin{array}{c}\text { Liquid } \\
\text { Production Rate, } \\
\left(\mathrm{m}^{3} \cdot \mathrm{d}^{-1} \cdot \mathrm{m}^{-1}\right)\end{array}$ & $\begin{array}{l}\text { Height of } \\
\text { Steam } \\
\text { Chamber, } \mathrm{m}\end{array}$ & $\begin{array}{c}\text { Annulus } \\
\text { Pressure, } \\
\text { MPa }\end{array}$ & $\begin{array}{c}\text { Steam Flux } \\
\text { Rate, } \\
\left(\mathrm{m}^{3} \cdot \mathrm{d}^{-1} \cdot \mathrm{m}^{-1}\right)\end{array}$ & $\begin{array}{c}\text { Liquid } \\
\text { Production Rate, } \\
\left(\mathrm{m}^{3} \cdot \mathrm{d}^{-1} \cdot \mathrm{m}^{-1}\right)\end{array}$ & $\begin{array}{l}\text { Height of } \\
\text { Steam } \\
\text { Chamber, } \mathrm{m}\end{array}$ \\
\hline \multirow{4}{*}{$\begin{array}{c}\text { Injector } \\
\text { wellbore } \\
\text { configuration }\end{array}$} & $0 \mathrm{~m}$ & $4.15 \times 10^{-2}$ & 0.812 & 0.854 & 0.395 & - & - & - & - \\
\hline & $150 \mathrm{~m}$ & $2.86 \times 10^{-2}$ & 0.692 & 0.774 & 0.318 & $31.08 \%$ & $14.78 \%$ & $9.37 \%$ & $19.49 \%$ \\
\hline & $275 \mathrm{~m}$ & $13.54 \times 10^{-2}$ & 0.815 & 0.947 & 0.432 & $-226.27 \%$ & $-0.37 \%$ & $-10.89 \%$ & $-9.37 \%$ \\
\hline & $425 \mathrm{~m}$ & $37.14 \times 10^{-2}$ & 1.074 & 1.552 & 0.487 & $-794.94 \%$ & $-32.27 \%$ & $-81.73 \%$ & $-23.29 \%$ \\
\hline \multirow{3}{*}{$\begin{array}{c}\text { Steam } \\
\text { injection ratio }\end{array}$} & $35: 75$ & $8.03 \times 10^{-2}$ & 0.866 & 0.981 & 0.491 & $-93.49 \%$ & $-6.65 \%$ & $-14.87 \%$ & $-2.29 \%$ \\
\hline & 55:55 & $4.15 \times 10^{-2}$ & 0.812 & 0.854 & 0.480 & - & - & - & - \\
\hline & 75:35 & $9.87 \times 10^{-2}$ & 0.868 & 0.982 & 0.494 & $-137.83 \%$ & $-6.89 \%$ & $-14.99 \%$ & $-2.91 \%$ \\
\hline \multirow{3}{*}{ Injection time } & $170 \mathrm{~d}$ & $4.15 \times 10^{-2}$ & 0.812 & 0.854 & 0.394 & - & - & - & - \\
\hline & $190 \mathrm{~d}$ & $7.17 \times 10^{-2}$ & 0.889 & 0.898 & 0.444 & $-72.77 \%$ & $-9.18 \%$ & $-5.15 \%$ & $-12.69 \%$ \\
\hline & $210 \mathrm{~d}$ & $9.90 \times 10^{-2}$ & 0.960 & 0.969 & 0.510 & $-138.55 \%$ & $-18.23 \%$ & $-13.47 \%$ & $-29.44 \%$ \\
\hline
\end{tabular}




\subsubsection{Effect of the Steam Injection Ratio}

In this section, the steam injection ratios of the long and short injection strings are set to $35: 75$, 55:55 and 75:35 to study the influence of the steam injection ratio on the steam conformance. In each scheme, the total steam injection rate was $110 \mathrm{~m}^{3} / \mathrm{d}$. The short string landed at the heel, and the long string landed at the toe for both the injector and the producer.

Figure 12 illustrates that with an increase in the steam injection ratio of the long and short injection strings, the fluctuation range of the injector annular pressure profile decreases first and then increases. The maximum pressure drops in the annulus are $104.76 \mathrm{kPa}, 45.49 \mathrm{kPa}$ and $125.91 \mathrm{kPa}$ as the steam injection ratios of the long and short injection strings are set to 35:75, 55:55 and 75:35, respectively. The smaller the difference in the steam injection rate between the long and short injection strings is, the more uniform the distribution of the annulus pressure of the injector. Therefore, when the steam injection ratio of the long and short injection strings is set to 55:55, the injector annular pressure profile uniformity can be improved.

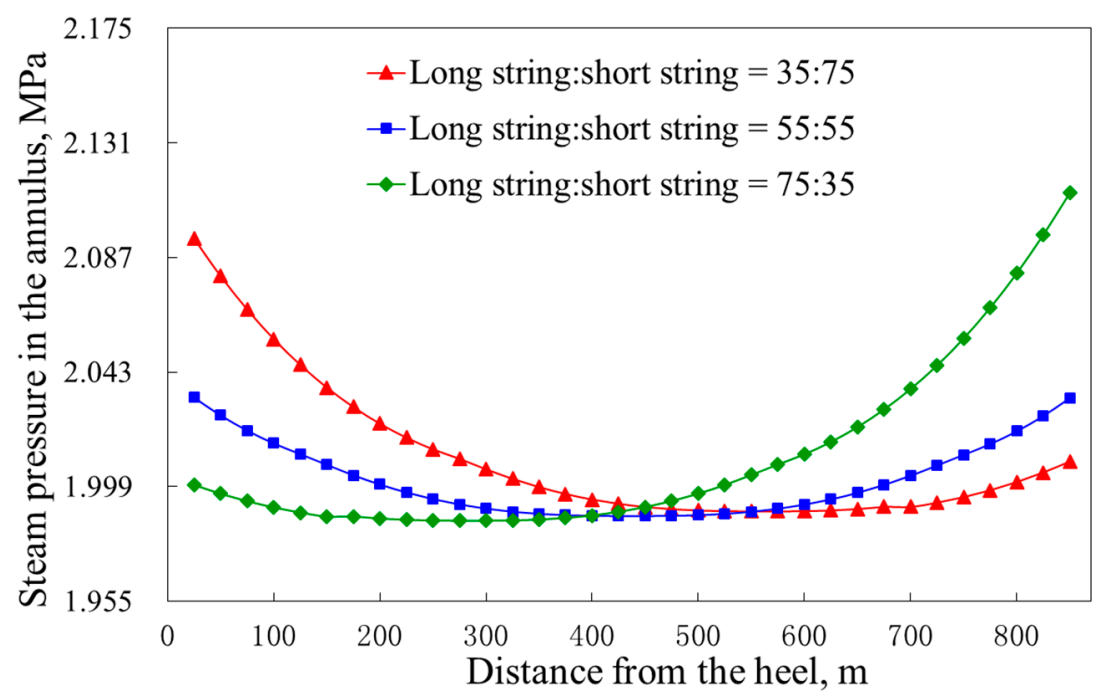

Figure 12. Effect of the steam injection ratio on the annulus pressure profiles of the injector.

Figure 13a illustrates that with an increase in the steam injection ratio of the long and short injection strings, the " $U$ "-shaped steam injection profile rotates counter-clockwise due to the distribution of the steam pressure in the annulus. It can be observed that the distribution trend of the liquid production profile is similar to the distribution trend of the steam injection profile, as shown in Figure 13b. The reason is discussed in Section 4.2.1.

In addition, the fluctuation ranges of the injection and production profiles initially decrease and then increase as the steam injection ratio of the long and short injection strings increases. When the steam injection ratio of the long and short injection strings is $35: 75,55: 55$ and 75:35, the fluctuation range of the steam injection profile is $0.0807 \mathrm{~m}^{3} /(\mathrm{d} \cdot \mathrm{m}), 0.0705 \mathrm{~m}^{3} /(\mathrm{d} \cdot \mathrm{m})$ and $0.0806 \mathrm{~m}^{3} /(\mathrm{d} \cdot \mathrm{m})$, respectively; the fluctuation range of the liquid production profile is $0.0873 \mathrm{~m}^{3} /(\mathrm{d} \cdot \mathrm{m}), 0.0724 \mathrm{~m}^{3} /(\mathrm{d} \cdot \mathrm{m})$ and $0.0875 \mathrm{~m}^{3} /(\mathrm{d} \cdot \mathrm{m})$, respectively. Consequently, to improve the uniformity of the injection and production profiles, setting the steam injection ratio of the long and short injection strings to 55:55 is suggested. 


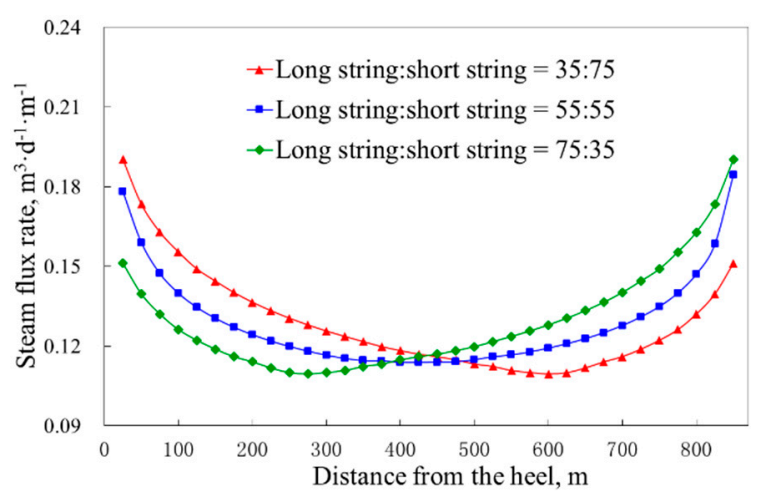

(a)

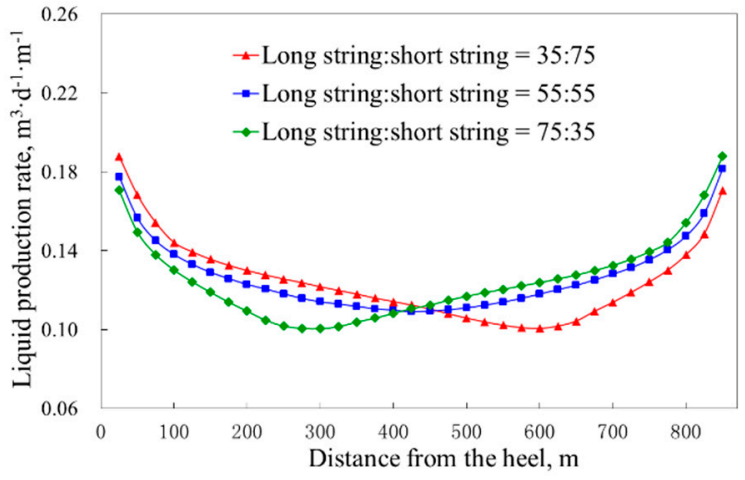

(b)

Figure 13. Effect of the steam injection ratio on the injection and production profiles: (a) steam flux rate; (b) liquid production rate.

Figure 14 shows the steam chamber along the well pair axis at 210 days, and it is found that the small difference in the steam injection rate between the long and short injection strings is beneficial for creating a more uniform steam chamber and improving cumulative oil production. Table 3 illustrates that in the base scheme (the steam injection ratio of long and short injection strings is set to 55:55), the uniformity of each parameter distribution along the wellbore is the highest. Thus, to establish a better steam conformance and ultimately improve oil recovery, using the same steam injection rate for the long and short injection strings is recommended.

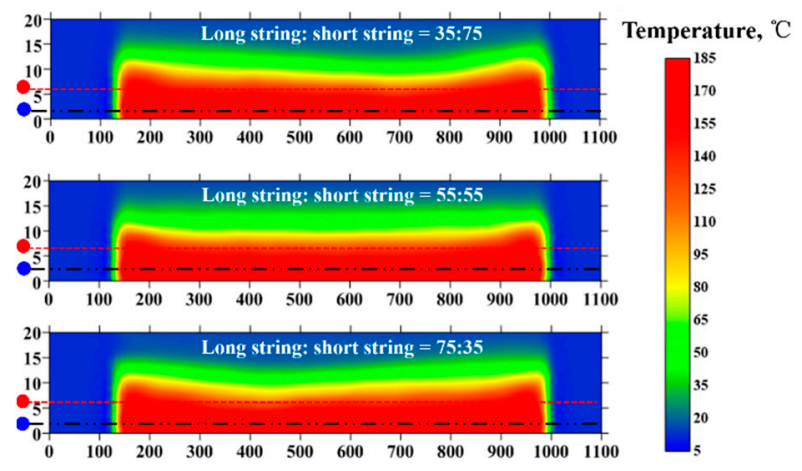

(a)

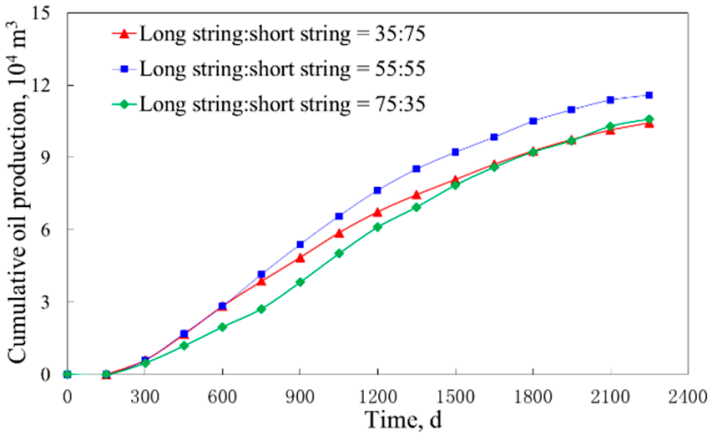

(b)

Figure 14. Effect of the steam injection ratio on the steam chamber and cumulative oil production: (a) steam chamber; (b) cumulative oil production.

\subsubsection{Effect of the Injection Time}

The injection time is one of the main factors affecting the development of the steam chamber. However, previous dual-string horizontal injection well models are analytical models that fail to consider the influence of the injection time on the variations in reservoir properties. In this Section, the effect of the injection time on the steam conformance is discussed.

Figure 15 illustrates that the pressure drop in the annulus increases with increasing injection time. When the injection time is 170 days, 190 days and 210 days, the injector annular pressure drops are $45.49 \mathrm{kPa}, 83.84 \mathrm{kPa}$ and $112.63 \mathrm{kPa}$, respectively. The non-uniformity of the steam pressure in the annulus will become more serious as steam injection proceeds. 


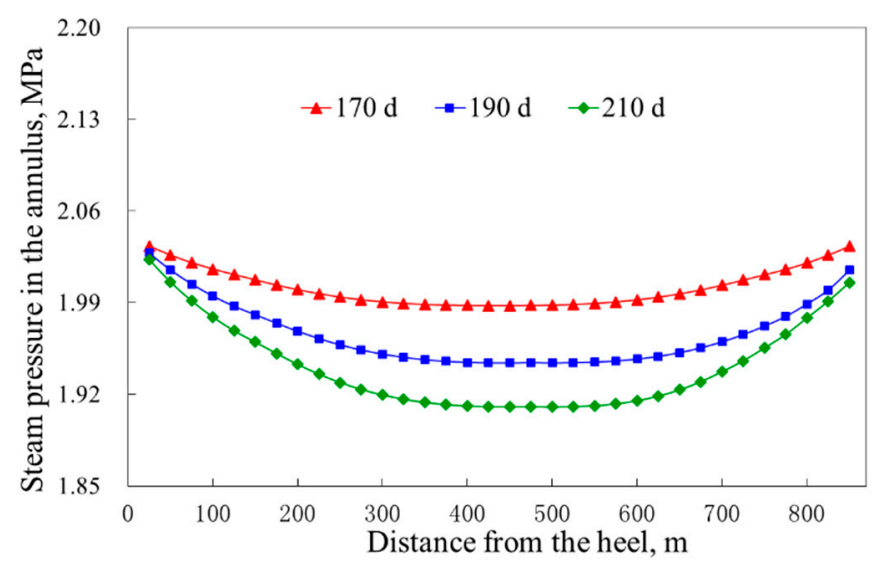

Figure 15. Effect of the injection time on the annulus pressure profiles of the injector.

Figure 16 illustrates that with the increase of the injection time, the steam flux rate and liquid production rate increase, and the fluctuation range of the injection and production profiles increases. When the injection time is 170 days, 190 days and 210 days, the fluctuation range of the steam injection profile is $0.071 \mathrm{~m}^{3} /(\mathrm{d} \cdot \mathrm{m}), 0.085 \mathrm{~m}^{3} /(\mathrm{d} \cdot \mathrm{m})$ and $0.995 \mathrm{~m}^{3} /(\mathrm{d} \cdot \mathrm{m})$, respectively; the fluctuation range of the liquid production profile is $0.072 \mathrm{~m}^{3} /(\mathrm{d} \cdot \mathrm{m}), 0.085 \mathrm{~m}^{3} /(\mathrm{d} \cdot \mathrm{m})$ and $0.107 \mathrm{~m}^{3} /(\mathrm{d} \cdot \mathrm{m})$, respectively. The non-uniformity of the injection and production profiles increases as time proceeds.

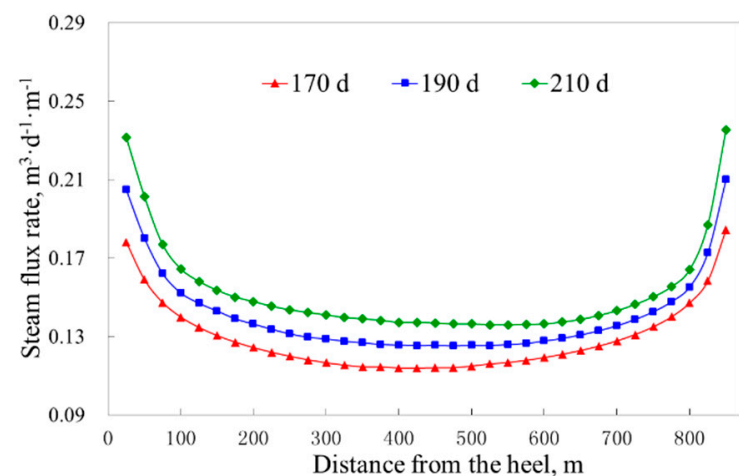

(a)

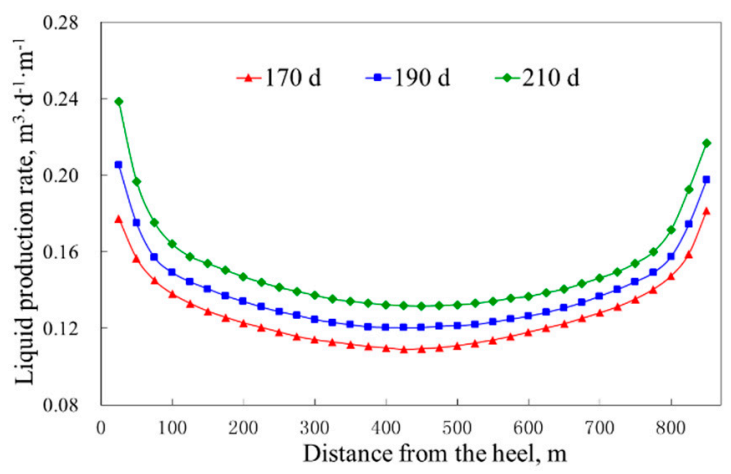

(b)

Figure 16. Effect of the injection time on the injection and production profiles: (a) steam flux rate; (b) liquid production rate.

Figure 17 illustrates the effect of the injection time on the steam chamber growth. It is found that the development of the steam chamber is sensitive to the injection time. The uniformity of the steam chamber decreases with increasing injection time. In particular, the heel-toe effect plays a crucial role in this non-uniformity. In addition, Figures $11 \mathrm{~b}$ and $14 \mathrm{~b}$ indicate that with the increase of the injection time, the cumulative oil production increases in the early time stage of the SAGD operation but only slightly increases at a certain time. Consequently, to achieve a better steam conformance and recover more reserves, the optimization method of steam chamber uniformity should be adjusted according to different injection times.

In addition, as shown in Table 3, the more uniform the injector annular pressure profile, the more uniform the injection and production profiles and the steam chamber. In other words, the uniformity of the injection and production profiles and the steam conformance can be achieved by obtaining a uniform distribution of steam pressure in the annulus of the injector. 


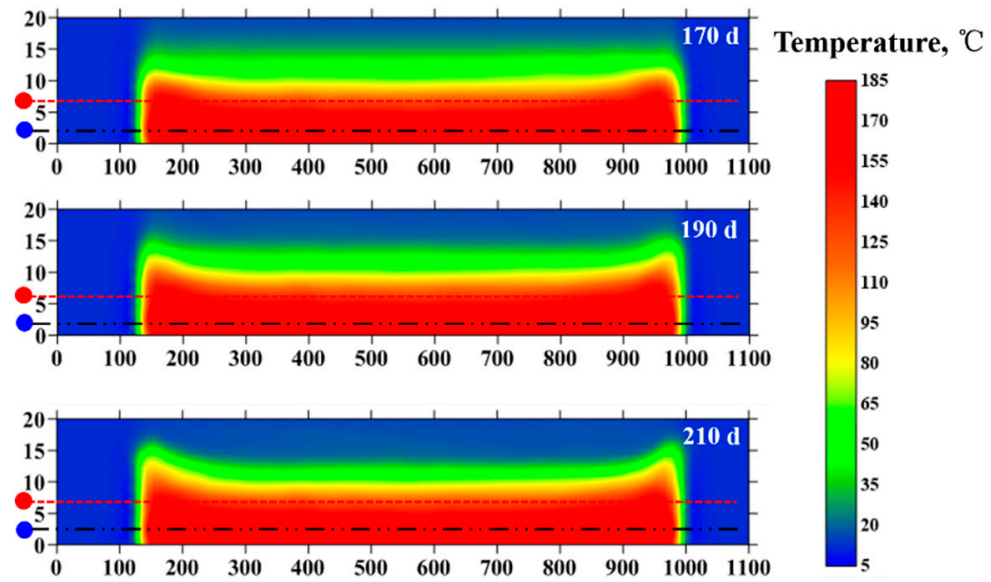

Figure 17. Effect of the injection time on the steam chamber.

Furthermore, under conditions of the same total steam injection rate $\left(110 \mathrm{~m}^{3} / \mathrm{d}\right)$, the cumulative oil production is $12.27 \times 10^{4} \mathrm{~m}^{3}$ after simulation when the short string is pushed $150 \mathrm{~m}$ into the horizontal section (Figure 11b). The cumulative oil production is $11.59 \times 10^{4} \mathrm{~m}^{3}$ after simulation when the steam injection ratio of the long and short injection strings are set to 55:55 (Figure 14b). Compared with the steam injection ratio of the long and short injection strings set to 55:55, a higher cumulative oil production can be obtained as the short string is landed at a suitable position. Therefore, the short string landing at a suitable position is recommended to achieve high cumulative long-term oil production. The suggestion for production engineers to adjust the landing position of the short string to achieve a uniform injector annular pressure profile and better steam conformance is discussed in Section 4.2.1. To the best of our knowledge, the heel-toe effect is not beneficial for oil production. When the short string is landed at a suitable position, the steam breakthrough phenomenon around the heel of the wellbore can be mitigated. Thus, how to reduce the steam breakthrough phenomenon around the toe of the wellbore is the key to improve the steam conformance and cumulative oil production. To reduce the effect of the steam breakthrough phenomenon around the toe of the wellbore on the steam conformance and oil production, it is suggested that production engineers close the long string for steam injection or decrease the steam injection pressure of the long string when the monitoring pressure drop in the $\mathrm{BD}$ section is larger than the pressure drop in the $\mathrm{AB}$ section.

The model developed in this paper is limited to a solution for saturated steam injection with a dual-string well configuration. For the injector, the well configuration includes short string injection, long string injection and simultaneous dual-string injection. For the producer, the well configuration contains short string production, long string production and simultaneous dual-string production. Production engineers can use the proposed model to predict the distribution of the wellbore parameters and the reservoir properties during the entire lifetime of a simulation process with different well configurations, and adopt appropriate measures to improve the steam chamber uniformity and increase oil production based on the simulation results.

\section{Conclusions}

(1) The predicted results of the developed model match well with the CMG calculation results and the experimental data. The proposed model is shown to be reliable.

(2) Under different injector wellbore configurations, the closer the differences in the pressure drop in the $\mathrm{AB}$ and $\mathrm{BD}$ sections, the better is the uniformity of the injector annular pressure profile, injection and production profiles and steam conformance. It is recommended that production engineers measure the pressure drop in the $\mathrm{AB}$ section and $\mathrm{BD}$ section and adjust the landing position of the short string to obtain an equal pressure drop in the $\mathrm{AB}$ and $\mathrm{BD}$ sections. 
(3) The smaller the difference in the steam injection rate between the long and short injection strings, the more uniform is the distribution of the injection and production profiles and the steam chamber.

(4) Creating a more uniform injector annular pressure profile is beneficial for improving the uniformity of the injection and production profiles and the steam conformance.

(5) The steam conformance decreases as time proceeds. The appropriate optimization method should be adopted for different injection times to improve the steam conformance.

Author Contributions: Conceptualization, P.L. and Y.Z.; methodology, P.L., Y.Z. and X.S.; software, P.L. and Y.Z.; validation, X.S. and H.C.; formal analysis, P.L., Y.Z., X.S., H.C. and Y.L.; investigation, P.L., Y.Z., X.S., and H.C.; data curation, Y.L.; writing — original draft preparation, P.L.; writing—review and editing, Y.Z.; funding acquisition, Y.Z., X.S., and H.C.; All authors have read and agreed to the published version of the manuscript.

Funding: This research was funded by the National Natural Science Foundation of China, grant number 51604293 and 51704190; the Shandong Provincial Natural Science Foundation, China, grant number ZR2016EEB30; the Fundamental Research Funds for the Central Universities, grant number 17CX02009A; the Qingdao Applied Basic Research Program, grant number 17-1-1-32-jch; the Scientific Research Foundation of China University of Petroleum for Talent Introduction, grant number YJ201601093; and the National Science and Technology Major Project, grant number 2016ZX05031-002.

Conflicts of Interest: The authors declare no conflict of interest.

\section{Nomenclature}

$A_{\mathrm{pa}} \quad$ effective cross-sectional area in the annulus $\left[\mathrm{m}^{2}\right]$

$A_{\mathrm{pl}} \quad$ effective cross-sectional area in the string $\left[\mathrm{m}^{2}\right]$

$B_{\mathrm{O}} \quad$ formation volume factor of oil $\left[\mathrm{m}^{3} / \mathrm{m}^{3}\right]$

$B_{\mathrm{W}} \quad$ formation volume factor of water $\left[\mathrm{m}^{3} / \mathrm{m}^{3}\right]$

$c_{\mathrm{R}} \quad$ specific heat capacity of rock $\left[\mathrm{J} /\left(\mathrm{kg} \cdot{ }^{\circ} \mathrm{C}\right)\right]$

$C_{\text {Jma }} \quad$ Joule-Thomson coefficient of steam in the annulus $\left[{ }^{\circ} \mathrm{C} / \mathrm{Pa}\right]$

$\mathrm{C}_{\mathrm{Jml}} \quad$ Joule-Thomson coefficient of steam in the string $\left[{ }^{\circ} \mathrm{C} / \mathrm{Pa}\right]$

$\mathrm{C}_{\mathrm{pma}} \quad$ heat capacity of steam in the annulus $\left[\mathrm{J} /\left(\mathrm{kg} \cdot{ }^{\circ} \mathrm{C}\right)\right]$

$C_{\mathrm{pml}} \quad$ heat capacity of steam in the string $\left[\mathrm{J} /\left(\mathrm{kg} \cdot{ }^{\circ} \mathrm{C}\right)\right]$

D depth [m]

$\mathrm{g}$

$h_{\mathrm{a}}$ gravitational acceleration $\left[\mathrm{m} / \mathrm{s}^{2}\right]$

steam enthalpy in the annulus $[\mathrm{J} / \mathrm{kg}]$

$h_{1} \quad$ steam enthalpy in the string $[\mathrm{J} / \mathrm{kg}]$

$h_{\mathrm{pa}} \quad$ fluid enthalpy in the annulus $[\mathrm{J} / \mathrm{kg}]$

$h_{\mathrm{pl}} \quad$ fluid enthalpy in the string $[\mathrm{J} / \mathrm{kg}]$

$H_{i} \quad$ enthalpy of the phase $i$ in the heat convection term $[\mathrm{J} / \mathrm{kg}]$

$I_{\mathrm{S}} \quad$ injection production ratio

$k \quad$ absolute permeability $\left[10^{-3} \mu \mathrm{m}^{2}\right]$

$k_{\mathrm{h}} \quad$ horizontal permeability $\left[\mathrm{m}^{2}\right]$

$k_{\text {ro }} \quad$ relative permeability of oil

$k_{\text {rw }} \quad$ relative permeability of water

$k_{\mathrm{rg}} \quad$ relative permeability of gas

$k_{\mathrm{v}} \quad$ vertical permeability $\left[\mathrm{m}^{2}\right]$

$m_{\mathrm{a}} \quad$ steam mass flow rate in the annulus $[\mathrm{kg} / \mathrm{s}]$

$m_{\mathrm{c}} \quad$ rate of steam condensation $\left[\mathrm{kg} /\left(\mathrm{m}^{3} \cdot \mathrm{s}\right)\right]$

$m_{\mathrm{af}} \quad$ steam mass injection rate from the annulus to the reservoir $[\mathrm{kg} /(\mathrm{m} \cdot \mathrm{s})]$

$m_{\mathrm{g}} \quad$ steam mass imbibition rate per unit length $[\mathrm{kg} / \mathrm{s}]$

$m_{1} \quad$ steam mass flow rate in the string $[\mathrm{kg} / \mathrm{s}]$

$m_{\text {liquid }} \quad$ liquid production rate per unit length $[\mathrm{kg} / \mathrm{s}]$

$m_{\mathrm{pa}} \quad$ fluid mass flow rate in the annulus $[\mathrm{kg} / \mathrm{s}]$

$m_{\text {paf }} \quad$ fluid mass inflow rate from the reservoir to the annulus $[\mathrm{kg} /(\mathrm{m} \cdot \mathrm{s})]$

$m_{\mathrm{pl}} \quad$ fluid mass flow rate in the string $[\mathrm{kg} / \mathrm{s}]$ 
$P \quad$ reservoir pressure $[\mathrm{Pa}]$

$P_{\mathrm{a}} \quad$ steam pressure in the annulus of the injector $[\mathrm{Pa}]$

$P_{\mathrm{a} \_\mathrm{AB}} \quad$ steam pressure in the $\mathrm{AB}$ section of the annulus $[\mathrm{Pa}]$

$P_{\mathrm{a} \_\mathrm{BD}} \quad$ steam pressure in the $\mathrm{BD}$ section of the annulus $[\mathrm{Pa}]$

$P_{1} \quad$ steam pressure in the string $[\mathrm{Pa}]$

$P_{\mathrm{O}} \quad$ oil pressure $[\mathrm{Pa}]$

$P_{\mathrm{pa}} \quad$ wellbore pressure in the annulus $[\mathrm{Pa}]$

$P_{\mathrm{pl}} \quad$ wellbore pressure in the string $[\mathrm{Pa}]$

$P_{\mathrm{W}} \quad$ water pressure $[\mathrm{Pa}]$

$P_{\mathrm{g}} \quad$ steam pressure $[\mathrm{Pa}]$

$q_{\mathrm{o}} \quad$ volume flow rate of oil per unit volume $\left[\mathrm{m}^{3} /\left(\mathrm{m}^{3} \cdot \mathrm{s}\right)\right]$

$q_{\mathrm{w}} \quad$ volume flow rate of water per unit volume $\left[\mathrm{m}^{3} /\left(\mathrm{m}^{3} \cdot \mathrm{s}\right)\right]$

$q_{\mathrm{g}} \quad$ volume flow rate of steam per unit volume $\left[\mathrm{m}^{3} /\left(\mathrm{m}^{3} \cdot \mathrm{s}\right)\right]$

$Q_{\mathrm{a}} \quad$ heat loss rate of the annulus of the injector [J/s]

$Q_{1} \quad$ heat loss rate of the long string of the injector $[\mathrm{J} / \mathrm{s}]$

$Q_{\mathrm{pa}} \quad$ heat loss rate of the annulus of the producer [J/s]

$Q_{\mathrm{pl}}$

$Q_{\mathrm{ps}}$

$Q_{\mathrm{s}}$

heat loss rate of the long string of the producer $[\mathrm{J} / \mathrm{s}]$

heat loss rate of the short string of the producer $[\mathrm{J} / \mathrm{s}]$

heat loss rate of the short string of the injector $[\mathrm{J} / \mathrm{s}]$

$Q_{\text {loss }} \quad$ heat loss rate to the surroundings $\left[\mathrm{J} /\left(\mathrm{m}^{3} \cdot \mathrm{s}\right)\right]$

$Q_{\mathrm{H}} \quad$ enthalpy production rate $\left[\mathrm{J} /\left(\mathrm{m}^{3} \cdot \mathrm{s}\right)\right]$

$S_{\mathrm{k}} \quad$ skin factor

$S_{\mathrm{O}} \quad$ oil saturation

$S_{\mathrm{w}} \quad$ water saturation

$S_{\mathrm{g}} \quad$ steam saturation

$r_{\mathrm{e}} \quad$ oil drainage radius [m]

$r_{\mathrm{W}} \quad$ wellbore radius [m]

$t \quad$ time [s]

T reservoir temperature $\left[{ }^{\circ} \mathrm{C}\right]$

$\mathrm{T}_{\mathrm{a}} \quad$ steam temperature in the annulus $\left[{ }^{\circ} \mathrm{C}\right]$

$T_{1} \quad$ steam temperature in the string $\left[{ }^{\circ} \mathrm{C}\right]$

$U_{i} \quad$ internal energy of the phase $i[\mathrm{~J} / \mathrm{kg}]$

$v_{\mathrm{a}} \quad$ steam flow velocity in the annulus $[\mathrm{m} / \mathrm{s}]$

$v_{\text {ar }} \quad$ steam flow velocity into the reservoir $[\mathrm{m} / \mathrm{s}]$

$v_{1} \quad$ steam flow velocity in the string $[\mathrm{m} / \mathrm{s}]$

$v_{\mathrm{pa}} \quad$ fluid flow velocity in the annulus $[\mathrm{m} / \mathrm{s}]$

$v_{\text {par }} \quad$ fluid inflow velocity from the reservoir $[\mathrm{m} / \mathrm{s}]$

$v_{\mathrm{pl}} \quad$ fluid flow velocity in the string $[\mathrm{m} / \mathrm{s}]$

$v_{\text {sga }} \quad$ superficial gas velocity in the annulus $[\mathrm{m} / \mathrm{s}]$

$v_{\mathrm{sgl}} \quad$ superficial gas velocity in the string $[\mathrm{m} / \mathrm{s}]$

$\bar{x} \quad$ average value of parameter $x$

$x_{j} \quad$ value of parameter $x$ in the micro-segment $j$

\section{Greek Symbols}

$\alpha_{1} \quad$ unit conversion coefficient

$\alpha_{2} \quad$ unit conversion coefficient

$\alpha_{3} \quad$ unit conversion coefficient

$\alpha_{x} \quad$ non-uniformity coefficient of parameter $x$

$\beta_{x} \quad$ uniformity improvement coefficient of parameter $x$

$\lambda_{\mathrm{R}} \quad$ thermal conductivity of the reservoir in the heat conduction term $\left[\mathrm{W} /\left(\mathrm{m} \cdot{ }^{\circ} \mathrm{C}\right)\right]$

$\varphi \quad$ porosity

$\mu_{\mathrm{o}} \quad$ oil viscosity [Pa·s]

$\mu_{\mathrm{w}} \quad$ water viscosity [Pa·s]

$\mu_{\mathrm{g}} \quad$ steam viscosity $[\mathrm{Pa} \cdot \mathrm{s}]$ 
$\rho_{\mathrm{a}} \quad$ steam density in the annulus of the injector $\left[\mathrm{kg} / \mathrm{m}^{3}\right]$

$\rho_{\mathrm{O}} \quad$ oil density $\left[\mathrm{kg} / \mathrm{m}^{3}\right]$

$\rho_{\mathrm{w}} \quad$ water density $\left[\mathrm{kg} / \mathrm{m}^{3}\right]$

$\rho_{\mathrm{g}} \quad$ steam density $\left[\mathrm{kg} / \mathrm{m}^{3}\right]$

$\rho_{\mathrm{R}} \quad$ rock density $\left[\mathrm{kg} / \mathrm{m}^{3}\right]$

$\rho_{\text {pa }} \quad$ fluid density in the annulus of the producer $\left[\mathrm{kg} / \mathrm{m}^{3}\right]$

$\rho_{\mathrm{pl}} \quad$ fluid density in the string of the producer $\left[\mathrm{kg} / \mathrm{m}^{3}\right]$

$\tau_{\mathrm{pa}} \quad$ friction when the fluid flows in the annulus of the producer $[\mathrm{N}]$

$\tau_{\mathrm{pl}} \quad$ friction when the fluid flows in the string of the producer $[\mathrm{N}]$

\section{Appendix A}

Appendix A presents the calculation of pressure drop in the long string and annulus.

(1) The calculation of pressure drop in the CD segment of the annulus

When the steam flows from the interface D to C. For a random micro-segment in the CD segment of the annulus, the equations of mass conservation and energy conservation can be developed as follows:

$$
\begin{gathered}
\frac{\mathrm{d} m_{\mathrm{a}}}{\mathrm{d} l}=-m_{\mathrm{af}} \\
\frac{\mathrm{d} Q_{\mathrm{a}}}{\mathrm{d} l}-\frac{\mathrm{d} Q_{\mathrm{l}}}{\mathrm{d} l}+m_{\mathrm{af}}\left(h_{\mathrm{a}}+\frac{v_{\mathrm{ar}}^{2}}{2}\right)=-\frac{\mathrm{d}}{\mathrm{d} l}\left[m_{\mathrm{a}}\left(h_{\mathrm{a}}+\frac{v_{\mathrm{a}}^{2}}{2}\right)\right]
\end{gathered}
$$

For pressure drop in the annulus, $\mathrm{Wu}$ et al. [23] and Sun et al. [38] treated the annulus as pipes, namely, effective diameter of annulus $\left(D_{\mathrm{e}}\right)$ was replaced by equivalent hydraulic diameter, $D_{\mathrm{e}}=2\left(r_{1 \mathrm{i}}-r_{\mathrm{io}}\right)$, where $r_{1 \mathrm{i}}$ is the inside radius of the long string and $r_{\mathrm{io}}$ is the inside radius of the slotted liners. As stated above, this may be a rough approximation. Here, a more rigorous method is presented to predict the steam pressure in the annulus [26-28].

Equation (A2) can be written as:

$$
\frac{\mathrm{d} Q_{\mathrm{a}}}{\mathrm{d} l}-\frac{\mathrm{d} Q_{\mathrm{l}}}{\mathrm{d} l}+\frac{\mathrm{d} m_{\mathrm{a}}}{\mathrm{d} l}\left(\frac{v_{\mathrm{a}}^{2}-v_{\mathrm{ar}}^{2}}{2}\right)=-m_{\mathrm{a}} \frac{\mathrm{d} h_{\mathrm{a}}}{\mathrm{d} l}-m_{\mathrm{a}} \frac{\mathrm{d}}{\mathrm{d} l}\left(\frac{v_{\mathrm{a}}^{2}}{2}\right)
$$

The first term of the right side in Equation (A3) represents the enthalpy gradient, which can be written in terms of temperature and pressure gradients based on thermodynamic principles [28]:

$$
\frac{\mathrm{d} h_{\mathrm{a}}}{\mathrm{d} l}=C_{\mathrm{pma}} \frac{\mathrm{d} T_{\mathrm{a}}}{\mathrm{d} l}-C_{\mathrm{Jma}} C_{\mathrm{pma}} \frac{\mathrm{d} P_{\mathrm{a}}}{\mathrm{d} l}
$$

To calculate Equation (A4), one of the most important tasks is to calculate the values of $C_{\text {pma }}$ and $C_{\text {Jma }}$. The calculation methods for $C_{\text {pma }}$ and $C_{\text {Jma }}$ are presented in detail as flows:

For steam/water two-phase flow system, the total enthalpy of mixture fluid is the sum of the enthalpy of each phase [28]. Therefore, the enthalpy gradient in the random micro-segment in the CD segment of the annulus can be given by:

$$
\frac{\mathrm{d} h_{\mathrm{a}}}{\mathrm{d} l}=\frac{m_{\mathrm{s}}}{m_{\mathrm{a}}} \frac{\mathrm{d} h_{\mathrm{s}}}{\mathrm{d} l}+\frac{m_{\mathrm{w}}}{m_{\mathrm{a}}} \frac{\mathrm{d} h_{\mathrm{w}}}{\mathrm{d} l}
$$

where $m_{\mathrm{s}}$ and $m_{\mathrm{w}}$ are the mass flow rates of steam and water, respectively;

and:

$$
\begin{aligned}
\frac{\mathrm{d} h_{\mathrm{s}}}{\mathrm{d} l} & =C_{\mathrm{ps}} \frac{\mathrm{d} T_{\mathrm{a}}}{\mathrm{d} l}-C_{\mathrm{Js}} C_{\mathrm{ps}} \frac{\mathrm{d} P_{\mathrm{a}}}{\mathrm{d} l} \\
\frac{\mathrm{d} h_{\mathrm{w}}}{\mathrm{d} l} & =C_{\mathrm{pw}} \frac{\mathrm{d} T_{\mathrm{a}}}{\mathrm{d} l}-C_{\mathrm{Jw}} C_{\mathrm{pw}} \frac{\mathrm{d} P_{\mathrm{a}}}{\mathrm{d} l}
\end{aligned}
$$


where $C_{\mathrm{ps}}$ and $C_{\mathrm{pw}}$ are the heat capacities of steam and water at constant pressure, respectively; $C_{\mathrm{Js}}$ and $C_{\mathrm{Jw}}$ are the Joule-Thompson coefficients of steam and water, respectively. $C_{\mathrm{ps}}, C_{\mathrm{pw}}, C_{\mathrm{Js}}$ and $C_{\mathrm{Jw}}$ are given by:

$$
\begin{gathered}
C_{\mathrm{ps}}=\left(\frac{\partial h_{\mathrm{s}}}{\partial T}\right)_{P} \\
C_{\mathrm{pw}}=\left(\frac{\partial h_{\mathrm{w}}}{\partial T}\right)_{P} \\
C_{\mathrm{Js}}=\frac{1}{C_{\mathrm{ps}}}\left\{T\left[\frac{\partial}{\partial T}\left(\frac{1}{\rho_{\mathrm{s}}}\right)\right]_{P}-\frac{1}{\rho_{\mathrm{s}}}\right\} \\
C_{\mathrm{Jw}}=\frac{1}{C_{\mathrm{pw}}}\left\{T\left[\frac{\partial}{\partial T}\left(\frac{1}{\rho_{\mathrm{w}}}\right)\right]_{P}-\frac{1}{\rho_{\mathrm{w}}}\right\}
\end{gathered}
$$

If the compressibility of water is ignored, Equation (A11) can be reduced to.

$$
C_{\mathrm{Jw}}=-\frac{1}{C_{\mathrm{pw}} \rho_{\mathrm{w}}}
$$

Substituting Equations (A6) and (A7) into Equation (A5) gives:

$$
\frac{\mathrm{d} h_{\mathrm{a}}}{\mathrm{d} l}==\frac{m_{\mathrm{s}} C_{\mathrm{ps}}+m_{\mathrm{w}} C_{\mathrm{pw}}}{m_{\mathrm{a}}} \frac{\mathrm{d} T_{\mathrm{a}}}{\mathrm{d} l}-\left(\frac{m_{\mathrm{s}} C_{\mathrm{Js}} C_{\mathrm{ps}}}{m_{\mathrm{a}}}+\frac{m_{\mathrm{w}} C_{\mathrm{Jw}} C_{\mathrm{pw}}}{m_{\mathrm{a}}}\right) \frac{\mathrm{d} P_{\mathrm{a}}}{\mathrm{d} l}
$$
fluid are.

Therefore, the heat capacity at constant pressure and the Joule-Thompson coefficient of mixture

$$
\begin{gathered}
C_{\mathrm{pma}}=\frac{m_{\mathrm{s}} C_{\mathrm{ps}}+m_{\mathrm{w}} C_{\mathrm{pw}}}{m_{\mathrm{a}}} \\
C_{\mathrm{Jma}}=\frac{1}{C_{\mathrm{pma}}}\left[\frac{m_{\mathrm{s}} C_{\mathrm{Js}} C_{\mathrm{ps}}}{m_{\mathrm{a}}}+\frac{m_{\mathrm{w}} C_{\mathrm{Jw}} C_{\mathrm{pw}}}{m_{\mathrm{a}}}\right]
\end{gathered}
$$

Substituting Equations (A10) and (A12) into Equation (A15), we have:

$$
C_{\mathrm{Jma}}=\frac{1}{C_{\mathrm{pma}} m_{\mathrm{a}}}\left\{m_{\mathrm{s}} T\left[\frac{\partial}{\partial T}\left(\frac{1}{\rho_{\mathrm{s}}}\right)\right]_{P}-\frac{m_{\mathrm{s}}}{\rho_{\mathrm{s}}}-\frac{m_{\mathrm{w}}}{\rho_{\mathrm{w}}}\right\}
$$

The values of $C_{\mathrm{pma}}$ and $C_{\mathrm{Jma}}$ can be calculated by Equations (A14) and (A16), respectively.

According to the derivation method proposed by Beggs and Brill [29], the kinetic energy change per unit mass of annulus fluid per unit length of the wellbore represented by the second term of the right side in Equation (A2) can also be rewritten as:

$$
\frac{\mathrm{d}}{\mathrm{d} l}\left(\frac{v_{\mathrm{a}}^{2}}{2}\right)=\frac{v_{\mathrm{a}} \mathrm{d} v_{\mathrm{a}}}{\mathrm{d} l}=-\frac{v_{\mathrm{a}} v_{\mathrm{sga}}}{P_{\mathrm{a}}} \frac{\mathrm{d} P_{\mathrm{a}}}{\mathrm{d} l}
$$

Incorporating Equations (A4) and (A17) into Equation (A2) results in:

$$
\frac{\mathrm{d} Q_{\mathrm{a}}}{\mathrm{d} l}-\frac{\mathrm{d} Q_{1}}{\mathrm{~d} l}+\frac{\mathrm{d} m_{\mathrm{a}}}{\mathrm{d} l}\left(\frac{v_{\mathrm{a}}^{2}-v_{\mathrm{ar}}^{2}}{2}\right)=m_{\mathrm{a}}\left(C_{\text {Jma }} C_{\mathrm{pma}} \frac{\mathrm{d} P_{\mathrm{a}}}{\mathrm{d} l}-C_{\mathrm{pma}} \frac{\mathrm{d} T_{\mathrm{a}}}{\mathrm{d} l}\right)+m_{\mathrm{a}} \frac{v_{\mathrm{a}} v_{\mathrm{sga}}}{P_{\mathrm{a}}} \frac{\mathrm{d} P_{\mathrm{a}}}{\mathrm{d} l}
$$

In this Section, the calculation of $\mathrm{d} T_{\mathrm{a}} / \mathrm{d} l$ in Equation (A18) is derived. A general relationship between temperature gradient and pressure gradient for saturated steam can be further created based on limit and derivative theories in mathematics. Figure A1 shows a random micro-segment in the CD segment of the annulus. Assuming that the steam temperature varies from $T_{\mathrm{a}, i}$ to $T_{\mathrm{a}, i+1}$ and the steam pressure varies from $P_{\mathrm{a}, i}$ to $P_{\mathrm{a}, i+1}$ when steam flows from the inlet to the outlet, then the temperature and the pressure changes over $\mathrm{d} l$ can be expressed as $\Delta T_{\mathrm{a}}=T_{\mathrm{a}, i+1}-T_{\mathrm{a}, i}$ and $\Delta P_{\mathrm{a}}=P_{\mathrm{a}, i+1}-P_{\mathrm{a}, i}$, 
respectively. Consequently, the temperature gradient can be obtained from the definition of derivative and the algorithm of limit:

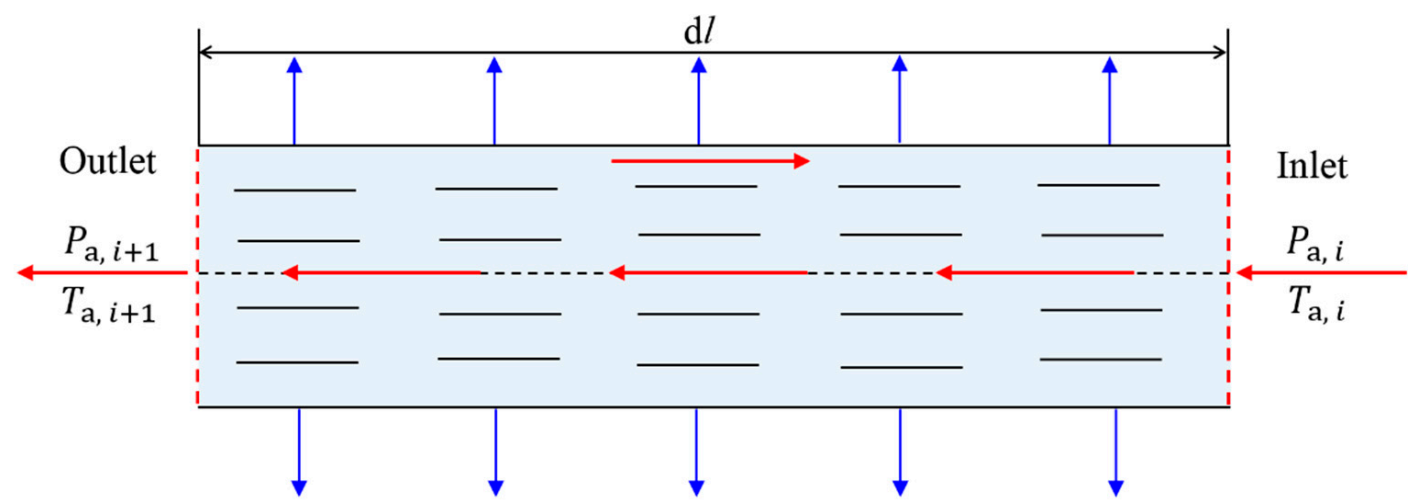

Figure A1. A random micro-segment in the CD segment of the annulus.

$$
\frac{\mathrm{d} T_{\mathrm{a}}}{\mathrm{d} l}=\lim _{\Delta l \rightarrow 0} \frac{\Delta T_{\mathrm{a}}}{\Delta l}=\lim _{\Delta l \rightarrow 0}\left(\frac{\Delta T_{\mathrm{a}}}{\Delta P_{\mathrm{a}}} \frac{\Delta P_{\mathrm{a}}}{\Delta l}\right)=\lim _{\Delta l \rightarrow 0} \frac{\Delta T_{\mathrm{a}}}{\Delta P_{\mathrm{a}}} \cdot \lim _{\Delta l \rightarrow 0} \frac{\Delta P_{\mathrm{a}}}{\Delta l}=\lim _{\Delta l \rightarrow 0} \frac{\Delta T_{\mathrm{a}}}{\Delta P_{\mathrm{a}}} \cdot \lim _{\Delta l \rightarrow 0} \frac{\mathrm{d} P_{\mathrm{a}}}{\mathrm{d} l}
$$

In Equation (A19), there are two methods to estimate the value of $\lim _{\Delta l \rightarrow 0} \frac{\Delta T_{\mathrm{a}}}{\Delta P_{\mathrm{a}}}$. The first one is interpolation of steam tables, however, not only is interpolation itself inconvenient in computer procedure, but also this method for solving Equation (A19) is time- and memory-consuming. That is because in order to ensure that the interpolated results are precise enough, the wellbore must be divided into a large number of segments so that the length of each segment $(\Delta l)$ is very small and $\lim _{\Delta l \rightarrow 0} \frac{\Delta T_{a}}{\Delta P_{\mathrm{a}}}$ is approximately equal to $\frac{\Delta T_{\mathrm{a}}}{\Delta P_{\mathrm{a}}}$. Here, a more practical approach is recommended. According to steam tables, there is one-to-one correspondence between saturated temperature and pressure. By regression analysis and polynomial interpolation, Ejiogu et al. [34] and Tortike et al. [33] proposed different empirical correlations to describe this relationship. In this paper, the empirical correlation suggested by Tortike et al. [33] is adopted due to its high accuracy, and the expression is given by:

$$
\begin{aligned}
T_{\mathrm{a}} & =f\left(P_{\mathrm{a}}\right)=\frac{\mathrm{d} T_{\mathrm{a}}}{\mathrm{d} P_{\mathrm{a}}}=280.034+14.0856 \ln \frac{P_{\mathrm{a}}}{1000}+1.38075\left(\ln \frac{P_{\mathrm{a}}}{1000}\right) 2-0.101806\left(\ln \frac{P_{\mathrm{a}}}{1000}\right) 3 \\
& +0.019017\left(\ln \frac{P_{\mathrm{a}}}{1000}\right) 4, \quad 611 \mathrm{~Pa} \leq \mathrm{P}_{\mathrm{a}} \leq 2.212 \times 10^{7} \mathrm{~Pa}
\end{aligned}
$$

Figure A2 shows a comparison of the results from Equation (A20) and those from steam tables. It is obviously found that the empirical correlation agrees very well with steam-table data, also, the maximum and the mean absolute residuals are only $0.13 \%$ and $0.06 \%$, respectively [33]. Therefore, Equation (A20) can be used to simulate the relationship between saturated temperature and pressure in the computer procedure. More importantly, the proposed empirical function is differentiable, which lays a foundation for further simplification of Equation (A19). 


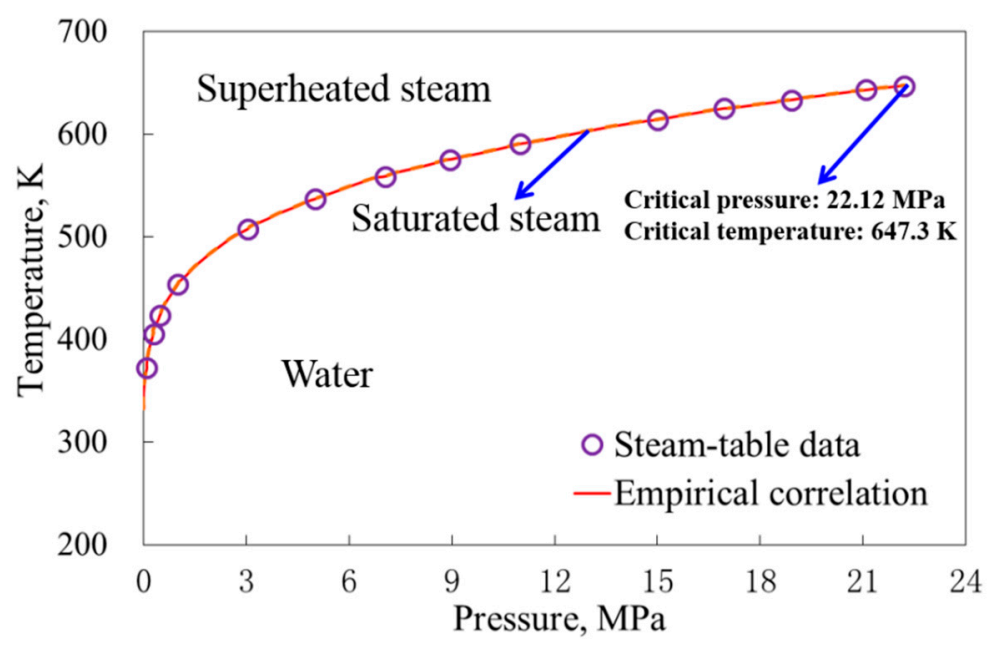

Figure A2. Comparison of empirical correlation with steam-table data.

In Figure A2, $\Delta l \rightarrow 0$ is equivalent to $P_{\mathrm{a}, i+1} \rightarrow P_{\mathrm{a}, i}$, so $\lim _{\Delta l \rightarrow 0}\left(\frac{\Delta T_{\mathrm{a}}}{\Delta P_{\mathrm{a}}}\right)$ can be developed into another form:

$$
\lim _{\Delta l \rightarrow 0} \frac{\Delta T_{\mathrm{a}}}{\Delta P_{\mathrm{a}}}=\lim _{\Delta l \rightarrow 0} \frac{T_{\mathrm{a}, i+1}-T_{\mathrm{a}, i}}{P_{\mathrm{a}, i+1}-P_{\mathrm{a}, i}}=\lim _{\Delta l \rightarrow 0} \frac{f\left(P_{\mathrm{a}, i+1}\right)-f\left(P_{\mathrm{a}, i}\right)}{P_{\mathrm{a}, i+1}-P_{\mathrm{a}, i}}=\lim _{P_{\mathrm{a}, i+1}-P_{\mathrm{a}, i}} \frac{f\left(P_{\mathrm{a}, i+1}\right)-f\left(P_{\mathrm{a}, i}\right)}{P_{\mathrm{a}, i+1}-P_{\mathrm{a}, i}}=\frac{\mathrm{d} f\left(P_{\mathrm{a}}\right)}{\mathrm{d} P_{\mathrm{a}}}=\frac{\mathrm{d} T_{\mathrm{a}}}{\mathrm{d} P_{\mathrm{a}}}
$$

where $\mathrm{d} T_{\mathrm{a}} / \mathrm{d} P_{\mathrm{a}}$ can be obtained from Equation (A20):

$$
\frac{\mathrm{d} T_{\mathrm{a}}}{\mathrm{d} P_{\mathrm{a}}}=\frac{1}{P_{\mathrm{a}}}\left[14.0856+2.7615\left(\ln \frac{P_{\mathrm{a}}}{1000}\right)-0.305418\left(\ln \frac{P_{\mathrm{a}}}{1000}\right)^{2}+0.076068\left(\ln \frac{P_{\mathrm{a}}}{1000}\right)^{3}\right]
$$

Substituting Equation (A21) into Equation (A19) yields the general relationship between temperature gradient and pressure gradient for saturated steam:

$$
\frac{\mathrm{d} T_{\mathrm{a}}}{\mathrm{d} l}=\frac{\mathrm{d} T_{\mathrm{a}}}{\mathrm{d} P_{\mathrm{a}}} \cdot \frac{\mathrm{d} P_{\mathrm{a}}}{\mathrm{d} l}
$$

Incorporating Equation (A23) into Equation (A18) reduces to the governing differential equation for steam pressure in the $\mathrm{CD}$ segment of the annulus.

$$
\frac{\mathrm{d} P_{\mathrm{a}_{\mathrm{a}} \mathrm{CD}}}{\mathrm{d} l}=\frac{\frac{\mathrm{d} Q_{\mathrm{a}}}{\mathrm{d} l}-\frac{\mathrm{d} Q_{\mathrm{l}}}{\mathrm{d} l}+\frac{\mathrm{d} m_{\mathrm{a}}}{\mathrm{d} l}\left(\frac{v_{\mathrm{a}}^{2}-v_{\mathrm{ar}}^{2}}{2}\right)}{m_{\mathrm{a}}\left(C_{\mathrm{Jma}} C_{\mathrm{pma}}-C_{\mathrm{pma}} \frac{\mathrm{d} T_{\mathrm{a}}}{\mathrm{d} P_{\mathrm{a}}}+\frac{v_{\mathrm{a}} v_{\mathrm{gga}}}{P_{\mathrm{a}}}\right)}
$$

Similarly, the steam pressure in the $B C$ segment of the annulus and the $A B$ segment of the annulus can be obtained, as shown in Equations (A25) and (A26), respectively.

$$
\begin{gathered}
\frac{\mathrm{d} P_{\mathrm{a} \_\mathrm{BC}}}{\mathrm{d} l}=\frac{\frac{\mathrm{d} Q_{\mathrm{a}}}{\mathrm{d} l}-\frac{\mathrm{d} Q_{1}}{\mathrm{~d} l}+\frac{\mathrm{d} m_{\mathrm{a}}}{\mathrm{d} l}\left(\frac{v_{\mathrm{a}}^{2}-v_{\mathrm{ar}}^{2}}{2}\right)}{m_{\mathrm{a}}\left(C_{\mathrm{Jma}} C_{\mathrm{pma}}-C_{\mathrm{pma}} \frac{\mathrm{d} T_{\mathrm{a}}}{\mathrm{d} P_{\mathrm{a}}}+\frac{v_{\mathrm{a}} v_{\mathrm{gga}}}{P_{\mathrm{a}}}\right)} \\
\frac{\mathrm{d} P_{\mathrm{a} \_\mathrm{AB}}}{\mathrm{d} l}=\frac{\frac{\mathrm{d} Q_{\mathrm{a}}}{\mathrm{d} l}-\frac{\mathrm{d} Q_{\mathrm{s}}}{\mathrm{d} l}-\frac{\mathrm{d} Q_{1}}{\mathrm{~d} l}+\frac{\mathrm{d} m_{\mathrm{a}}}{\mathrm{d} l}\left(\frac{v_{\mathrm{v}}^{2}-v_{\mathrm{ar}}^{2}}{2}\right)}{m_{\mathrm{a}}\left(C_{\mathrm{Jma}} C_{\mathrm{pma}}-C_{\mathrm{pma}} \frac{\mathrm{d} T_{\mathrm{a}}}{\mathrm{d} P_{\mathrm{a}}}+\frac{v_{\mathrm{a}} v_{\mathrm{gga}}}{P_{\mathrm{a}}}\right)}
\end{gathered}
$$

(2) The calculation of pressure drop in the long string 
When steam flows in the long string, the steam mass flow rate remains unchanged. In this case, the equations of mass conservation and energy conservation for steam flow in the long string are derived as follows:

$$
\begin{gathered}
\frac{\mathrm{d} m_{1}}{\mathrm{~d} l}=0 \\
\frac{\mathrm{d} Q_{1}}{\mathrm{~d} l}=-\frac{\mathrm{d}}{\mathrm{d} l}\left[m_{1}\left(h_{1}+\frac{v_{1}^{2}}{2}\right)\right]
\end{gathered}
$$

The calculation method of pressure drop in the long string is similar to that in the annulus. The pressure drop in the long string can be given by:

$$
\frac{\mathrm{d} P_{1}}{\mathrm{~d} l}=\frac{\frac{\mathrm{d} Q_{1}}{\mathrm{~d} l}}{m_{1}\left(C_{\mathrm{Jml}} C_{\mathrm{pml}}-C_{\mathrm{pml}} \frac{\mathrm{d} T_{1}}{\mathrm{~d} P_{1}}+\frac{v_{1} v_{\mathrm{sgl}}}{P_{1}}\right)}
$$

\section{Appendix B}

Appendix B presents modeling of steam flow in the string and annulus considering phase change.

(1) Calculation of pressure and temperature in the CD segment of the annulus

The steam may condense to water in the horizontal wellbore due to heat losses. Thus, the mass, momentum and energy balance equations for water flow in the annulus are given as follows:

Mass balance equation:

$$
\frac{\mathrm{d} m_{\mathrm{a}}}{\mathrm{d} l}=-m_{\mathrm{af}}
$$

Momentum balance equation:

$$
A_{\mathrm{a}} \frac{\mathrm{d} P_{\mathrm{a}}}{\mathrm{d} l}=-\frac{\tau_{\mathrm{a}}}{\mathrm{d} l}-m_{\mathrm{a}} \frac{\mathrm{d} v_{\mathrm{a}}}{\mathrm{d} l}-v_{\mathrm{a}} \frac{\mathrm{d} m_{\mathrm{a}}}{\mathrm{d} l}
$$

Energy balance equation:

$$
\frac{\mathrm{d} Q_{\mathrm{a}}}{\mathrm{d} l}-\frac{\mathrm{d} Q_{1}}{\mathrm{~d} l}+m_{\mathrm{af}}\left(h_{\mathrm{w}}+\frac{v_{\mathrm{ar}}^{2}}{2}\right)=-\frac{\mathrm{d}}{\mathrm{d} l}\left[m_{\mathrm{a}}\left(h_{\mathrm{w}}+\frac{v_{\mathrm{a}}^{2}}{2}\right)\right]
$$

Equation (A32) can be written as:

$$
\frac{\mathrm{d} Q_{\mathrm{a}}}{\mathrm{d} l}-\frac{\mathrm{d} Q_{1}}{\mathrm{~d} l}+\frac{\mathrm{d} m_{\mathrm{a}}}{\mathrm{d} l}\left(\frac{v_{\mathrm{a}}^{2}-v_{\mathrm{ar}}^{2}}{2}\right)=-m_{\mathrm{a}} \frac{\mathrm{d} h_{\mathrm{w}}}{\mathrm{d} l}-m_{\mathrm{a}} \frac{\mathrm{d}}{\mathrm{d} l}\left(\frac{v_{\mathrm{a}}^{2}}{2}\right)
$$

where $v_{\mathrm{ar}}$ is the radial outflow velocity of water, $\mathrm{m} / \mathrm{s} ; m_{\mathrm{a}}$ is the mass flow rate of water, $\mathrm{kg} / \mathrm{s} ; m_{\mathrm{af}}$ is the mass flow velocity of water from annulus to reservoir, $\mathrm{kg} /(\mathrm{m} \cdot \mathrm{s}) ; P_{\mathrm{a}}$ is the annulus pressure, $\mathrm{Pa} ; A_{\mathrm{a}}$ is the cross-sectional area of the annulus, $\mathrm{m}^{2} ; v_{\mathrm{a}}$ is the water flow velocity in the annulus, $\mathrm{m} / \mathrm{s} ; \tau_{\mathrm{a}}$ is the friction force in the annulus; and $h_{\mathrm{a}}$ is the water enthalpy in the annulus, $\mathrm{J} / \mathrm{kg}$.

$\frac{\mathrm{d} h h_{\mathrm{w}}}{\mathrm{d} l}$ is the enthalpy gradient of water, which can be expressed as Equation (A34).

The enthalpy drop of water can be calculated as:

$$
\frac{\mathrm{d} h_{\mathrm{w}}}{\mathrm{d} l}=-\mu_{\mathrm{wJ}} C_{\mathrm{w}} \frac{\mathrm{d} P_{\mathrm{a}}}{\mathrm{d} l}+C_{\mathrm{w}} \frac{\mathrm{d} T_{\mathrm{a}}}{\mathrm{d} l}
$$

Using the definition of thermal expansion coefficient of water:

$$
\beta_{\mathrm{w}}=\frac{\mathrm{d} V}{V \mathrm{~d} T}=-\frac{\mathrm{d} \rho_{\mathrm{w}}}{\rho_{\mathrm{w}} \mathrm{d} T_{\mathrm{a}}}
$$

where $\rho_{\mathrm{a}}$ is the water density, $\mathrm{kg} / \mathrm{m}^{3}$. 
The density of water can be expressed as:

$$
\rho_{\mathrm{w}}=C_{0} e^{-\beta_{\mathrm{w}} T_{\mathrm{a}}}
$$

The coefficient $C_{0}$ in Equation (A36) can be obtained from the initial condition: $\left.\rho_{\mathrm{w}}\right|_{T=20}=C_{0} e^{-\beta_{\mathrm{w}} 20}$, then the coefficient $C_{0}$ can be given by.

$$
C_{0}=\left.\rho_{\mathrm{w}}\right|_{T=20} / e^{-\beta_{\mathrm{w}} 20}
$$

Substituting Equation (A37) into Equation (A36):

$$
\mathrm{d}\left(\frac{1}{\rho_{\mathrm{w}}}\right)=\frac{\beta_{\mathrm{w}} e^{\beta_{\mathrm{w}} T_{\mathrm{a}}} e^{-\beta_{\mathrm{w}} 20}}{\left.\rho_{\mathrm{w}}\right|_{T=20}} \mathrm{~d} T_{\mathrm{a}}
$$

According to the equation $v_{\mathrm{a}}=m_{\mathrm{a}} /\left(\rho_{\mathrm{w}} A_{\mathrm{a}}\right)$, we can obtain:

$$
\frac{\mathrm{d} v_{\mathrm{a}}}{\mathrm{d} l}=\frac{\mathrm{d}\left(m_{\mathrm{a}} /\left(\rho_{\mathrm{w}} A_{\mathrm{a}}\right)\right)}{\mathrm{d} l}=\frac{1}{\rho_{\mathrm{w}} A_{\mathrm{a}}} \frac{\mathrm{d} m_{\mathrm{a}}}{\mathrm{d} l}+\frac{m_{\mathrm{a}}}{A_{\mathrm{a}}} \frac{\mathrm{d}\left(1 / \rho_{\mathrm{w}}\right)}{\mathrm{d} l}
$$

Substituting Equations (A34) and (A39) into Equations (A31) and (A33), the pressure and temperature in the micro-segment in the $\mathrm{CD}$ segment of the annulus can be expressed as:

$$
\begin{aligned}
\frac{\mathrm{d} P_{\mathrm{a}}}{\mathrm{d} l}= & -\frac{1}{A_{\mathrm{a}}}\left[\frac{\tau_{\mathrm{a}}}{\mathrm{d} l}+2 v_{\mathrm{a}} \frac{\mathrm{d} m_{\mathrm{a}}}{\mathrm{d} l}+\frac{m_{\mathrm{a}}^{2}}{A_{\mathrm{a}}} \frac{\beta_{\mathrm{w}} e^{\beta_{\mathrm{w}} T_{\mathrm{a}}} e^{-\beta_{\mathrm{w}} 20}}{\left.\rho_{\mathrm{w}}\right|_{T=20}} \frac{\mathrm{d} T_{\mathrm{a}}}{\mathrm{d} l}\right] \\
T_{\mathrm{a}} & =\exp \left(-\frac{C_{2}}{C_{1}} l\right) \cdot\left[-\frac{C_{3}}{C_{2}} \exp \left(\frac{C_{2}}{C_{1}} l\right)+T_{\mathrm{a} 0}+\frac{C_{3}}{C_{2}}\right]
\end{aligned}
$$

where:

$$
\begin{gathered}
C_{1}=m_{\mathrm{a}}\left(C_{\mathrm{w}}+\frac{m_{\mathrm{a}} v_{\mathrm{a}}}{A_{\mathrm{a}}} \frac{\beta_{\mathrm{w}} e^{\beta_{\mathrm{w}} T_{\mathrm{a}}} e^{-\beta_{\mathrm{w}} 20}}{\left.\rho_{\mathrm{w}}\right|_{T=20}}\right) \\
C_{2}=\frac{1}{R_{\mathrm{a}}} \\
C_{3}=-\frac{T_{\mathrm{e}}}{R_{\mathrm{a}}}+\frac{\mathrm{d} W_{\mathrm{a}}}{\mathrm{d} l}+\frac{\mathrm{d} m_{\mathrm{a}}}{\mathrm{d} l}\left(\frac{v_{\mathrm{a}}^{2}-v_{\mathrm{ar}}^{2}}{2}\right)+m_{\mathrm{a}}\left(-\mu_{\mathrm{wJ}} C_{\mathrm{w}} \frac{\mathrm{d} P_{\mathrm{a}}}{\mathrm{d} l}+\frac{v_{\mathrm{a}}}{\rho_{\mathrm{w}} A_{\mathrm{a}}} \frac{\mathrm{d} m_{\mathrm{a}}}{\mathrm{d} l}\right)
\end{gathered}
$$

Similarly, the pressure and temperature in the $\mathrm{BC}$ segment of the annulus and the $\mathrm{AB}$ segment of the annulus can be obtained by using the same method.

(2) Calculation of pressure and temperature in the long string

The calculation method of pressure and temperature in the long string is similar to that in the annulus. The pressure and temperature in the long string can be given by.

$$
\begin{gathered}
\frac{\mathrm{d} P_{1}}{\mathrm{~d} l}=-\frac{1}{A_{1}}\left[\frac{\tau_{1}}{\mathrm{~d} l}+\frac{m_{1}^{2}}{A_{1}} \frac{\beta_{\mathrm{w}} e^{\beta_{\mathrm{w}} T_{1}} e^{-\beta_{\mathrm{w}} 20}}{\left.\rho_{\mathrm{w}}\right|_{T=20}} \frac{\mathrm{d} T_{1}}{\mathrm{~d} l}\right] \\
T_{1}=\exp \left(-\frac{C_{2}}{C_{1}} l\right) \cdot\left[-\frac{C_{3}}{C_{2}} \exp \left(\frac{C_{2}}{C_{1}} l\right)+T_{10}+\frac{C_{3}}{C_{2}}\right]
\end{gathered}
$$

where:

$$
C_{1}=m_{1}\left(C_{\mathrm{w}}+\frac{m_{1} v_{1}}{A_{1}} \frac{\beta_{\mathrm{w}} e^{\beta_{\mathrm{w}} T_{1}} e^{-\beta_{\mathrm{w}} 20}}{\left.\rho_{\mathrm{w}}\right|_{T=20}}\right)
$$




$$
\begin{gathered}
C_{2}=\frac{1}{R_{1}} \\
C_{3}=-\frac{T_{\mathrm{a}}}{R_{1}}+\frac{\mathrm{d} W_{1}}{\mathrm{~d} l}-m_{1} \mu_{\mathrm{wJ}} C_{\mathrm{w}} \frac{\mathrm{d} P_{1}}{\mathrm{~d} l}
\end{gathered}
$$

\section{Appendix C}

Appendix $C$ presents the linearization of reservoir equations.

The reservoir seepage and heat transfer model is a strong nonlinear model. To solve the non-linear equations, the equations need to be transformed into linear equations first.

The difference equations of the mathematical models of seepage and heat transfer in reservoirs can be derived as follows:

$$
\begin{aligned}
& \Delta T_{\mathrm{o}}^{l+1} \Delta P_{\mathrm{o}}^{l+1}-\Delta T_{\mathrm{o}}^{l+1} \Delta\left(\rho_{\mathrm{o}} g D\right)^{l+1}+M_{\mathrm{o} i, j, k}^{l+1}=\frac{V_{\mathrm{B}}}{\Delta t}\left[\left(\rho_{\mathrm{o}} \varphi S_{\mathrm{o}}\right)_{i, j, k}^{l+1}-\left(\rho_{\mathrm{o}} \varphi S_{\mathrm{o}}\right)_{i, j, k}^{l}\right] \\
& \Delta T_{\mathrm{w}}^{l+1} \Delta P_{\mathrm{o}}^{l+1}-\Delta T_{\mathrm{w}}^{l+1} \Delta\left(P_{\text {cow }}+\rho_{\mathrm{w}} g D\right)^{l+1}+M_{\mathrm{wi}, j, k}^{l+1}+\Delta T_{\mathrm{g}}^{l+1} \Delta P_{\mathrm{o}}^{l+1}+\Delta T_{\mathrm{g}}^{l+1} \Delta\left(P_{\text {cgo }}-\rho_{\mathrm{g} g} D\right)^{l+1}+ \\
& M_{\mathrm{g} i, j, k}^{l+1}=\frac{V_{\mathrm{B}}}{\Delta t}\left[\left(\rho_{\mathrm{w}} \varphi S_{\mathrm{w}}\right)_{i, j, k}^{l+1}-\left(\rho_{\mathrm{w}} \varphi S_{\mathrm{w}}\right)_{i, j, k}^{l}\right]+\frac{V_{\mathrm{B}}}{\Delta t}\left[\left(\rho_{\mathrm{g}} \varphi S_{\mathrm{g}}\right)_{i, j, k}^{l+1}-\left(\rho_{\mathrm{g}} \varphi S_{\mathrm{g}}\right)_{i, j, k}^{l}\right] \\
& \Delta T_{\mathrm{R}}^{l+1} \Delta T^{l+1}+\Delta T_{\mathrm{ho}}^{l+1} \Delta\left(P_{\mathrm{o}}-\rho_{\mathrm{o}} g D\right)^{l+1}+\Delta T_{\mathrm{hw}}^{l+1} \Delta\left(P_{\mathrm{o}}-P_{\text {cow }}-\rho_{\mathrm{w}} g D\right)^{l+1}+ \\
& \Delta T_{\mathrm{hg}}^{l+1} \Delta\left(P_{\mathrm{o}}+P_{\mathrm{cgo}}-\rho_{\mathrm{g} g} g\right)^{l+1}-Q_{\mathrm{loss} i, j, k}^{l+1}+Q_{\mathrm{H} i, j, k}^{l+1}+Q_{\mathrm{welli}, j, k}^{l+1} \\
& =\frac{V_{\mathrm{B}}}{\Delta t}\left[\begin{array}{l}
\left((1-\varphi) M_{\mathrm{R}} T\right)_{i, j, k}^{l+1}-\left((1-\varphi) M_{\mathrm{R}} T\right)_{i, j, k}^{l}+\left(\varphi\left(S_{\mathrm{o}} \rho_{\mathrm{o}} U_{\mathrm{o}}+S_{\mathrm{w}} \rho_{\mathrm{w}} U_{\mathrm{w}}+S_{\mathrm{g}} \rho_{\mathrm{g}} U_{\mathrm{g}}\right)\right)_{i, j, k}^{l+1}- \\
\left(\varphi\left(S_{\mathrm{o}} \rho_{\mathrm{o}} U_{\mathrm{o}}+S_{\mathrm{w}} \rho_{\mathrm{w}} U_{\mathrm{w}}+S_{\mathrm{g}} \rho_{\mathrm{g}} U_{\mathrm{g}}\right)\right)_{i, j, k}^{l}
\end{array}\right] \\
& T^{l+1}=f(P)^{l+1}
\end{aligned}
$$

where $i, j$ and $k$ are the grid coordinates in the $x, y, z$ directions, respectively; $T_{0}, T_{\mathrm{w}}$ and $T_{\mathrm{g}}$ are the mass transfer coefficients of oil, water and steam in the grid, respectively, $(\mathrm{kg} \cdot \mathrm{mD}) /\left(\mathrm{m}^{2} \cdot \mathrm{mPa} \cdot \mathrm{s}\right)$; $M_{\mathrm{o}}, M_{\mathrm{w}}$ and $M_{\mathrm{g}}$ are the mass flow velocities of oil, water and steam in the grid (injection is " + ", and production is "-"), respectively, $\mathrm{kg} / \mathrm{s} ; T_{\mathrm{ho}}, T_{\mathrm{hw}}$ and $T_{\mathrm{hg}}$ are the thermal conductivities related to the thermal convection of oil, water and steam in the grid, respectively, $(\mathrm{kg} \cdot \mathrm{mD}) /\left(\mathrm{m}^{2} \cdot \mathrm{mPa} \cdot \mathrm{s}\right) ; T_{\mathrm{R}}$ is the thermal conductivity related to heat conduction, $(\mathrm{kg} \cdot \mathrm{mD}) /\left(\mathrm{m}^{2} \cdot \mathrm{mPa} \cdot \mathrm{s}\right) ; M_{\mathrm{R}}$ is the volumetric heat capacity, $\mathrm{J} /\left(\mathrm{m}^{3} \cdot{ }^{\circ} \mathrm{C}\right) ; V_{\mathrm{B}}$ is the grid volume, $\mathrm{m}^{3} ; Q_{\text {well }}$ is the heat exchange rate between the wellbore and reservoir, $\mathrm{J} / \mathrm{s}$.

Equations (A44)-(A47) contain five unknowns: $P_{\mathrm{o}}, S_{\mathrm{o}}, S_{\mathrm{w}}, S_{\mathrm{g}}$ and $T$. As $S_{\mathrm{o}}$ can be calculated from the saturation equation $S_{\mathrm{o}}+S_{\mathrm{w}}+S_{\mathrm{g}}=1$ according to $S_{\mathrm{w}}$ and $S_{\mathrm{g}}$, therefore, Equations (A44)-(A47) can be simplified into the form of $A X=B$ using a fully implicit finite difference method. The coefficient matrix $A$ is a seven-diagonal $4 \times 4$ block matrix, and the unknowns $X=\left[\delta P_{\mathrm{o}}, \delta T, \delta S_{\mathrm{w}}, \delta S_{\mathrm{g}}\right]^{\mathrm{T}}$. Finally, the equation $A X=B$ can be solved by an iterative technique.

The relative permeability of the oil phase is a function of both water saturation and gas saturation, and the densities of oil and water are functions of both temperature and pressure.

$$
\begin{gathered}
k_{\mathrm{ro}}=k_{\mathrm{rowc}}\left[\left(\frac{k_{\mathrm{row}}}{k_{\mathrm{rowc}}}+k_{\mathrm{rw}}\right)\left(\frac{k_{\mathrm{rog}}}{k_{\mathrm{rowc}}}+k_{\mathrm{rg}}\right)-k_{\mathrm{rw}}-k_{\mathrm{rg}}\right] \\
\rho_{o}=\rho_{\mathrm{or}}\left[1+C_{\mathrm{op}}\left(P-P_{\mathrm{r}}\right)-C_{\mathrm{ot}}\left(T-T_{\mathrm{r}}\right)\right] \\
\rho_{\mathrm{w}}=\rho_{\mathrm{wr}}\left[1+C_{\mathrm{wp}}\left(P-P_{\mathrm{r}}\right)-C_{\mathrm{wt}}\left(T-T_{\mathrm{r}}\right)\right]
\end{gathered}
$$

Here $k_{\text {rowc }}$ is the relative permeability of the oil phase at irreducible water saturation; $k_{\text {row }}$ is the relative permeability of the oil phase in the oil-water system; $k_{\text {rog }}$ is the relative permeability of 
the oil phase in the oil-gas system; $\rho_{\text {or }}$ and $\rho_{\mathrm{wr}}$ are the densities of oil and water at the reference temperature and pressure, respectively, $\mathrm{kg} / \mathrm{m}^{3} ; C_{\mathrm{op}}$ and $C_{\mathrm{wp}}$ are the compressibility value of oil and water, respectively, $1 / \mathrm{MPa} ; C_{\mathrm{ot}}$ and $C_{\mathrm{wt}}$ are the coefficients of thermal expansion of oil and water, respectively, $1 /{ }^{\circ} \mathrm{C} ; P_{\mathrm{r}}$ is the reference pressure, $\mathrm{Pa}$; and $T_{\mathrm{r}}$ is the reference temperature, ${ }^{\circ} \mathrm{C}$.

The oil phase difference equation is taken as an example to illustrate the linearization process of the equations.

(1) The first two terms on the left side of the oil phase difference Equation (A44) can be derived as follows:

$$
\begin{aligned}
& \Delta T_{\mathrm{o}}^{l+1} \Delta P_{\mathrm{o}}^{l+1}-\Delta T_{\mathrm{o}}^{l+1} \Delta\left(\rho_{\mathrm{o} g D}\right)^{l+1}=\Delta T_{\mathrm{o}}^{l+1} \Phi_{\mathrm{o}}^{l+1} \\
& =T_{\mathrm{o} i+\frac{1}{2}, j, k}^{l+1}\left(\Phi_{\mathrm{o} i+1, j, k}^{l+1}-\Phi_{\mathrm{o} i, j, k}^{l+1}\right)+T_{\mathrm{o} i-\frac{1}{2}, j, k}^{l+1}\left(\Phi_{\mathrm{o} i-1, j, k}^{l+1}-\Phi_{\mathrm{o} i, j, k}^{l+1}\right)+T_{\mathrm{o} i, j+\frac{1}{2}, k}^{l+1}\left(\Phi_{\mathrm{o} i, j+1, k}^{l+1}-\Phi_{\mathrm{o} i, j, k}^{l+1}\right) \\
& +T_{\mathrm{o} i, j-\frac{1}{2}, k}^{l+1}\left(\Phi_{\mathrm{o} i, j-1, k}^{l+1}-\Phi_{\mathrm{o} i, j, k}^{l+1}\right)+T_{\mathrm{o} i, j, k+\frac{1}{2}}^{l+1}\left(\Phi_{\mathrm{o} i, j, k+1}^{l+1}-\Phi_{\mathrm{o} i, j, k}^{l+1}\right)+T_{\mathrm{o} i, j, k-\frac{1}{2}}^{l+1}\left(\Phi_{\mathrm{o} i, j, k-1}^{l+1}-\Phi_{\mathrm{o} i, j, k}^{l+1}\right) \\
& =\left(T_{\mathrm{o} i+\frac{1}{2}, j, k}^{l}+\delta T_{\mathrm{o} i+\frac{1}{2}, j, k}\right)\left(\Phi_{\mathrm{o} i+1, j, k}^{l}+\delta \Phi_{\mathrm{o} i+1, j, k}-\Phi_{\mathrm{o} i, j, k}^{l}-\delta \Phi_{\mathrm{o} i, j, k}\right)+ \\
& \left(T_{\mathrm{o} i-\frac{1}{2}, j, k}^{l}+\delta T_{\mathrm{o} i-\frac{1}{2}, j, k}\right) \\
& \left(T_{\mathrm{o} i, j+\frac{1}{2}, k}^{l}+\delta T_{\mathrm{o} i, j+\frac{1}{2}, k}\right)\left(\Phi_{\mathrm{o} i, j, j, k}^{l}+\delta \Phi_{\mathrm{o} i-1, j, k}-\Phi_{\mathrm{o} i, j, k}^{l}-\delta \Phi_{\mathrm{o} i, j, k}\right)+ \\
& \left(T_{\mathrm{o} i, j-\frac{1}{2}, k}^{l}+\delta T_{\mathrm{o} i, j-\frac{1}{2}, k}\right) \\
& \left(T_{\mathrm{o} i, j, k+\frac{1}{2}}^{l}+\delta T_{\mathrm{o} i, j, j+\frac{1}{2}}\right)\left(\Phi_{\mathrm{o} i, j, k}^{l}+\delta \Phi_{\mathrm{o} i, j-1, k}-\Phi_{\mathrm{o} i, j, k}^{l}-\delta \Phi_{\mathrm{o} i, j, j, k}\right)+ \\
& \left(T_{\mathrm{o} i, j, k-\frac{1}{2}}^{l}+\delta T_{\mathrm{o} i, j, k-\frac{1}{2}}^{l}\right)\left(\Phi_{\mathrm{o} i, j, k-1}^{l}+\delta \Phi_{\mathrm{o} i, j, k}\right)+
\end{aligned}
$$

The term $\left(T_{\mathrm{o} i \pm \frac{1}{2}, j, k}=\frac{(A k)_{i \pm \frac{1}{2}, j, k}}{0.5\left(\Delta x_{i}+\Delta x_{i \pm 1}\right)}\left(\frac{k_{\mathrm{ro}} \rho_{\mathrm{o}}}{\mu_{\mathrm{o}}}\right)_{i \pm \frac{1}{2}, j, k}\right)$ in Equation (A50) can be derived as follows:

$$
\begin{aligned}
& \delta T_{\mathrm{o} i \pm \frac{1}{2}, j, k}=\frac{(A k)_{i \pm \frac{1}{2}, j, k}}{0.5\left(\Delta x_{i}+\Delta x_{i \pm 1}\right)} \delta\left(\frac{k_{\mathrm{ro}} \rho_{\mathrm{o}}}{\mu_{\mathrm{o}}}\right)_{i \pm \frac{1}{2}, j, k} \\
& =\frac{(A k)_{i \pm \frac{1}{2}, j, k}}{0.5\left(\Delta x_{i}+\Delta x_{i \pm 1}\right)}\left(\begin{array}{c}
\frac{\partial}{\partial P_{\mathrm{o}}}\left(\frac{k_{\mathrm{ro}} \rho_{\mathrm{o}}}{\mu_{\mathrm{o}}}\right) \delta P_{o}+\frac{\partial}{\partial T}\left(\frac{k_{\mathrm{ro}} \rho_{\mathrm{o}}}{\mu_{\mathrm{o}}}\right) \delta T+ \\
\frac{\partial}{\partial S_{\mathrm{w}}}\left(\frac{k_{\mathrm{ro}} \rho_{\mathrm{o}}}{\mu_{\mathrm{o}}}\right) \delta S_{w}+\frac{\partial}{\partial S_{\mathrm{g}}}\left(\frac{k_{\mathrm{ro}} \rho_{\mathrm{o}}}{\mu_{\mathrm{o}}}\right) \delta S_{\mathrm{g}}
\end{array}\right)_{i \pm \frac{1}{2}, j, k} \\
& =\frac{(A k)_{i \pm \frac{1}{2}, j, k}}{0.5\left(\Delta x_{i}+\Delta x_{i \pm 1}\right)}\left(\begin{array}{l}
\frac{k_{\mathrm{ro}}}{\mu_{\mathrm{o}}} \frac{\partial \rho_{\mathrm{o}}}{\partial P_{\mathrm{o}}} \delta P_{\mathrm{o}}+\frac{k_{\mathrm{ro}}}{\mu_{\mathrm{o}}} \frac{\partial \rho_{\mathrm{o}}}{\partial T} \delta T+k_{\mathrm{ro}} \rho_{\mathrm{o}} \frac{\partial}{\partial T}\left(\frac{1}{\mu_{\mathrm{o}}}\right) \delta T+ \\
\frac{\rho_{\mathrm{o}}}{\mu_{\mathrm{o}}} \frac{\partial k_{\mathrm{ro}}}{\partial S_{\mathrm{w}}} \delta S_{\mathrm{w}}+\frac{\rho_{\mathrm{o}}}{\mu_{\mathrm{o}}} \frac{\partial k_{\mathrm{r}}}{\partial S_{\mathrm{g}}} \delta S_{\mathrm{g}}
\end{array}\right)_{i \pm \frac{1}{2}, j, k} \\
& =\frac{(A k)_{i \pm \frac{1}{2}, j, k}}{0.5\left(\Delta x_{i}+\Delta x_{i \pm 1}\right)}\left(\begin{array}{l}
\frac{k_{\mathrm{ro}} \rho_{\mathrm{or}} C_{\mathrm{op}}}{\mu_{\mathrm{o}}} \delta P_{\mathrm{o}}-\frac{k_{\mathrm{ro}} \rho_{\mathrm{or}} C_{\mathrm{op}}}{\mu_{\mathrm{o}}} \delta T-\frac{k_{\mathrm{ro}} \rho_{\mathrm{o}}}{\mu_{\mathrm{o}}^{2}} \frac{\partial \mu_{\mathrm{o}}}{\partial T} \delta T+ \\
\frac{\rho_{\mathrm{o}}}{\mu_{\mathrm{o}}} \frac{\partial k_{\mathrm{ro}}}{\partial S_{\mathrm{w}}} \delta S_{\mathrm{w}}+\frac{\rho_{\mathrm{o}}}{\mu_{\mathrm{o}}} \frac{\partial k_{\mathrm{r}}}{\partial S_{\mathrm{g}}} \delta S_{\mathrm{g}}
\end{array}\right)_{i \pm \frac{1}{2}, j, k}
\end{aligned}
$$


Similarly, terms $\delta T_{\mathrm{o} i, j \pm \frac{1}{2}, k}$ and $\delta T_{\mathrm{o} i, j, k \pm \frac{1}{2}}$ in Equation (A50) can be derived as follows:

$$
\begin{aligned}
& \delta T_{\mathrm{o} i, j \pm \frac{1}{2}, k}=\frac{(A k)_{i, j \pm \frac{1}{2}, k}}{0.5\left(\Delta y_{j}+\Delta y_{j \pm 1}\right)} \delta\left(\frac{k_{\mathrm{ro}} \rho_{\mathrm{o}}}{\mu_{\mathrm{o}}}\right)_{i, j \pm \frac{1}{2}, k} \\
& =\frac{(A k)_{i, j \pm \frac{1}{2}, k}}{0.5\left(\Delta y_{j}+\Delta y_{j \pm 1}\right)}\left(\begin{array}{l}
\frac{\partial}{\partial P_{\mathrm{o}}}\left(\frac{k_{\mathrm{ro}} \rho_{\mathrm{o}}}{\mu_{\mathrm{o}}}\right) \delta P_{\mathrm{o}}+\frac{\partial}{\partial T}\left(\frac{k_{\mathrm{ro}} \rho_{\mathrm{o}}}{\mu_{\mathrm{o}}}\right) \delta T+ \\
\frac{\partial}{\partial S_{\mathrm{w}}}\left(\frac{k_{\mathrm{ro}} \rho_{\mathrm{o}}}{\mu_{\mathrm{o}}}\right) \delta S_{\mathrm{w}}+\frac{\partial}{\partial S_{\mathrm{g}}}\left(\frac{k_{\mathrm{ro}} \rho_{\mathrm{o}}}{\mu_{\mathrm{o}}}\right) \delta S_{\mathrm{g}}
\end{array}\right)_{i, j \pm \frac{1}{2}, k}
\end{aligned}
$$

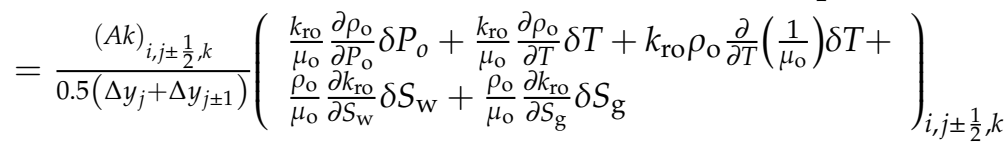

$$
\begin{aligned}
& =\frac{(A k)_{i, j \pm \frac{1}{2}, k}}{0.5\left(\Delta y_{j}+\Delta y_{j \pm 1}\right)}\left(\begin{array}{l}
\frac{k_{\mathrm{ro}} \rho_{\mathrm{or}} C_{\mathrm{op}}}{\mu_{\mathrm{o}}} \delta P_{\mathrm{o}}-\frac{k_{\mathrm{ro}} \rho_{\mathrm{or}} C_{\mathrm{op}}}{\mu_{\mathrm{o}}} \delta T-\frac{k_{\mathrm{ro}} \rho_{\mathrm{o}}}{\mu_{\mathrm{o}}^{2}} \frac{\partial \mu_{\mathrm{o}}}{\partial T} \delta T+ \\
\frac{\rho_{\mathrm{o}}}{\mu_{\mathrm{o}}} \frac{\partial k_{\mathrm{r}}}{\partial S_{\mathrm{w}}} \delta S_{\mathrm{w}}+\frac{\rho_{\mathrm{o}}}{\mu_{\mathrm{o}}} \frac{\partial \mathrm{k}_{\mathrm{ro}}}{\partial S_{\mathrm{g}}} \delta S_{\mathrm{g}}
\end{array}\right)_{i, j \pm \frac{1}{2}, k} \\
& \delta T_{\mathrm{o} i, j, k \pm \frac{1}{2}}=\frac{(A k)_{i, j, k \pm \frac{1}{2}}}{0.5\left(\Delta z_{k}+\Delta z_{k \pm 1}\right)} \delta\left(\frac{k_{\mathrm{ro}} \rho_{\mathrm{o}}}{\mu_{\mathrm{o}}}\right)_{i, j, k \pm \frac{1}{2}} \\
& =\frac{(A k)_{i, j, k \pm \frac{1}{2}}}{0.5\left(\Delta z_{k}+\Delta z_{k \pm 1}\right)}\left(\begin{array}{c}
\frac{\partial}{\partial P_{\mathrm{o}}}\left(\frac{k_{\mathrm{ro}} \rho_{\mathrm{o}}}{\mu_{\mathrm{o}}}\right) \delta P_{\mathrm{o}}+\frac{\partial}{\partial T}\left(\frac{k_{\mathrm{ro}} \rho_{\mathrm{o}}}{\mu_{\mathrm{o}}}\right) \delta T+ \\
\frac{\partial}{\partial S_{\mathrm{w}}}\left(\frac{k_{\mathrm{ro}} \rho_{\mathrm{o}}}{\mu_{\mathrm{o}}}\right) \delta S_{\mathrm{w}}+\frac{\partial}{\partial S_{\mathrm{g}}}\left(\frac{k_{\mathrm{ro}} \rho_{\mathrm{o}}}{\mu_{\mathrm{o}}}\right) \delta S_{\mathrm{g}}
\end{array}\right)_{i, j, k \pm \frac{1}{2}}
\end{aligned}
$$

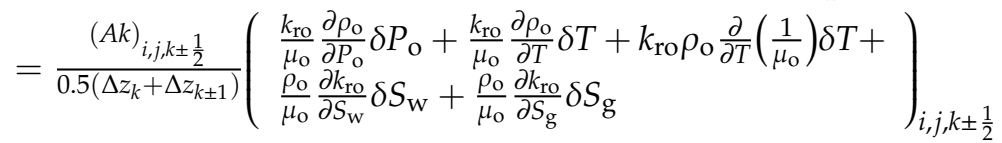

$$
\begin{aligned}
& =\frac{(A k)_{i, j, k \pm \frac{1}{2}}}{0.5\left(\Delta z_{k}+\Delta z_{k \pm 1}\right)}\left(\begin{array}{l}
\frac{k_{\mathrm{ro}} \rho_{\mathrm{or}} C_{\mathrm{op}}}{\mu_{\mathrm{o}}} \delta P_{\mathrm{o}}-\frac{k_{\mathrm{ro}} \rho_{\mathrm{or}} C_{\mathrm{op}}}{\mu_{\mathrm{o}}} \delta T-\frac{k_{\mathrm{ro}} \rho_{\mathrm{o}}}{\mu_{\mathrm{o}}^{2}} \frac{\partial \mu_{\mathrm{o}}}{\partial T} \delta T+ \\
\frac{\rho_{\mathrm{o}}}{\mu_{\mathrm{o}}} \frac{\partial k_{\mathrm{ro}}}{\partial S_{\mathrm{w}}} \delta S_{\mathrm{w}}+\frac{\rho_{\mathrm{o}}}{\mu_{\mathrm{o}}} \frac{\partial k_{\mathrm{ro}}}{\partial S_{\mathrm{g}}} \delta S_{\mathrm{g}}
\end{array}\right)_{i, j, k \pm \frac{1}{2}}
\end{aligned}
$$

Finally, Equation (A50) can be expressed as:

$$
\begin{aligned}
& \Delta T_{\mathrm{o}}^{l+1} \Delta P_{\mathrm{o}}^{l+1}-\Delta T_{\mathrm{o}}^{l+1} \Delta\left(\rho_{\mathrm{o} g} D\right)^{l+1}=\Delta T_{\mathrm{o}}^{l+1} \Phi_{\mathrm{o}}^{l+1} \\
& =T_{\mathrm{o} i+\frac{1}{2}, j, k}^{l}\left(\Phi_{\mathrm{o} i+1, j, k}^{l}-\Phi_{\mathrm{o} i, j, k}^{l}\right)+T_{\mathrm{o} i+\frac{1}{2}, j, k}^{l}\left(\delta P_{\mathrm{o} i+1, j, k}^{l}-\delta P_{\mathrm{o} i, j, k}^{l}\right)+ \\
& \left(\frac{\partial T_{\mathrm{o}}}{\partial P_{\mathrm{o}}} \delta P_{\mathrm{o}}+\frac{\partial T_{\mathrm{o}}}{\partial T} \delta T+\frac{\partial T_{\mathrm{o}}}{\partial S_{\mathrm{w}}} \delta S_{\mathrm{w}}+\frac{\partial T_{\mathrm{o}}}{\partial S_{\mathrm{g}}} \delta S_{\mathrm{g}}\right)_{i+\frac{1}{2}, j, k}\left(\Phi_{\mathrm{o} i+1, j, k}^{l}-\Phi_{\mathrm{o} i, j, k}^{l}\right)+ \\
& T_{\mathrm{o} i-\frac{1}{2}, j, k}^{l}\left(\Phi_{\mathrm{o} i-1, j, k}^{l}-\Phi_{\mathrm{o} i, j, k}^{l}\right)+T_{\mathrm{o} i-\frac{1}{2}, j, k}^{l}\left(\delta P_{\mathrm{o} i-1, j, k}^{l}-\delta P_{\mathrm{o} i, j, k}^{l}\right)+ \\
& \left(\frac{\partial T_{\mathrm{o}}}{\partial P_{\mathrm{o}}} \delta P_{\mathrm{o}}+\frac{\partial T_{\mathrm{o}}}{\partial T} \delta T+\frac{\partial T_{\mathrm{o}}}{\partial S_{\mathrm{w}}} \delta S_{\mathrm{w}}+\frac{\partial T_{\mathrm{o}}}{\partial S_{\mathrm{g}}} \delta S_{\mathrm{g}}\right)_{i-\frac{1}{2}, j, k}\left(\Phi_{\mathrm{o} i-1, j, k}^{l}-\Phi_{\mathrm{o} i, j, k}^{l}\right)+ \\
& T_{\mathrm{o} i, j+\frac{1}{2}, k}^{l}\left(\Phi_{\mathrm{o} i, j+1, k}^{l}-\Phi_{\mathrm{o} i, j, k}^{l}\right)+T_{\mathrm{o} i, j+\frac{1}{2}, k}^{l}\left(\delta P_{\mathrm{o} i, j+1, k}^{l}-\delta P_{\mathrm{o} i, j, k}^{l}\right)+ \\
& \left(\frac{\partial T_{\mathrm{o}}}{\partial P_{\mathrm{o}}} \delta P_{\mathrm{o}}+\frac{\partial T_{\mathrm{o}}}{\partial T} \delta T+\frac{\partial T_{\mathrm{o}}}{\partial S_{\mathrm{w}}} \delta S_{\mathrm{w}}+\frac{\partial T_{\mathrm{o}}}{\partial S_{\mathrm{g}}} \delta S_{\mathrm{g}}\right)_{i, j+\frac{1}{2}, k}\left(\Phi_{\mathrm{o} i, j+1, k}^{l}-\Phi_{\mathrm{o} i, j, k}^{l}\right)+ \\
& T_{\mathrm{o} i, j-\frac{1}{2}, k}^{l}\left(\Phi_{\mathrm{o} i, j-1, k}^{l}-\Phi_{\mathrm{o} i, j, k}^{l}\right)+T_{\mathrm{o} i, j-\frac{1}{2}, k}^{l}\left(\delta P_{\mathrm{o} i, j-1, k}^{l}-\delta P_{\mathrm{o} i, j, k}^{l}\right)+ \\
& \left(\frac{\partial T_{\mathrm{o}}}{\partial P_{\mathrm{o}}} \delta P_{\mathrm{o}}+\frac{\partial T_{\mathrm{o}}}{\partial T} \delta T+\frac{\partial T_{\mathrm{o}}}{\partial S_{\mathrm{w}}} \delta S_{\mathrm{w}}+\frac{\partial T_{\mathrm{o}}}{\partial S_{\mathrm{g}}} \delta S_{\mathrm{g}}\right)_{i, j-\frac{1}{2}, k}\left(\Phi_{\mathrm{o} i, j-1, k}^{l}-\Phi_{\mathrm{o} i, j, k}^{l}\right)+ \\
& \left.T_{\mathrm{o} i, j, k+\frac{1}{2}}^{l}\left(\Phi_{\mathrm{o} i, j, k+1}^{l}-\Phi_{\mathrm{o} i, j, k}^{l}\right)+T_{\mathrm{o} i, j, k+\frac{1}{2}}^{l} \delta P_{\mathrm{o} i, j, k+1}^{l}-\delta P_{\mathrm{o} i, j, k}^{l}\right)+ \\
& \left(\frac{\partial T_{\mathrm{o}}}{\partial P_{\mathrm{o}}} \delta P_{\mathrm{o}}+\frac{\partial T_{\mathrm{o}}}{\partial T} \delta T+\frac{\partial T_{\mathrm{o}}}{\partial S_{\mathrm{w}}} \delta S_{\mathrm{w}}+\frac{\partial T_{\mathrm{o}}}{\partial S_{\mathrm{g}}} \delta S_{\mathrm{g}}\right)_{i, j, k+\frac{1}{2}}\left(\Phi_{\mathrm{o} i, j, k+1}^{l}-\Phi_{\mathrm{o} i, j, k}^{l}\right)+ \\
& T_{\mathrm{o} i, j, k-\frac{1}{2}}^{l}\left(\Phi_{\mathrm{o} i, j, k-1}^{l}-\Phi_{\mathrm{o} i, j, k}^{l}\right)+T_{\mathrm{o} i, j, k-\frac{1}{2}}^{l}\left(\delta P_{\mathrm{o} i, j, k-1}^{l}-\delta P_{\mathrm{o} i, j, k}^{l}\right)+ \\
& \left(\frac{\partial T_{\mathrm{o}}}{\partial P_{\mathrm{o}}} \delta P_{\mathrm{o}}+\frac{\partial T_{\mathrm{o}}}{\partial T} \delta T+\frac{\partial T_{\mathrm{o}}}{\partial S_{\mathrm{w}}} \delta S_{\mathrm{w}}+\frac{\partial T_{\mathrm{o}}}{\partial S_{\mathrm{g}}} \delta S_{\mathrm{g}}\right)_{i, j, k-\frac{1}{2}}\left(\Phi_{\mathrm{o} i, j, k-1}^{l}-\Phi_{\mathrm{o} i, j, k}^{l}\right)
\end{aligned}
$$


(2)The source and sink terms of oil phase difference Equation (A44) can be treated as follows:

$$
\begin{aligned}
& M_{\mathrm{o} i, j, k}^{l+1}=\left(\frac{2 \pi k h}{\ln \frac{r_{\mathrm{e}}}{r_{\mathrm{w}}}+S-0.75} \frac{k_{\mathrm{ro}} \rho_{\mathrm{o}}}{\mu_{\mathrm{o}}}\right)_{i, j, k}^{l+1}\left(P_{\mathrm{o} i, j, k}^{l+1}-P_{\mathrm{wfi}, j, k}^{l+1}\right) \\
& =\left(W I \frac{k_{\mathrm{ro}} \rho_{\mathrm{o}}}{\mu_{\mathrm{o}}}\right)_{i, j, k}^{l+1}\left(P_{\mathrm{o} i, j, k}^{l+1}-P_{\mathrm{wfi}, j, k}^{l+1}\right)
\end{aligned}
$$

WI can be expressed as:

$$
W I=\frac{2 \pi h k}{\ln \frac{r_{\mathrm{e}}}{r_{\mathrm{W}}}+S-0.75}
$$

When the bottom-hole pressure is fixed for oil production, $P_{\mathrm{wfi}, j, k}^{l+1}$ is known, and Equation (A55) can be simplified as:

$$
\begin{aligned}
& M_{\mathrm{o} i, j, k}^{l+1}=\left(W I \frac{k_{\mathrm{ro}} \rho_{\mathrm{o}}}{\mu_{\mathrm{o}}}\right)_{i, j, k}^{l+1}\left(P_{\mathrm{o} i, j, k}^{l+1}-P_{\mathrm{wfi}, j, k}^{l+1}\right) \\
& =W I\left[\left(\frac{k_{\mathrm{ro}} \rho_{\mathrm{o}}}{\mu_{\mathrm{o}}}\right)_{i, j, k}^{l}+\delta\left(\frac{k_{\mathrm{ro}} \rho_{\mathrm{o}}}{\mu_{\mathrm{o}}}\right)_{i, j, k}\right]\left(P_{\mathrm{o} i, j, k}^{l}+\delta P_{\mathrm{o} i, j, k}-P_{\mathrm{wfi} i j, k}\right) \\
& =W I\left[\left(\frac{k_{\mathrm{ro}} \rho_{\mathrm{o}}}{\mu_{\mathrm{o}}}\right)_{i, j, k}^{l}+\left(\begin{array}{l}
\frac{k_{\mathrm{ro}} \rho_{\mathrm{or}} C_{\mathrm{op}}}{\mu_{\mathrm{o}}} \delta P_{\mathrm{o}}-\frac{k_{\mathrm{ro}} \rho_{\mathrm{or}} \mathrm{C}_{\mathrm{op}}}{\mu_{\mathrm{o}}} \delta T-\frac{k_{\mathrm{ro}} \rho_{\mathrm{o}}}{\mu_{\mathrm{o}}^{2}} \frac{\partial \mu_{\mathrm{o}}}{\partial T} \delta T+ \\
\frac{\rho_{\mathrm{o}}}{\mu_{\mathrm{o}}} \frac{\partial k_{\mathrm{ro}}}{\partial S_{\mathrm{w}}} \delta S_{\mathrm{W}}+\frac{\rho_{\mathrm{o}}}{\mu_{\mathrm{o}}} \frac{\partial k_{\mathrm{ro}}}{\partial S_{\mathrm{g}}} \delta S_{\mathrm{g}}
\end{array}\right)_{i, j, k}\right] \\
& \left(P_{\mathrm{o} i, j, k}^{l}+\delta P_{\mathrm{o} i, j, k}-P_{\mathrm{wf} i, j, k}\right) \\
& =W I\left(\frac{k_{\mathrm{ro}} \rho_{\mathrm{o}}}{\mu_{\mathrm{o}}}\right)_{i, j, k}^{l}\left(P_{\mathrm{o} i, j, k}^{l}+\delta P_{\mathrm{o} i, j, k}-P_{\mathrm{wfi} i, j, k}\right)+ \\
& W I\left(\begin{array}{l}
\frac{k_{\mathrm{ro}} \rho_{\mathrm{or}} C_{\mathrm{op}}}{\mu_{\mathrm{o}}} \delta P_{\mathrm{o}}-\frac{k_{\mathrm{ro}} \rho_{\mathrm{or}} C_{\mathrm{op}}}{\mu_{\mathrm{o}}} \delta T-\frac{k_{\mathrm{ro}} \rho_{\mathrm{o}}}{\mu_{\mathrm{o}}^{2}} \frac{\partial \mu_{\mathrm{o}}}{\partial T} \delta T+ \\
\frac{\rho_{\mathrm{o}}}{\mu_{\mathrm{o}}} \frac{\partial k_{\mathrm{ro}}}{\partial S_{\mathrm{w}}} \delta S_{\mathrm{w}}+\frac{\rho_{\mathrm{o}}}{\mu_{\mathrm{o}}} \frac{\partial k_{\mathrm{ro}}}{\partial S_{\mathrm{g}}} \delta S_{\mathrm{g}}
\end{array}\right)_{i, j, k}\left(P_{\mathrm{oi}, j, k}^{l}-P_{\mathrm{wfi}, j, k}\right)
\end{aligned}
$$

(3) The term on the right side of the oil phase difference Equation (A44) can be derived as follows:

$$
\begin{aligned}
& \frac{V_{\mathrm{B}}}{\Delta t}\left(\left(\rho_{\mathrm{o}} \varphi S_{\mathrm{O}}\right)_{i, j, k}^{l+1}-\left(\rho_{\mathrm{o}} \varphi S_{\mathrm{o}}\right)_{i, j, k}^{n}\right) \\
& =\frac{V_{\mathrm{B}}}{\Delta t}\left(\left(\rho_{\mathrm{o}} \varphi S_{\mathrm{o}}\right)_{i, j, k}^{l}+\delta\left(\rho_{\mathrm{o}} \varphi S_{\mathrm{o}}\right)_{i, j, k}-\left(\rho_{\mathrm{o}} \varphi S_{\mathrm{o}}\right)_{i, j, k}^{n}\right) \\
& =\frac{V_{\mathrm{B}}}{\Delta t}\left(\left(\rho_{\mathrm{o}} \varphi S_{\mathrm{o}}\right)_{i, j, k}^{l}+\left(S_{\mathrm{o}} \delta\left(\rho_{\mathrm{o}} \varphi\right)+\rho_{\mathrm{o}} \varphi \delta S_{\mathrm{o}}\right)_{i, j, k}-\left(\rho_{\mathrm{o}} \varphi S_{\mathrm{o}}\right)_{i, j, k}^{n}\right) \\
& =\frac{V_{\mathrm{B}}}{\Delta t}\left\{\begin{array}{l}
{\left[S_{\mathrm{O}}\left(\varphi \frac{\partial \rho_{\mathrm{o}}}{\partial P_{\mathrm{o}}} \delta P_{\mathrm{o}}+\varphi \frac{\partial \rho_{\mathrm{o}}}{\partial T} \delta T+\rho_{\mathrm{o}} \frac{\partial \varphi}{\partial P_{\mathrm{o}}} \delta P_{\mathrm{o}}\right)-\rho_{\mathrm{o}} \varphi \delta\left(S_{\mathrm{W}}+S_{\mathrm{g}}\right)\right]_{i, j, k}+} \\
\left(\rho_{\mathrm{o}} \varphi S_{\mathrm{o}}\right)_{i, j, k}^{l}-\left(\rho_{\mathrm{o}} \varphi S_{\mathrm{o}}\right)_{i, j, k}^{n}
\end{array}\right\}
\end{aligned}
$$

In summary, Equations (A54), (A57) and (A58) constitute a complete linearization coefficient difference equation of the oil phase, and the variables in the equation are $\delta P_{\mathrm{o}}, \delta T, \delta S_{\mathrm{w}}$ and $\delta S_{\mathrm{g}}$.

Similarly, the water and steam phase difference Equation (A45) can be derived as follows:

$$
\begin{aligned}
& T_{\mathrm{w} i+\frac{1}{2}, j, k}^{l}\left(\Phi_{\mathrm{w} i+1, j, k}^{l}-\Phi_{\mathrm{w} i, j, k}^{l}\right)+T_{\mathrm{w} i+\frac{1}{2}, j, k}^{l}\left(\delta P_{\mathrm{o} i+1, j, k}^{l}-\delta P_{\mathrm{o} i j, j, k}^{l}\right)-T_{\mathrm{w} i+\frac{1}{2}, j, k}^{l}\left(\delta P_{\mathrm{cow} i+1, j, k}^{l}-\delta P_{\mathrm{cow} i, j, k}^{l}\right) \\
& +\left(\frac{\partial T_{\mathrm{w}}}{\partial P_{\mathrm{o}}} \delta P_{\mathrm{o}}+\frac{\partial T_{\mathrm{w}}}{\partial T} \delta T+\frac{\partial T_{\mathrm{w}}}{\partial S_{\mathrm{w}}} \delta S_{\mathrm{w}}\right)_{i+\frac{1}{2}, j, k}\left(\Phi_{\mathrm{w} i+1, j, k}^{l}-\Phi_{\mathrm{w} i, j, k}^{l}\right)+ \\
& T_{\mathrm{w} i-\frac{1}{2}, j, k}^{l}\left(\Phi_{\mathrm{w} i-1, j, k}^{l}-\Phi_{\mathrm{w} i, j, k}^{l}\right)+T_{\mathrm{w} i-\frac{1}{2}, j, k}^{l}\left(\delta P_{\mathrm{o} i-1, j, k}^{l}-\delta P_{\mathrm{o} i, j, k}^{l}\right)-T_{\mathrm{w} i-\frac{1}{2}, j, k}^{l}\left(\delta P_{\mathrm{cow} i-1, j, k}^{l}-\delta P_{\mathrm{cow} i, j, k}^{l}\right) \\
& +\left(\frac{\partial T_{\mathrm{w}}}{\partial P_{\mathrm{o}}} \delta P_{\mathrm{o}}+\frac{\partial T_{\mathrm{w}}}{\partial T} \delta T+\frac{\partial T_{\mathrm{w}}}{\partial S_{\mathrm{w}}} \delta S_{\mathrm{w}}\right)_{i-\frac{1}{2}, j, k}\left(\Phi_{\mathrm{w} i-1, j, k}^{l}-\Phi_{\mathrm{w} i, j, k}^{l}\right)+
\end{aligned}
$$


Energies 2020, 13, 3981

31 of 36

$$
\begin{aligned}
& T_{\mathrm{w} i, j+\frac{1}{2}, k}^{l}\left(\Phi_{\mathrm{w} i, j+1, k}^{l}-\Phi_{\mathrm{w} i, j, k}^{l}\right)+T_{\mathrm{w} i, j+\frac{1}{2}, k}^{l}\left(\delta P_{\mathrm{o} i, j+1, k}^{l}-\delta P_{\mathrm{o} i, j, k}^{l}\right)-T_{\mathrm{w} i, j+\frac{1}{2}, k}^{l}\left(\delta P_{\mathrm{cow} i, j+1, k}^{l}-\delta P_{\mathrm{cow} i, j, k}^{l}\right) \\
& +\left(\frac{\partial T_{\mathrm{w}}}{\partial P_{\mathrm{o}}} \delta P_{\mathrm{o}}+\frac{\partial T_{\mathrm{w}}}{\partial T} \delta T+\frac{\partial T_{\mathrm{w}}}{\partial S_{\mathrm{w}}} \delta S_{\mathrm{w}}\right)_{i, j+\frac{1}{2}, k}\left(\Phi_{\mathrm{w} i, j+1, k}^{l}-\Phi_{\mathrm{w} i, j, k}^{l}\right)+ \\
& T_{\mathrm{w} i, j-\frac{1}{2}, k}^{l}\left(\Phi_{\mathrm{w} i, j-1, k}^{l}-\Phi_{\mathrm{w} i, j, k}^{l}\right)+T_{\mathrm{w} i, j-\frac{1}{2}, k}^{l}\left(\delta P_{\mathrm{o} i, j-1, k}^{l}-\delta P_{\mathrm{o} i, j, k}^{l}\right)-T_{\mathrm{w} i, j-\frac{1}{2}, k}^{l}\left(\delta P_{\mathrm{cow} i, j-1, k}^{l}-\delta P_{\mathrm{cow} i, j, k}^{l}\right) \\
& +\left(\frac{\partial T_{\mathrm{w}}}{\partial P_{\mathrm{o}}} \delta P_{\mathrm{o}}+\frac{\partial T_{\mathrm{w}}}{\partial T} \delta T+\frac{\partial T_{\mathrm{w}}}{\partial S_{\mathrm{w}}} \delta S_{\mathrm{w}}\right)_{i, j-\frac{1}{2}, k}\left(\Phi_{\mathrm{w} i, j-1, k}^{l}-\Phi_{\mathrm{w} i, j, k}^{l}\right)+ \\
& T_{\mathrm{w} i, j, k+\frac{1}{2}}^{l}\left(\Phi_{\mathrm{w} i, j, k+1}^{l}-\Phi_{\mathrm{w} i, j, k}^{l}\right)+T_{\mathrm{w} i, j, k+\frac{1}{2}}^{l}\left(\delta P_{\mathrm{o} i, j, k+1}^{l}-\delta P_{\mathrm{o} i, j, k}^{l}\right)-T_{\mathrm{w} i, j, k+\frac{1}{2}}^{l}\left(\delta P_{\mathrm{cow} i, j, k+1}^{l}-\delta P_{\mathrm{cow} i, j, k}^{l}\right) \\
& +\left(\frac{\partial T_{\mathrm{w}}}{\partial P_{\mathrm{o}}} \delta P_{\mathrm{o}}+\frac{\partial T_{\mathrm{w}}}{\partial T} \delta T+\frac{\partial T_{\mathrm{w}}}{\partial S_{\mathrm{w}}} \delta S_{\mathrm{w}}\right)_{i, j, k+\frac{1}{2}}\left(\Phi_{\mathrm{w} i, j, k+1}^{l}-\Phi_{\mathrm{w} i, j, k}^{l}\right)+ \\
& T_{\mathrm{w} i, j, k-\frac{1}{2}}^{l}\left(\Phi_{\mathrm{w} i, j, k-1}^{l}-\Phi_{\mathrm{w} i, j, k}^{l}\right)+T_{\mathrm{w} i, j, k-\frac{1}{2}}^{l}\left(\delta P_{\mathrm{o} i, j, k-1}^{l}-\delta P_{\mathrm{o} i, j, k}^{l}\right)-T_{\mathrm{w} i, j, k-\frac{1}{2}}^{l}\left(\delta P_{\text {cow } i, j, k-1}^{l}-\delta P_{\text {cow } i, j, k}^{l}\right) \\
& +\left(\frac{\partial T_{\mathrm{w}}}{\partial P_{\mathrm{o}}} \delta P_{\mathrm{o}}+\frac{\partial T_{\mathrm{w}}}{\partial T} \delta T+\frac{\partial T_{\mathrm{w}}}{\partial S_{\mathrm{w}}} \delta S_{\mathrm{w}}\right)_{i, j, k-\frac{1}{2}}\left(\Phi_{\mathrm{w} i, j, k-1}^{l}-\Phi_{\mathrm{w} i, j, k}^{l}\right) \\
& T_{\mathrm{g} i+\frac{1}{2}, j, k}^{l}\left(\Phi_{\mathrm{g} i+1, j, k}^{l}-\Phi_{\mathrm{g} i, j, k}^{l}\right)+T_{\mathrm{g} i+\frac{1}{2}, j, k}^{l}\left(\delta P_{\mathrm{o} i+1, j, k}^{l}-\delta P_{\mathrm{o} i, j, k}^{l}\right)+T_{\mathrm{g} i+\frac{1}{2}, j, k}^{l}\left(\delta P_{\mathrm{cgoi}+1, j, k}^{l}-\delta P_{\mathrm{cgoi}, j, k}^{l}\right) \\
& +\left(\frac{\partial T_{\mathrm{g}}}{\partial T} \delta T+\frac{\partial T_{\mathrm{g}}}{\partial S_{\mathrm{g}}} \delta S_{\mathrm{g}}\right)_{i+\frac{1}{2}, j, k}\left(\Phi_{\mathrm{g} i+1, j, k}^{l}-\Phi_{\mathrm{g} i, j, k}^{l}\right)+ \\
& T_{\mathrm{g} i-\frac{1}{2}, j, k}^{l}\left(\Phi_{\mathrm{g} i-1, j, k}^{l}-\Phi_{\mathrm{g} i, j, k}^{l}\right)+T_{\mathrm{g} i-\frac{1}{2}, j, k}^{l}\left(\delta P_{\mathrm{o} i-1, j, k}^{l}-\delta P_{\mathrm{o} i, j, k}^{l}\right)+T_{\mathrm{g} i-\frac{1}{2}, j, k}^{l}\left(\delta P_{\text {cgoi-1,j,k }}^{l}-\delta P_{\text {cgoi,j,k }}^{l}\right) \\
& +\left(\frac{\partial^{2} T_{\mathrm{g}}}{\partial T} \delta T+\frac{\partial T_{\mathrm{g}}}{\partial S_{\mathrm{g}}} \delta S_{\mathrm{g}}\right)_{i-\frac{1}{2}, j, k}\left(\Phi_{\mathrm{g} i-1, j, k}^{l}-\Phi_{\mathrm{g} i, j, k}^{l}\right)+ \\
& T_{\mathrm{g} i, j+\frac{1}{2}, k}^{l}\left(\Phi_{\mathrm{g} i, j+1, k}^{l}-\Phi_{\mathrm{g} i, j, k}^{l}\right)+T_{\mathrm{g} i, j+\frac{1}{2}, k}^{l}\left(\delta P_{\mathrm{o} i, j+1, k}^{l}-\delta P_{\mathrm{o} i, j, k}^{l}\right)+T_{\mathrm{g} i, j+\frac{1}{2}, k}^{l}\left(\delta P_{\mathrm{cgoi}, j+1, k}^{l}-\delta P_{\mathrm{cgo} i, j, k}^{l}\right) \\
& +\left(\frac{\partial T_{\mathrm{g}}}{\partial T} \delta T+\frac{\partial T_{\mathrm{g}}}{\partial S_{\mathrm{g}}} \delta S_{\mathrm{g}}\right)_{i, j+\frac{1}{2}, k}\left(\Phi_{\mathrm{g} i, j+1, k}^{l}-\Phi_{\mathrm{g} i, j, k}^{l}\right)+ \\
& T_{\mathrm{g} i, j-\frac{1}{2}, k}^{l}\left(\Phi_{\mathrm{g} i, j-1, k}^{l}-\Phi_{\mathrm{g} i, j, k}^{l}\right)+T_{\mathrm{g} i, j-\frac{1}{2}, k}^{l}\left(\delta P_{\mathrm{o} i, j-1, k}^{l}-\delta P_{\mathrm{o} i, j, k}^{l}\right)+T_{\mathrm{g} i, j-\frac{1}{2}, k}^{l}\left(\delta P_{\mathrm{cgo} i, j-1, k}^{l}-\delta P_{\mathrm{cgoi}, j, k}^{l}\right) \\
& +\left(\frac{\partial T_{\mathrm{g}}}{\partial T} \delta T+\frac{\partial T_{\mathrm{g}}}{\partial S_{\mathrm{g}}} \delta S_{\mathrm{g}}\right)_{i, j-\frac{1}{2}, k}\left(\Phi_{\mathrm{g} i, j-1, k}^{l}-\Phi_{\mathrm{g} i, j, k}^{l}\right)+ \\
& T_{\mathrm{g} i, j, k+\frac{1}{2}}^{l}\left(\Phi_{\mathrm{g} i, j, k+1}^{l}-\Phi_{\mathrm{g} i, j, k}^{l}\right)+T_{\mathrm{g} i, j, k+\frac{1}{2}}^{l}\left(\delta P_{\mathrm{o} i, j, k+1}^{l}-\delta P_{\mathrm{o} i, j, k}^{l}\right)+T_{\mathrm{g} i, j, k+\frac{1}{2}}^{l}\left(\delta P_{\mathrm{cgo} i, j, k+1}^{l}-\delta P_{\mathrm{cgoi}, j, k}^{l}\right) \\
& +\left(\frac{\partial T_{\mathrm{g}}}{\partial T} \delta T+\frac{\partial T_{\mathrm{g}}}{\partial S_{\mathrm{g}}} \delta S_{\mathrm{g}}\right)_{i, j, k+\frac{1}{2}}\left(\Phi_{\mathrm{g} i, j, k+1}^{l}-\Phi_{\mathrm{g} i, j, k}^{l}\right)+ \\
& T_{\mathrm{g} i, j, k-\frac{1}{2}}^{l}\left(\Phi_{\mathrm{g} i, j, k-1}^{l}-\Phi_{\mathrm{g} i, j, k}^{l}\right)+T_{\mathrm{g} i, j, k-\frac{1}{2}}^{l}\left(\delta P_{\mathrm{o} i, j, k-1}^{l}-\delta P_{\mathrm{o} i, j, k}^{l}\right)+T_{\mathrm{g} i, j, k-\frac{1}{2}}^{l}\left(\delta P_{\mathrm{cgoi}, j, k-1}^{l}-\delta P_{\text {cgo } i, j, k}^{l}\right) \\
& +\left(\frac{\partial T_{\mathrm{g}}}{\partial T} \delta T+\frac{\partial T_{\mathrm{g}}}{\partial S_{\mathrm{g}}} \delta S_{\mathrm{g}}\right)_{i, j, k-\frac{1}{2}}\left(\Phi_{\mathrm{g} i, j, k-1}^{l}-\Phi_{\mathrm{g} i, j, k}^{l}\right)+M_{\mathrm{w} i, j, k}^{l+1}+M_{\mathrm{g} i, j, k}^{l+1} \\
& =\frac{V_{\mathrm{B}}}{\Delta t}\left(\left(\rho_{\mathrm{w}} \varphi S_{\mathrm{w}}\right)_{i, j, k}^{l}+\delta\left(\rho_{\mathrm{w}} \varphi S_{\mathrm{w}}\right)_{i, j, k}-\left(\rho_{\mathrm{w}} \varphi S_{\mathrm{w}}\right)_{i, j, k}^{n}\right)+\frac{V_{\mathrm{B}}}{\Delta t}\left(\left(\rho_{\mathrm{g}} \varphi S_{\mathrm{g}}\right)_{i, j, k}^{l}+\delta\left(\rho_{\mathrm{g}} \varphi S_{\mathrm{g}}\right)_{i, j, k}-\left(\rho_{\mathrm{g}} \varphi S_{\mathrm{g}}\right)_{i, j, k}^{n}\right) \\
& =\frac{V_{\mathrm{B}}}{\Delta t}\left\{\begin{array}{l}
\left(\rho_{\mathrm{w}} \varphi S_{\mathrm{w}}\right)_{i, j, k}^{l}-\left(\rho_{\mathrm{w}} \varphi S_{\mathrm{w}}\right)_{i, j, k}^{n}+\left[\rho_{\mathrm{w}} \varphi \delta S_{\mathrm{w}}+S_{\mathrm{w}} \varphi \frac{\partial \rho_{\mathrm{w}}}{\partial P_{\mathrm{o}}} \delta P_{\mathrm{o}}+S_{\mathrm{w}} \varphi \frac{\partial \rho_{\mathrm{w}}}{\partial T} \delta T+S_{\mathrm{w}} \rho_{\mathrm{w}} \frac{\partial \varphi}{\partial P_{\mathrm{o}}} \delta P_{\mathrm{o}}\right]_{i, j, k}+ \\
\left(\rho_{\mathrm{g}} \varphi S_{\mathrm{g}}\right)_{i, j, k}^{l}-\left(\rho_{\mathrm{g}} \varphi S_{\mathrm{g}}\right)_{i, j, k}^{n}+\left[\rho_{\mathrm{g}} \varphi \delta S_{\mathrm{g}}+S_{\mathrm{g}} \varphi \frac{\partial \rho_{\mathrm{g}}}{\partial T} \delta T+S_{\mathrm{g}} \rho_{\mathrm{g}} \frac{\partial \varphi}{\partial P_{\mathrm{o}}} \delta P_{\mathrm{o}}\right]_{i, j, k}
\end{array}\right\}
\end{aligned}
$$


The linearized energy difference Equation (A46) is:

$$
\begin{aligned}
& T_{\mathrm{R} i+\frac{1}{2}, j, k}\left(T_{i+1, j, k}^{l}-T_{i, j, k}^{l}\right)+T_{\mathrm{R} i+\frac{1}{2}, j, k}\left(\delta T_{i+1, j, k}-\delta T_{i, j, k}\right)+T_{\mathrm{R} i-\frac{1}{2}, j, k}\left(T_{i-1, j, k}^{l}-T_{i, j, k}^{l}\right)+ \\
& T_{\mathrm{R} i-\frac{1}{2}, j, k}\left(\delta T_{i-1, j, k}-\delta T_{i, j, k}\right)+T_{\mathrm{R} i, j+\frac{1}{2}, k}\left(T_{i, j+1, k}^{l}-T_{i, j, k}^{l}\right)+T_{\mathrm{R} i, j+\frac{1}{2}, k}\left(\delta T_{i, j+1, k}-\delta T_{i, j, k}\right)+ \\
& T_{\mathrm{R} i, j-\frac{1}{2}, k}\left(T_{i, j-1, k}^{l}-T_{i, j, k}^{l}\right)+T_{\mathrm{R} i, j-\frac{1}{2}, k}\left(\delta T_{i, j-1, k}-\delta T_{i, j, k}\right)+T_{\mathrm{R} i, j, k+\frac{1}{2}}\left(T_{i, j, k+1}^{l}-T_{i, j, k}^{l}\right)+ \\
& T_{\mathrm{R} i, j, k+\frac{1}{2}}\left(\delta T_{i, j, k+1}-\delta T_{i, j, k}\right)+T_{\mathrm{R} i, j, k-\frac{1}{2}}\left(T_{i, j, k-1}^{l}-T_{i, j, k}^{l}\right)+T_{\mathrm{R} i, j, k-\frac{1}{2}}\left(\delta T_{i, j, k-1}-\delta T_{i, j, k}\right)+ \\
& T_{\mathrm{hoi}+\frac{1}{2}, j, k}^{l}\left(\Phi_{\mathrm{o} i+1, j, k}^{l}-\Phi_{\mathrm{o} i, j, k}^{l}\right)+T_{\mathrm{hoi}+\frac{1}{2}, j, k}^{l}\left(\delta P_{\mathrm{o} i+1, j, k}^{l}-\delta P_{\mathrm{o} i, j, k}^{l}\right)+ \\
& \left(\frac{\partial T_{\mathrm{ho}}}{\partial P_{\mathrm{o}}} \delta P_{\mathrm{o}}+\frac{\partial T_{\mathrm{ho}}}{\partial T} \delta T+\frac{\partial T_{\mathrm{ho}}}{\partial S_{\mathrm{w}}} \delta S_{\mathrm{w}}+\frac{\partial T_{\mathrm{ho}}}{\partial S_{\mathrm{g}}} \delta S_{\mathrm{g}}\right)_{i+\frac{1}{2}, j, k}\left(\Phi_{\mathrm{o} i+1, j, k}^{l}-\Phi_{\mathrm{o} i, j, k}^{l}\right)+ \\
& T_{\text {hoi- } \frac{1}{2}, j, k}^{l}\left(\Phi_{\mathrm{o} i-1, j, k}^{l}-\Phi_{\mathrm{o} i, j, k}^{l}\right)+T_{\mathrm{ho} i-\frac{1}{2}, j, k}^{l}\left(\delta P_{\mathrm{o} i-1, j, k}^{l}-\delta P_{\mathrm{o} i, j, k}^{l}\right)+ \\
& \left(\frac{\partial T_{\mathrm{ho}}}{\partial P_{\mathrm{o}}} \delta P_{\mathrm{o}}+\frac{\partial T_{\mathrm{ho}}}{\partial T} \delta T+\frac{\partial T_{\mathrm{ho}}}{\partial S_{\mathrm{w}}} \delta S_{\mathrm{w}}+\frac{\partial T_{\mathrm{ho}}}{\partial S_{\mathrm{g}}} \delta S_{\mathrm{g}}\right)_{i-\frac{1}{2}, j, k}\left(\Phi_{\mathrm{o} i-1, j, k}^{l}-\Phi_{\mathrm{o} i, j, k}^{l}\right)+ \\
& T_{\mathrm{ho} i, j+\frac{1}{2}, k}^{l}\left(\Phi_{\mathrm{o} i, j+1, k}^{l}-\Phi_{\mathrm{o} i, j, k}^{l}\right)+T_{\mathrm{ho} i, j+\frac{1}{2}, k}^{l}\left(\delta P_{\mathrm{o} i, j+1, k}^{l}-\delta P_{\mathrm{o} i, j, k}^{l}\right)+ \\
& \left(\frac{\partial T_{\mathrm{ho}}}{\partial P_{\mathrm{o}}} \delta P_{\mathrm{o}}+\frac{\partial T_{\mathrm{ho}}}{\partial T} \delta T+\frac{\partial T_{\mathrm{ho}}}{\partial S_{\mathrm{w}}} \delta S_{\mathrm{w}}+\frac{\partial T_{\mathrm{ho}}}{\partial S_{\mathrm{g}}} \delta S_{\mathrm{g}}\right)_{i, j+\frac{1}{2}, k}\left(\Phi_{\mathrm{o} i, j+1, k}^{l}-\Phi_{\mathrm{o} i, j, k}^{l}\right)+
\end{aligned}
$$

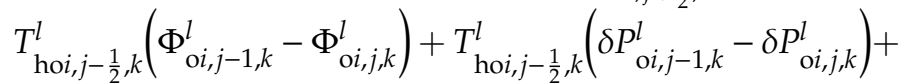

$$
\begin{aligned}
& \left(\frac{\partial T_{\mathrm{ho}}}{\partial P_{\mathrm{o}}} \delta P_{\mathrm{o}}+\frac{\partial T_{\mathrm{ho}}}{\partial T} \delta T+\frac{\partial T_{\mathrm{ho}}}{\partial S_{\mathrm{w}}} \delta S_{\mathrm{w}}+\frac{\partial T_{\mathrm{ho}}}{\partial S_{\mathrm{g}}} \delta S_{\mathrm{g}}\right)_{i, j-\frac{1}{2}, k}\left(\Phi_{\mathrm{o} i, j-1, k}^{l}-\Phi_{\mathrm{o} i, j, k}^{l}\right)+ \\
& T_{\mathrm{hoi}, j, k+\frac{1}{2}}^{l}\left(\Phi_{\mathrm{o} i, j, k+1}^{l}-\Phi_{\mathrm{o} i, j, k}^{l}\right)+T_{\mathrm{hoi}, j, k+\frac{1}{2}}^{l}\left(\delta P_{\mathrm{o} i, j, k+1}^{l}-\delta P_{\mathrm{o} i, j, k}^{l}\right)+ \\
& \left(\frac{\partial T_{\mathrm{ho}}}{\partial P_{\mathrm{o}}} \delta P_{\mathrm{o}}+\frac{\partial T_{\mathrm{ho}}}{\partial T} \delta T+\frac{\partial T_{\mathrm{ho}}}{\partial S_{\mathrm{w}}} \delta S_{\mathrm{w}}+\frac{\partial T_{\mathrm{ho}}}{\partial S_{\mathrm{g}}} \delta S_{\mathrm{g}}\right)_{i, j, k+\frac{1}{2}}\left(\Phi_{\mathrm{o} i, j, k+1}^{l}-\Phi_{\mathrm{o} i, j, k}^{l}\right)+ \\
& T_{\text {hoi } i, j, k-\frac{1}{2}}^{l}\left(\Phi_{\mathrm{o} i, j, k-1}^{l}-\Phi_{\mathrm{o} i, j, k}^{l}\right)+T_{\mathrm{hoi}, j, k-\frac{1}{2}}^{l}\left(\delta P_{\mathrm{o} i, j, k-1}^{l}-\delta P_{\mathrm{o} i, j, k}^{l}\right)+ \\
& \left(\frac{\partial T_{\mathrm{ho}}}{\partial P_{\mathrm{o}}} \delta P_{o}+\frac{\partial T_{\mathrm{ho}}}{\partial T} \delta T+\frac{\partial T_{\mathrm{ho}}}{\partial S_{\mathrm{w}}} \delta S_{\mathrm{w}}+\frac{\partial T_{\mathrm{ho}}}{\partial S_{\mathrm{g}}} \delta S_{\mathrm{g}}\right)_{i, j, k-\frac{1}{2}}\left(\Phi_{\mathrm{o} i, j, k-1}^{l}-\Phi_{\mathrm{o} i, j, k}^{l}\right)+ \\
& T_{\mathrm{hw} i+\frac{1}{2}, j, k}^{l}\left(\Phi_{\mathrm{w} i+1, j, k}^{l}-\Phi_{\mathrm{w} i, j, k}^{l}\right)+T_{\mathrm{hw} i+\frac{1}{2}, j, k}^{l}\left(\delta P_{\mathrm{o} i+1, j, k}^{l}-\delta P_{\mathrm{o} i, j, k}^{l}\right)-T_{\mathrm{hw} i+\frac{1}{2}, j, k}^{l}\left(\delta P_{\mathrm{cow} i+1, j, k}^{l}-\delta P_{\mathrm{cow} i, j, k}^{l}\right)+ \\
& \left(\frac{\partial T_{\mathrm{hw}}}{\partial P_{\mathrm{o}}} \delta P_{\mathrm{o}}+\frac{\partial T_{\mathrm{hw}}}{\partial T} \delta T+\frac{\partial T_{\mathrm{hw}}}{\partial S_{\mathrm{w}}} \delta S_{\mathrm{w}}\right)_{i+\frac{1}{2}, j, k}\left(\Phi_{\mathrm{w} i+1, j, k}^{l}-\Phi_{\mathrm{w} i, j, k}^{l}\right)+ \\
& T_{\mathrm{hw} i-\frac{1}{2}, j, k}^{l}\left(\Phi_{\mathrm{w} i-1, j, k}^{l}-\Phi_{\mathrm{w} i, j, k}^{l}\right)+T_{\mathrm{hw} i-\frac{1}{2}, j, k}^{l}\left(\delta P_{\mathrm{o} i-1, j, k}^{l}-\delta P_{\mathrm{o} i, j, k}^{l}\right)-T_{\mathrm{hw} i-\frac{1}{2}, j, k}^{l}\left(\delta P_{\text {cowi-1,j,k }}^{l}-\delta P_{\text {cowi } i, j, k}^{l}\right)+ \\
& \left(\frac{\partial T_{\mathrm{hw}}}{\partial P_{\mathrm{o}}} \delta P_{\mathrm{o}}+\frac{\partial T_{\mathrm{hw}}}{\partial T} \delta T+\frac{\partial T_{\mathrm{hw}}}{\partial S_{\mathrm{w}}} \delta S_{\mathrm{w}}\right)_{i-\frac{1}{2}, j, k}\left(\Phi_{\mathrm{w} i-1, j, k}^{l}-\Phi_{\mathrm{w} i, j, k}^{l}\right)+ \\
& T_{\mathrm{hw} i, j+\frac{1}{2}, k}^{l}\left(\Phi_{\mathrm{w} i, j+1, k}^{l}-\Phi_{\mathrm{w} i, j, k}^{l}\right)+T_{\mathrm{hw} i, j+\frac{1}{2}, k}^{l}\left(\delta P_{\mathrm{o} i, j+1, k}^{l}-\delta P_{\mathrm{o} i, j, k}^{l}\right)-T_{\mathrm{hw} i, j+\frac{1}{2}, k}^{l}\left(\delta P_{\mathrm{cow} i, j+1, k}^{l}-\delta P_{\mathrm{cow} i, j, k}^{l}\right)+ \\
& \left(\frac{\partial T_{\mathrm{hw}}}{\partial P_{\mathrm{o}}} \delta P_{\mathrm{o}}+\frac{\partial T_{\mathrm{hw}}}{\partial T} \delta T+\frac{\partial T_{\mathrm{hw}}}{\partial S_{\mathrm{w}}} \delta S_{\mathrm{w}}\right)_{i, j+\frac{1}{2}, k}\left(\Phi_{\mathrm{w} i, j+1, k}^{l}-\Phi_{\mathrm{w} i, j, k}^{l}\right)+ \\
& T_{\mathrm{hwi} i,-\frac{1}{2}, k}^{l}\left(\Phi_{\mathrm{w} i, j-1, k}^{l}-\Phi_{\mathrm{w} i, j, k}^{l}\right)+T_{\mathrm{hw} i, j-\frac{1}{2}, k}^{l}\left(\delta P_{\mathrm{o} i, j-1, k}^{l}-\delta P_{\mathrm{o} i, j, k}^{l}\right)-T_{\mathrm{hwi} i,-\frac{1}{2}, k}^{l}\left(\delta P_{\mathrm{cow} i, j-1, k}^{l}-\delta P_{\mathrm{cow} i, j, k}^{l}\right)+ \\
& \left(\frac{\partial T_{\mathrm{hw}}}{\partial P_{\mathrm{o}}} \delta P_{\mathrm{o}}+\frac{\partial T_{\mathrm{hw}}}{\partial T} \delta T+\frac{\partial T_{\mathrm{hw}}}{\partial S_{\mathrm{w}}} \delta S_{\mathrm{w}}\right)_{i, j-\frac{1}{2}, k}\left(\Phi_{\mathrm{w} i, j-1, k}^{l}-\Phi_{\mathrm{w} i, j, k}^{l}\right)+ \\
& T_{\mathrm{hw} i, j, k+\frac{1}{2}}^{l}\left(\Phi_{\mathrm{w} i, j, k+1}^{l}-\Phi_{\mathrm{w} i, j, k}^{l}\right)+T_{\mathrm{hw} i, j, k+\frac{1}{2}}^{l}\left(\delta P_{\mathrm{o} i, j, k+1}^{l}-\delta P_{\mathrm{o} i, j, k}^{l}\right)-T_{\mathrm{hwi} i, j, k+\frac{1}{2}}^{l}\left(\delta P_{\mathrm{cow} i, j, k+1}^{l}-\delta P_{\mathrm{cow} i, j, k}^{l}\right)+ \\
& \left(\frac{\partial T_{\mathrm{hw}}}{\partial P_{\mathrm{o}}} \delta P_{\mathrm{o}}+\frac{\partial T_{\mathrm{hw}}}{\partial T} \delta T+\frac{\partial T_{\mathrm{hw}}}{\partial S_{\mathrm{w}}} \delta S_{\mathrm{w}}\right)_{i, j, k+\frac{1}{2}}\left(\Phi_{\mathrm{w} i, j, k+1}^{l}-\Phi_{\mathrm{w} i, j, k}^{l}\right)+ \\
& T_{\mathrm{hwi} i, j, k-\frac{1}{2}}^{l}\left(\Phi_{\mathrm{w} i, j, k-1}^{l}-\Phi_{\mathrm{w} i, j, k}^{l}\right)+T_{\mathrm{hw} i, j, k-\frac{1}{2}}^{l}\left(\delta P_{\mathrm{o} i, j, k-1}^{l}-\delta P_{\mathrm{o} i, j, k}^{l}\right)-T_{\mathrm{hwi}, j, k-\frac{1}{2}}^{l}\left(\delta P_{\mathrm{cow} i, j, k-1}^{l}-\delta P_{\mathrm{cow} i, j, k}^{l}\right)+ \\
& \left(\frac{\partial T_{\mathrm{hw}}}{\partial P_{\mathrm{o}}} \delta P_{\mathrm{o}}+\frac{\partial T_{\mathrm{hw}}}{\partial T} \delta T+\frac{\partial T_{\mathrm{hw}}}{\partial S_{\mathrm{w}}} \delta S_{\mathrm{w}}\right)_{i, j, k-\frac{1}{2}}\left(\Phi_{\mathrm{w} i, j, k-1}^{l}-\Phi_{\mathrm{w} i, j, k}^{l}\right)+ \\
& T_{\mathrm{hg} i+\frac{1}{2}, j, k}^{l}\left(\Phi_{\mathrm{g} i+1, j, k}^{l}-\Phi_{\mathrm{g} i, j, k}^{l}\right)+T_{\mathrm{hg} i+\frac{1}{2}, j, k}^{l}\left(\delta P_{\mathrm{o} i+1, j, k}^{l}-\delta P_{\mathrm{o} i, j, k}^{l}\right)+T_{\mathrm{hg} i+\frac{1}{2}, j, k}^{l}\left(\delta P_{\mathrm{cgoi}+1, j, k}^{l}-\delta P_{\mathrm{cgoi}, j, k}^{l}\right)+ \\
& \left(\frac{\partial T_{\mathrm{hg}}}{\partial T} \delta T+\frac{\partial T_{\mathrm{hg}}}{\partial S_{\mathrm{g}}} \delta S_{\mathrm{g}}\right)_{i+\frac{1}{2}, j, k}\left(\Phi_{\mathrm{g} i+1, j, k}^{l}-\Phi_{\mathrm{g} i, j, k}^{l}\right)+
\end{aligned}
$$




$$
\begin{aligned}
& T_{\mathrm{hg} i-\frac{1}{2}, j, k}^{l}\left(\Phi_{\mathrm{g} i-1, j, k}^{l}-\Phi_{\mathrm{g} i, j, k}^{l}\right)+T_{\mathrm{hg} i-\frac{1}{2}, j, k}^{l}\left(\delta P_{\mathrm{o} i-1, j, k}^{l}-\delta P_{\mathrm{o} i, j, k}^{l}\right)+T_{\mathrm{hg} i-\frac{1}{2}, j, k}^{l}\left(\delta P_{\mathrm{cgoi-1,j,k}}^{l}-\delta P_{\mathrm{cgoi}, j, k}^{l}\right) \\
& +\left(\frac{\partial T_{\mathrm{hg}}}{\partial T} \delta T+\frac{\partial T_{\mathrm{hg}}}{\partial S_{\mathrm{g}}} \delta S_{\mathrm{g}}\right)_{i-\frac{1}{2}, j, k}\left(\Phi_{\mathrm{g} i-1, j, k}^{l}-\Phi_{\mathrm{g} i, j, k}^{l}\right)+ \\
& T_{\mathrm{hg} i, j+\frac{1}{2}, k}^{l}\left(\Phi_{\mathrm{g} i, j+1, k}^{l}-\Phi_{\mathrm{g} i, j, k}^{l}\right)+T_{\mathrm{hg} i, j+\frac{1}{2}, k}^{l}\left(\delta P_{\mathrm{o} i, j+1, k}^{l}-\delta P_{\mathrm{o} i, j, k}^{l}\right)+T_{\mathrm{hg} i, j+\frac{1}{2}, k}^{l}\left(\delta P_{\mathrm{cgoi}, j+1, k}^{l}-\delta P_{\mathrm{cgoi}, j, k}^{l}\right)+ \\
& \left(\frac{\partial T_{\mathrm{hg}}}{\partial T} \delta T+\frac{\partial T_{\mathrm{hg}}}{\partial S_{\mathrm{g}}} \delta S_{\mathrm{g}}\right)_{i, j+\frac{1}{2}, k}\left(\Phi_{\mathrm{g} i, j+1, k}^{l}-\Phi_{\mathrm{g} i, j, k}^{l}\right)+ \\
& T_{\mathrm{hg} i, j-\frac{1}{2}, k}^{l}\left(\Phi_{\mathrm{g} i, j-1, k}^{l}-\Phi_{\mathrm{g} i, j, k}^{l}\right)+T_{\mathrm{hg} i, j-\frac{1}{2}, k}^{l}\left(\delta P_{\mathrm{o} i, j-1, k}^{l}-\delta P_{\mathrm{o} i, j, k}^{l}\right)+T_{\mathrm{hg} i, j-\frac{1}{2}, k}^{l}\left(\delta P_{\mathrm{cgoi}, j-1, k}^{l}-\delta P_{\mathrm{cgoi}, j, k}^{l}\right)+ \\
& \left(\frac{\partial T_{\mathrm{hg}}}{\partial T} \delta T+\frac{\partial T_{\mathrm{hg}}}{\partial S_{\mathrm{g}}} \delta S_{g}\right)_{i, j-\frac{1}{2}, k}\left(\Phi_{\mathrm{g} i, j-1, k}^{l}-\Phi_{\mathrm{g} i, j, k}^{l}\right)+ \\
& T_{\mathrm{hg} i, j, k+\frac{1}{2}}^{l}\left(\Phi_{\mathrm{g} i, j, k+1}^{l}-\Phi_{\mathrm{g} i, j, k}^{l}\right)+T_{\mathrm{hg} i, j, k+\frac{1}{2}}^{l}\left(\delta P_{\mathrm{o} i, j, k+1}^{l}-\delta P_{\mathrm{o} i, j, k}^{l}\right)+T_{\mathrm{hg} i, j, k+\frac{1}{2}}^{l}\left(\delta P_{\mathrm{cgoi}, j, k+1}^{l}-\delta P_{\mathrm{cgoi}, j, k}^{l}\right)+ \\
& \left(\frac{\partial T_{\mathrm{hg}}}{\partial T} \delta T+\frac{\partial T_{\mathrm{hg}}}{\partial S_{\mathrm{g}}} \delta S_{\mathrm{g}}\right)_{i, j, k+\frac{1}{2}}\left(\Phi_{\mathrm{g} i, j, k+1}^{l}-\Phi_{\mathrm{g} i, j, k}^{l}\right)+ \\
& T_{\mathrm{hg} i, j, k-\frac{1}{2}}^{l}\left(\Phi_{\mathrm{g} i, j, k-1}^{l}-\Phi_{\mathrm{g} i, j, k}^{l}\right)+T_{\mathrm{hg} i, j, k-\frac{1}{2}}^{l}\left(\delta P_{\mathrm{o} i, j, k-1}^{l}-\delta P_{\mathrm{o} i, j, k}^{l}\right)+T_{\mathrm{hg} i, j, k-\frac{1}{2}}^{l}\left(\delta P_{\mathrm{cgoi}, j, k-1}^{l}-\delta P_{\mathrm{cgoi}, j, k}^{l}\right)+ \\
& \left(\frac{\partial T_{\mathrm{hg}}}{\partial T} \delta T+\frac{\partial \mathrm{T}_{\mathrm{hg}}}{\partial S_{\mathrm{g}}} \delta S_{\mathrm{g}}\right)_{i, j, k-\frac{1}{2}}\left(\Phi_{\mathrm{g} i, j, k-1}^{l}-\Phi_{\mathrm{g} i, j, k}^{l}\right)-Q_{1 i, j, k}^{l+1}+Q_{\mathrm{h} i, j, k}^{l+1}+Q_{\mathrm{welli} i, j, k}^{l+1} \\
& =\frac{V_{\mathrm{B}}}{\Delta t}\left[\begin{array}{l}
\left((1-\varphi) M_{\mathrm{R}} T\right)_{i, j, k}^{l+1}-\left((1-\varphi) M_{\mathrm{R}} T\right)_{i, j, k}^{n}+\left(\varphi\left(S_{\mathrm{o}} \rho_{\mathrm{o}} U_{\mathrm{o}}+S_{\mathrm{w}} \rho_{\mathrm{w}} U_{\mathrm{w}}+S_{\mathrm{g}} \rho_{\mathrm{g}} U_{\mathrm{g}}\right)\right)_{i, j, k}^{l+1} \\
-\left(\varphi\left(S_{\mathrm{o}} \rho_{\mathrm{o}} U_{\mathrm{o}}+S_{\mathrm{w}} \rho_{\mathrm{w}} U_{\mathrm{w}}+S_{\mathrm{g}} \rho_{\mathrm{g}} U_{\mathrm{g}}\right)\right)_{i, j, k}^{n}
\end{array}\right] \\
& =\frac{V_{\mathrm{B}}}{\Delta t}\left\{\begin{array}{l}
{\left[(1-\varphi) M_{\mathrm{R}} T\right]_{i, j, k}^{l}-\left[(1-\varphi) M_{\mathrm{R}} T\right]_{i, j, k}^{n}+(1-\varphi) M_{\mathrm{R}} \delta T_{i, j, k}-M_{\mathrm{R}} T \frac{\partial \varphi}{\partial P_{\mathrm{o}}} \delta P_{\mathrm{o} i, j, k}+} \\
{\left[\varphi\left(S_{\mathrm{o}} \rho_{\mathrm{o}} U_{\mathrm{o}}+S_{\mathrm{w}} \rho_{\mathrm{w}} U_{\mathrm{w}}+S_{\mathrm{g}} \rho_{\mathrm{g}} U_{\mathrm{g}}\right)\right]_{i, j, k}^{l}-\left[\varphi\left(S_{\mathrm{o}} \rho_{\mathrm{o}} U_{\mathrm{o}}+S_{\mathrm{w}} \rho_{\mathrm{w}} U_{\mathrm{w}}+S_{\mathrm{g}} \rho_{\mathrm{g}} U_{\mathrm{g}}\right)\right]_{i, j, k}^{n}+} \\
U_{\mathrm{o}}\left[-\rho_{\mathrm{o}} \varphi \delta\left(S_{\mathrm{w}}+S_{\mathrm{g}}\right)+\left(1-S_{\mathrm{w}}-S_{\mathrm{g}}\right)\left(\varphi \frac{\partial \rho_{\mathrm{o}}}{\partial P_{\mathrm{o}}} \delta P_{\mathrm{o}}+\varphi \frac{\partial \rho_{\mathrm{o}}}{\partial T} \delta T+\rho_{\mathrm{o}} \frac{\partial \varphi}{\partial P_{\mathrm{o}}} \delta P_{\mathrm{o}}\right)\right]_{i, j, k}+ \\
U_{\mathrm{w}}\left(\rho_{\mathrm{w}} \varphi \delta S_{\mathrm{w}}+S_{\mathrm{w}} \varphi \frac{\partial \rho_{\mathrm{w}}}{\partial P_{\mathrm{o}}} \delta P_{\mathrm{o}}+S_{\mathrm{w}} \varphi \frac{\partial \rho_{\mathrm{w}}}{\partial T} \delta T+S_{\mathrm{w}} \rho_{\mathrm{w}} \frac{\partial \varphi}{\partial P_{\mathrm{o}}} \delta P_{\mathrm{o}}\right)_{i, j, k}+ \\
U_{\mathrm{g}}\left(\rho_{\mathrm{g}} \varphi \delta S_{\mathrm{g}}+S_{\mathrm{g}} \varphi \frac{\partial \rho_{\mathrm{g}}}{\partial T} \delta T+S_{\mathrm{g}} \rho_{\mathrm{g}} \frac{\partial \varphi}{\partial P_{\mathrm{o}}} \delta P_{\mathrm{o}}\right)_{i, j, k}+ \\
\left(\varphi S_{\mathrm{o}} \rho_{\mathrm{o}} \frac{\partial U_{\mathrm{g}}}{\partial T} \delta T+\varphi S_{\mathrm{w}} \rho_{\mathrm{w}} \frac{\partial U_{\mathrm{w}}}{\partial T} \delta T+\varphi S_{\mathrm{g}} \rho_{\mathrm{g}} \frac{\partial u_{\mathrm{g}}}{\partial T} \delta T\right)_{i, j, k}
\end{array}\right\}
\end{aligned}
$$

(4) Equilibrium Equation (A47) can be changed as shown below:

$$
\delta T-\frac{\partial f(P)}{\partial P} \delta P=f(P)^{n}-T^{l}
$$

After linearizing difference Equations (A44)-(A47), Equations (A44)-(A47) can be simplified as:

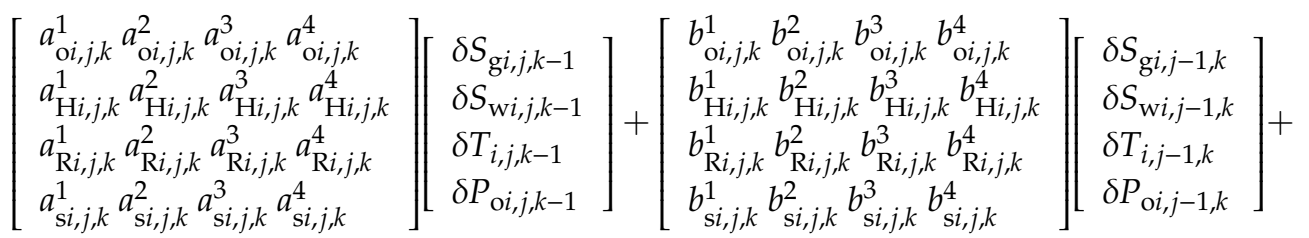




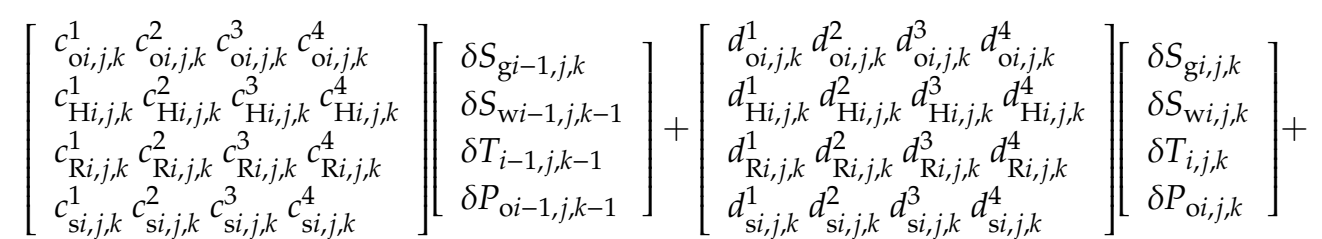

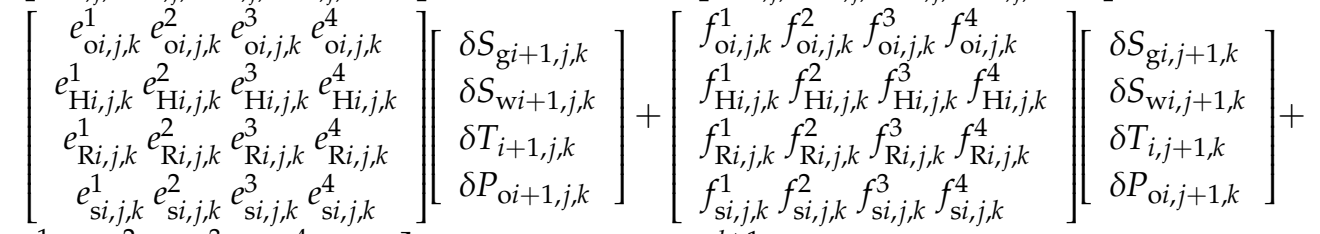

$$
\begin{aligned}
& {\left[\begin{array}{l}
g_{\mathrm{o} i, j, k}^{1} g_{\mathrm{o} i, j, k}^{2} g_{\mathrm{o} i, j, k}^{3} g_{\mathrm{o} i, j, k}^{4} \\
g_{\mathrm{H} i, j, k}^{1} g_{\mathrm{H} i, j, k}^{2} g_{\mathrm{H} i, j, k}^{3} g_{\mathrm{H} i, j, k}^{4} \\
g_{\mathrm{R} i, j, k}^{1} g_{\mathrm{R} i, j, k}^{2} g_{\mathrm{R} i, j, k}^{3} g_{\mathrm{R} i, j, k}^{4} \\
g_{\mathrm{si}, j, k}^{1} g_{\mathrm{si}, j, k}^{2} g_{\mathrm{si}, j, k}^{3} g_{\mathrm{s} i, j, k}^{4}
\end{array}\right]\left[\begin{array}{l}
\delta S_{\mathrm{g} i, j, k+1} \\
\delta S_{\mathrm{w} i, j, k+1}^{4} \\
\delta T_{i, j, k+1} \\
\delta P_{\mathrm{o} i, j, k+1}
\end{array}\right]+\left[\begin{array}{l}
M_{\mathrm{o} i, j, k}^{l+1} \\
M_{\mathrm{wi} i, j, k}^{l+1}+M_{\mathrm{g} i, j, k}^{l+1} \\
-Q_{\mathrm{loss} i, j, k}^{l+1}+Q_{\mathrm{H} i, j, k}^{l+1}+Q_{\mathrm{welli}, j, k}^{l+1} \\
0
\end{array}\right]=\left[\begin{array}{l}
h_{\mathrm{o} i, j, k} \\
h_{\mathrm{H} i, j, k} \\
h_{\mathrm{R} i, j, k} \\
h_{\mathrm{si}, j, k}
\end{array}\right]}
\end{aligned}
$$

where $a, b, c, d, e, f$, and $g$ are the coefficients of the corresponding variables. Supposing $I I$ is the number of grid points in the $x$ direction, $J J$ is the number of grid points in the $y$ direction, and $K K$ is the number of grid points in the $z$ direction, there are $I I \times J J \times K K$ grid nodes; thus, the above equations are $4 \times I I$ $\times J J \times K K$ order equations with four unknowns: $\delta P_{\mathrm{o}}, \delta T, \delta S_{\mathrm{w}}$ and $\delta S_{\mathrm{g}}$. The equations are simplified as follows:

$$
A X=B
$$

where $A$ is a seven-diagonal $4 \times 4$ block matrix, $X$ consists of the unknown variables, $X=\left[\delta P_{\mathrm{o}}, \delta T\right.$, $\left.\delta S_{\mathrm{w}}, \delta S_{\mathrm{g}}\right]^{\mathrm{T}}$, and $\boldsymbol{B}$ is a constant term at the right side of the equation.

\section{References}

1. Sun, X.; Song, Z.; Cai, L.; Zhang, Y.; Li, P. Phase behavior of heavy oil-solvent mixture systems under reservoir conditions. Pet. Sci. 2020. [CrossRef]

2. Sun, X.; Zhang, Y.; Gai, Z.; Zhao, H.; Chen, G.; Song, Z. Comprehensive experimental study of the interfacial stability of foamy oil and identification of the characteristic responsible for foamy oil formation. Fuel 2019, 238, 514-525. [CrossRef]

3. Sun, X.; Zhao, H.; Zhang, Y.; Liu, Y.; Chen, G.; Wang, W. An experimental study on the oil-soluble surfactant-assisted cyclic mixed solvent injection process for heavy oil recovery after primary production. Fuel 2019, 254, 115656. [CrossRef]

4. Zhou, W.; Xin, C.; Chen, S.; Yu, Q.; Wang, K. Polymer-Enhanced Foam Flooding for Improving Heavy Oil Recovery in Thin Reservoirs. Energy Fuels 2020, 34, 4116-4128. [CrossRef]

5. Zhou, X.; Zeng, F.; Zhang, L. Improving Steam-Assisted Gravity Drainage performance in oil sands with a top water zone using polymer injection and the fishbone well pattern. Fuel 2016, 184, 449-465. [CrossRef]

6. Jiang, Q.; Butler, R.; Yee, C. The Steam and Gas Push (SAGP)-2:Mechanism Analysis and Physical Model Testing. J. Can. Pet. Technol. 2000, 39. [CrossRef]

7. Dong, X.; Liu, H.; Chen, Z.; Wu, K.; Lu, N.; Zhang, Q. Enhanced oil recovery techniques for heavy oil and oilsands reservoirs after steam injection. Appl. Energy 2019, 239, 1190-1211. [CrossRef]

8. Lyu, X.; Liu, H.; Pang, Z.; Sun, Z. Visualized study of thermochemistry assisted steam flooding to improve oil recovery in heavy oil reservoir with glass micromodels. Fuel 2018, 218, 118-126. [CrossRef]

9. Yao, Y.; Yao, Y.; Li, G.; Liu, W. A numerical model for wet steam circulating in horizontal wellbores during starting stage of the steam-assisted-gravity-drainage process. Heat Mass Transf. 2019, 55, 2209-2220. [CrossRef]

10. Liu, H.; Cheng, L.; Huang, S.; Jia, P.; Chen, M. Evolution characteristics of SAGD steam chamber and its impacts on heavy oil production and heat consumption. Int. J. Heat Mass Transf. 2018, 121, 579-596. [CrossRef]

11. Li, S.; Yu, T.; Li, Z.; Li, S. Experimental investigation of nitrogen-assisted SAGD in heavy-oil reservoirs: A two-dimensional visual analysis. Fuel 2019, 257, 116013. [CrossRef] 
12. Sadeghi, A.; Hassanzadeh, H.; Harding, T.G. A comparative study of oil sands preheating using electromagnetic waves, electrical heaters and steam circulation. Int. J. Heat Mass Transf. 2017, 111, 908-916. [CrossRef]

13. Parappilly, R.; Zhao, L. SAGD with a Longer Wellbore. J. Can. Pet. Technol. 2009, 48, 71-77. [CrossRef]

14. Huang, S.; Cao, M.; Xia, Y.; Chen, X.; Yang, M. Heat and mass transfer characteristics of steam in a horizontal wellbore with multi-point injection technique considering wellbore stock liquid. Int. J. Heat Mass Transf. 2018, 127, 949-958. [CrossRef]

15. Huang, S.; Xia, Y.; Xiong, H.; Liu, H.; Chen, X. A three-dimensional approach to model steam chamber expansion and production performance of SAGD process. Int. J. Heat Mass Transf. 2018, 127, 29-38. [CrossRef]

16. Stone, T.W.; Brown, G.; Guyaguler, B.; Bailey, W.J.; Law, D.H. Practical Control of SAGD Wells With Dual-Tubing Strings. J. Can. Pet. Technol. 2014, 53, 32-47. [CrossRef]

17. Kumar, A.; Oballa, V.; Card, C. Fully-Coupled Wellbore Design and Optimization for Thermal Operations. In Proceedings of the Canadian Unconventional Resources and International Petroleum Conference, Calgary, AB, Canada, 19-21 October 2010. SPE-137427-MS. [CrossRef]

18. Rivas, D.A.; Gates, I. SAGD Circulation Phase: Thermal Efficiency Evaluation of Five Wellbore Completion Designs in Lloydminster Reservoir. In Proceedings of the SPE Thermal Well Integrity and Design Symposium, Banff, AB, Canada, 27-29 November 2018. [CrossRef]

19. Dong, X.; Liu, H.; Lu, N.; Wu, K.; Wang, K.; Chen, Z. Steam Conformance along Horizontal Well with Different Well Configurations of Single Tubing: An Experimental and Numerical Investigation. SPE Prod. Oper. 2020, 1-15. [CrossRef]

20. Sun, F.; Yao, Y.; Li, X.; Li, G.; Liu, Q.; Han, S.; Zhou, Y. Effect of friction work on key parameters of steam at different state in toe-point injection horizontal wellbores. J. Pet. Sci. Eng. 2018, 164, 655-662. [CrossRef]

21. Lin, R.; Qi, S.; Shen, W.; Yang, J.; Wang, X.; Wang, H.; Wang, S.; Shu, Z. Study on parameters of steam injection in SAGD circulating preheating section. J. China Univ. Pet. 2018, 42, 134-141.

22. Sun, F.; Yao, Y.; Li, X.; Li, G.; Sun, Z. A numerical model for predicting distributions of pressure and temperature of superheated steam in multi-point injection horizontal wells. Int. J. Heat Mass Transf. 2018, 121, 282-289. [CrossRef]

23. Wu, Y.; Li, X.; Sun, X.; Ma, D.; Wang, H. Key parameters forecast model of injector wellbores during the dual-well sagd process. Pet. Explor. Dev. 2012, 39, 514-521. [CrossRef]

24. Yu, T.; Zhang, H.-Q.; Li, M.; Sarica, C. A Mechanistic Model for Gas/Liquid Flow in Upward Vertical Annuli. SPE Prod. Oper. 2010, 25, 285-295. [CrossRef]

25. Caetano, E.F.; Shoham, O.; Brill, J.P. Upward Vertical Two-Phase Flow Through an Annulus-Part I: Single-Phase Friction Factor, Taylor Bubble Rise Velocity, and Flow Pattern Prediction. J. Energy Resour. Technol. 1992, 114, 1-13. [CrossRef]

26. Gu, H.; Cheng, L.; Huang, S.; Du, B.; Hu, C. Prediction of thermophysical properties of saturated steam and wellbore heat losses in concentric dual-tubing steam injection wells. Energy 2014, 75, 419-429. [CrossRef]

27. Gu, H.; Cheng, L.; Huang, S.; Li, B.; Shen, F.; Fang, W.; Hu, C. Steam injection for heavy oil recovery: Modeling of wellbore heat efficiency and analysis of steam injection performance. Energy Convers. Manag. 2015, 97, 166-177. [CrossRef]

28. Alves, I.; Alhanati, F.; Shoham, O. A Unified Model for Predicting Flowing Temperature Distribution in Wellbores and Pipelines. SPE Prod. Eng. 1992, 7, 363-367. [CrossRef]

29. Beggs, D.; Brill, J. A Study of Two-Phase Flow in Inclined Pipes. J. Pet. Technol. 1973, 25, 607-617. [CrossRef]

30. Cheng, W.; Huang, Y.; Lu, D.-T.; Yin, H.-R. A novel analytical transient heat-conduction time function for heat transfer in steam injection wells considering the wellbore heat capacity. Energy 2011, 36, 4080-4088. [CrossRef]

31. Nian, Y.-L.; Cheng, W.; Li, T.-T.; Wang, C.-L. Study on the effect of wellbore heat capacity on steam injection well heat loss. Appl. Therm. Eng. 2014, 70, 763-769. [CrossRef]

32. Cheng, W.-L.; Han, B.-B.; Nian, Y.-L.; Wang, C.-L. Study on wellbore heat loss during hot water with multiple fluids injection in offshore well. Appl. Therm. Eng. 2016, 95, 247-263. [CrossRef]

33. Tortike, W.; Ali, S.F. Saturated-Steam-Property Functional Correlations for Fully Implicit Thermal Reservoir Simulation. SPE Reserv. Eng. 1989, 4, 471-474. [CrossRef]

34. Ejiogu, G.; Fiori, M. High-Pressure Saturated-Steam Correlations. J. Pet. Technol. 1987, 39, $1585-1590$. [CrossRef] 
35. Li, M.; Chen, H.; Zhang, Y.; Li, W.; Wang, Y.; Yu, M. A Coupled Reservoir/Wellbore Model to Simulate the Steam Injection Performance of Horizontal Wells. Energy Technol. 2015, 3, 535-542. [CrossRef]

36. Mozaffari, S.; Nikookar, M.; Ehsani, M.R.; Sahranavard, L.; Roayaie, E.; Mohammadi, A.H. Numerical modeling of steam injection in heavy oil reservoirs. Fuel 2013, 112, 185-192. [CrossRef]

37. Sun, X.; Zhang, Y.; Wang, S.; Song, Z.; Li, P.; Wang, C. Experimental study and new three-dimensional kinetic modeling of foamy solution-gas drive processes. Sci. Rep. 2018, 8, 4369. [CrossRef]

38. Sun, F.; Yao, Y.; Li, G.; Li, X.; Zhang, T.; Lu, C.; Liu, W. An improved two-phase model for saturated steam flow in multi-point injection horizontal wells under steady-state injection condition. J. Pet. Sci. Eng. 2018, 167, 844-856. [CrossRef]

39. Oballa, V.; Buchanan, L. Flexible wellbore model coupled to thermal reservoir simulator. In Proceedings of the World Heavy Oil Congress, Puerto La Cruz, Venezuela, 3-5 November 2009.

(C) 2020 by the authors. Licensee MDPI, Basel, Switzerland. This article is an open access article distributed under the terms and conditions of the Creative Commons Attribution (CC BY) license (http://creativecommons.org/licenses/by/4.0/). 